\title{
ESTUDO DA INFLUÊNCIA DO SOBREMETAL EXCEDENTE DE DESBASTE NA OPERAÇÃO DE ACABAMENTO APLICANDO USINAGEM COM ALTAS VELOCIDADES.
}

\author{
Eng. Renato Lemes Capla
}

\begin{abstract}
Dissertação apresentada à Escola de Engenharia de São Carlos da Universidade de São Paulo, como parte dos requisitos para a obtenção do título de Mestre em Engenharia Mecânica.
\end{abstract}

ORIENTADOR: Prof. PhD Reginaldo Teixeira Coelho

São Carlos

2006 
FOLHA DE JULGAMENTO

Candidato: Engenheiro RENATO LEMES CAPLA

Dissertação defendida e julgada em 15/12/2006 perante a Comissão Julgadora:

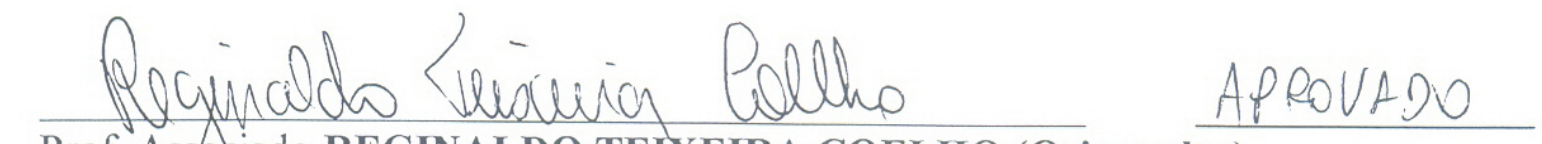

Prof. Associado REGINALDO TEIXEIRA COELHO (Orientador)

(Escola de Engenharia de São Carlos/USP)

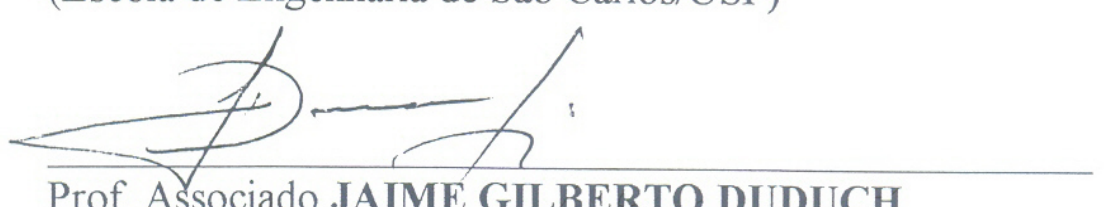

APROVADO

Prof. Associado JAIME GILBERTO DUDUCH

(Escola de Engenharia de São Carlos/USP)

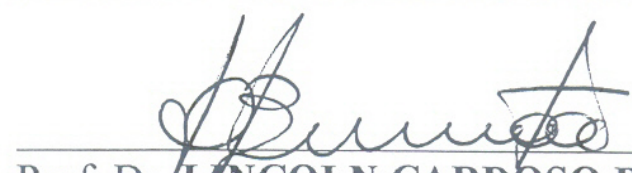

Prof. Dr IANCOLN CARDOSO BRANDÃO

APROVADO

(Universidade Federal de São João del-Rei/UFSJ)

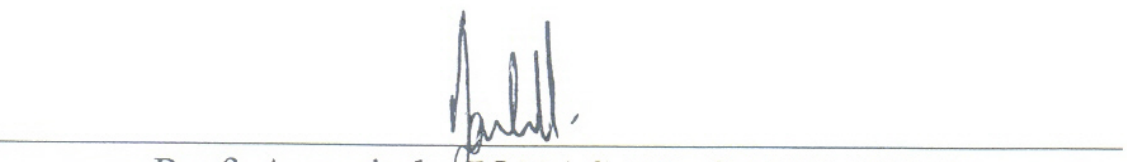

Prof. Associado/JONAS DE CARVALHO

Coordenador do Programa de Pós-Graduação

em Engenharia Mecânica

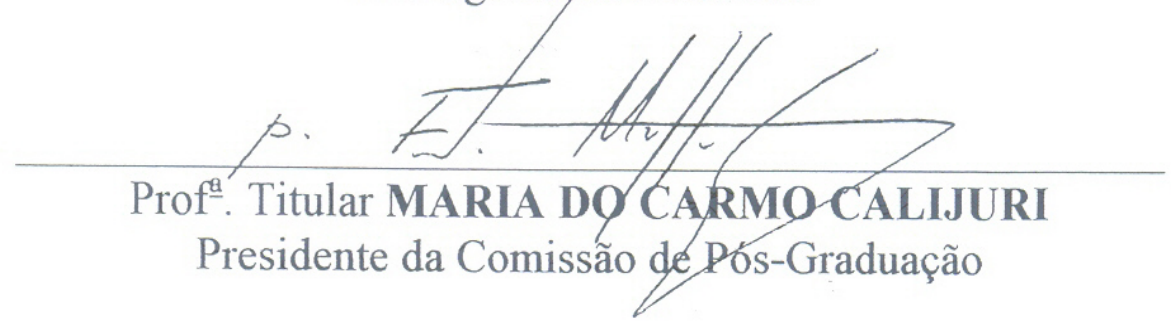




\section{Dedicatória}

Aos meus pais, Vani e Genésio

- Fonte de inspiração, coragem e conforto exemplos de dignidade, amor e luta Dedico este trabalho. 



\section{Agradecimentos}

Ao professor Reginaldo Teixeira Coelho, pela orientação, confiança e paciência.

À família OPF, Adriano Fagali, Fábio Ferrraz, Lincoln Brandão e muito outros pelo apoio e amizade.

A todos os funcionários do Departamento de Engenharia Mecânica da EESC-USP, pela cooperação.

A minha eterna namorada Ana Graziela Pertile Paggiaro pela demonstração de amor e compreensão nesses anos todos.

Sobretudo a Deus, que me deu a alegria da vida, a coragem para lutar e o sabor dos dias.

A todos que de uma forma ou de outra me ajudaram, o meu sincero agradecimento. 



\section{SUMÁRIO}

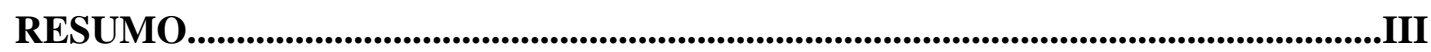

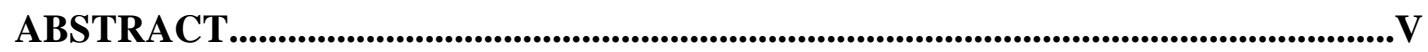

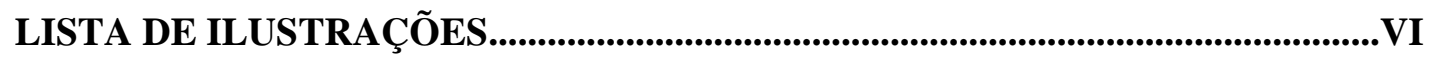

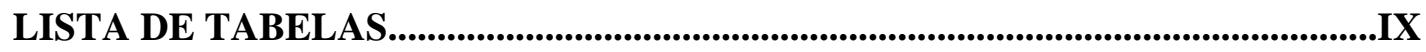

LISTA DAS NOTAÇÕES E SÍMBOLOS.....................................................................

LISTA DE ABREVIATURAS E SIGLAS...................................................................II

1. INTRODUÇÃ

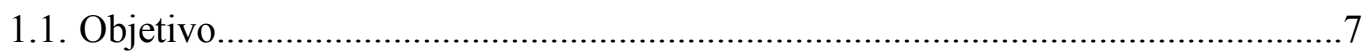

1.2. Estrutura da Dissertação...................................................................................

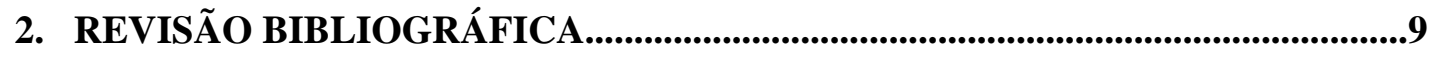

2.1. Breve Histórico da Usinagem com Altas Velocidades.........................................9

2.2. Conceito da Usinagem em Altas Velocidades.......................................................11

2.3. Aplicações, Vantagens e Desvantagens da usinagem HSC..................................17

2.4. Manufatura de moldes e matrizes.......................................................................22

2.5. Tecnologia da usinagem com alta velocidade de corte.........................................23

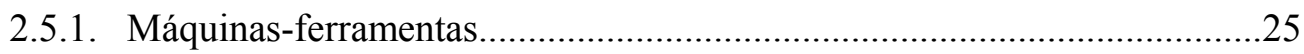

2.5.2. Considerações sobre Ferramentas de corte...............................................32

2.5.3. Interface eixo-árvore da máquina, porta ferramenta e da ferramenta.........33

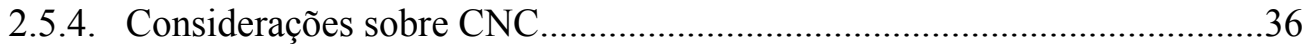

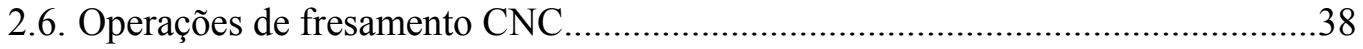

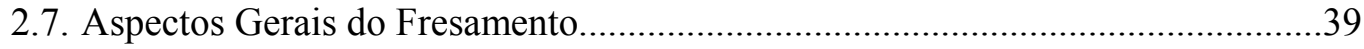

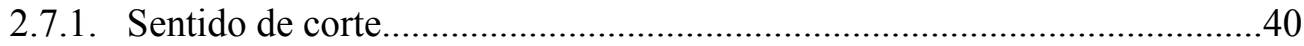

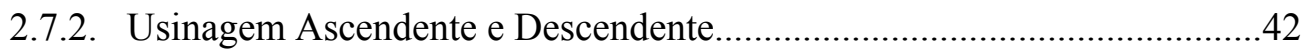

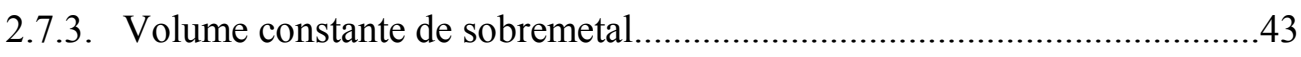

2.7.4. Geometria do processo de fresamento com uma fresa de topo esférico....44

2.7.5. Consideração sobre o cavaco gerado durante o fresamento.......................49

2.8. Análise da flexão sobre o erro dimensional......................................................50

2.9. Aspectos básicos das forças de corte.................................................................52 
2.9.1. Comportamento da força com alta velocidade.........................................58

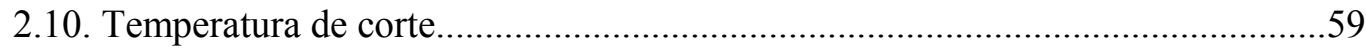

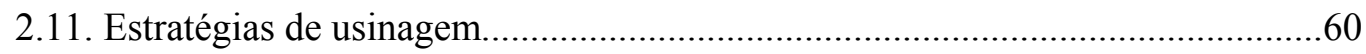

2.12. Fatores que influenciam no acabamento final de usinagem..............................62

3. PROCEDIMENTO EXPERIMENTAL_......................................................67

3.1. Máquina-ferramenta e acessórios.............................................................67

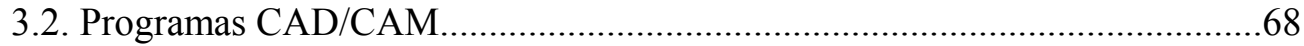

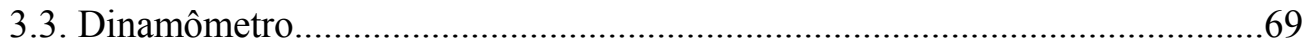

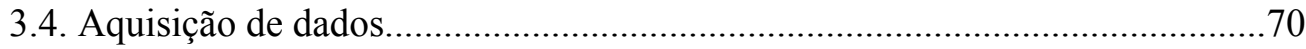

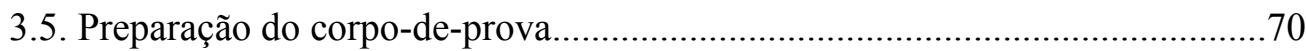

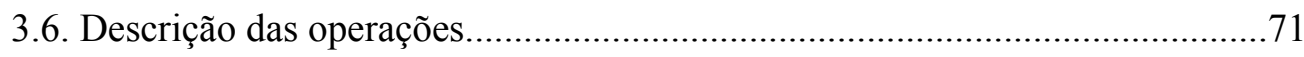

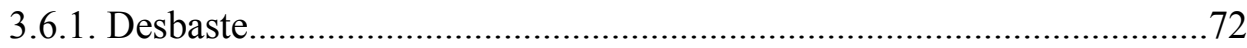

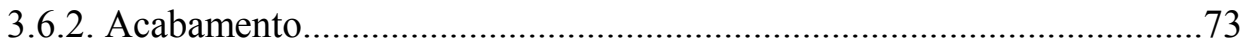

3.7. Medição experimental da rigidez estática da ferramenta................................75

3.8. Medição do perfil usinado...............................................................................76

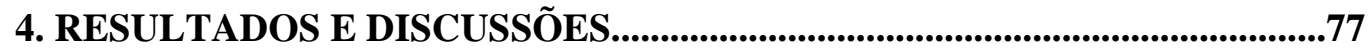

4.1. Análise da variação do sobremetal resultante da operação de desbaste deixado

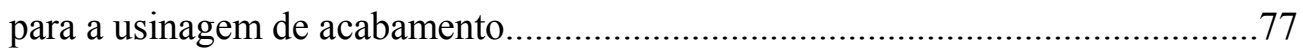

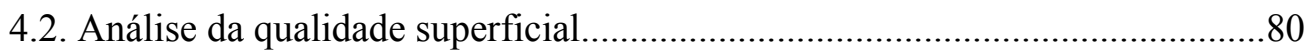

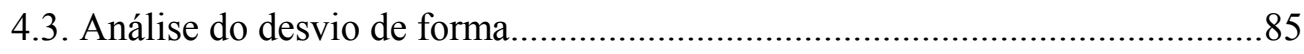

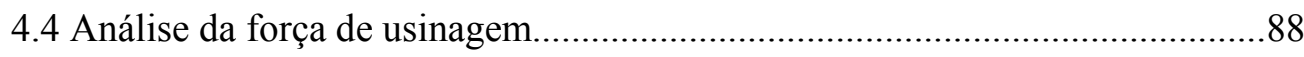

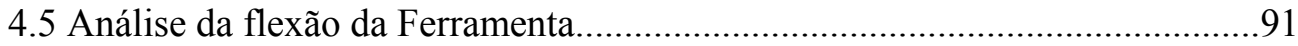

5. CONCLUSÕES E SUGESTÕES PARA FUTUROS TRABALHOS..................93

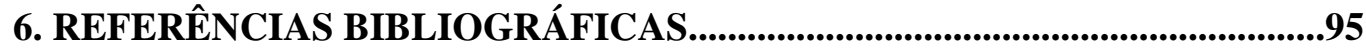

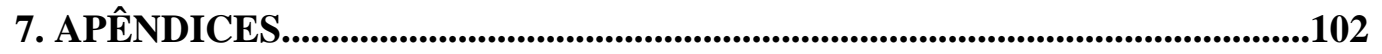




\section{RESUMO}

CAPLA, R. L. (2006). Estudo da influência do sobremetal excedente de desbaste na operação de acabamento aplicando usinagem com altas velocidades. São Carlos, 2006. Dissertação - Escola de Engenharia de São Carlos, Universidade de São Paulo.

Atualmente, devido à globalização das empresas e de seus produtos, tem havido uma competição acirrada no mercado mundial entre as organizações. Estas empresas se veêm obrigadas a contemplar as expectativas do mercado quanto à alta tecnologia, a qualidade do produto, os baixos custos e a redução dos tempos de desenvolvimento do produto. Todo este mecanismo gera uma busca continua de desenvolvimento da tecnologia dentro das empresas na área de fabricação, as quais estão intimamente relacionadas ao surgimento de novos materiais de difícil usinagem, assim como de novos revestimentos para ferramentas e de máquinas-ferramentas cada vez mais rápidas e eficientes. A utilização da tecnologia de usinagem com altas velocidades de corte - HSM (High Speed Machining) tem demonstrado grande eficiência para a fabricação de moldes e matrizes com formas complexas, propiciando uma vantagem competitiva para as organizações. Entretanto, o fresamento de formas complexas ainda apresenta vários gargalos na linha produção. Após as operações de desbaste, além do sobremetal deixado para as operações de acabamento, um volume excedente de material indesejado permanece na geometria. Este volume está relacionado à estratégia de desbaste em 2 1/2 eixos, ao grau de curvatura da superfície e à geometria da ferramenta de desbaste. Por não ser uniforme esta quantidade excedente de material acaba prejudicando o processo, especialmente quando uma das exigências é uma extrema precisão dimensional. Este trabalho procura identificar as características mais relevantes para preservar a qualidade superficial em função da flexão da ferramenta, devido a esse excedente de sobremetal. Desta forma, as variáveis de influência consideradas foram o balanço e o diâmetro da ferramenta, sua trajetória e o volume não-uniforme de material a ser removido. Os piores valores de rugosidade ocorreram com o máximo balanço independentemente de sua inclinação. Também foi possível constatar que a estratégia de usinagem ascendente gerou uma melhor rugosidade comparada com a descendente. Contudo em superfícies com pouca inclinação horizontal e com variações brusca de sobremetal a usinagem descendente obteve melhores resultados do que a ascendente. 
Palavras-chave: Usinagem com Altas Velocidades; Moldes e Matrizes; Qualidade Superficial; Rugosidade; sobremetal excedente; volume não uniforme de material. 


\section{ABSTRACT}

CAPLA, R. L. (2006). "Study of the stock removal remaining influence of the roughing operations in the finishing operations applying the High Speed Milling”. São Carlos, USP, 2006. Faculdade de Engenharia Mecânica, Escola de Engenharia de São Carlos, Universidade de São Paulo.

Nowadays the companies and their products have become global and, consequently, are facing an intense competition in the world market. These companies are forced to match the expectations of the market regarding technology, product quality, low costs and reduction of product development time. This entire mechanism generates continue search for the development of manufacturing technology, which are intimately linked to the arise of new and difficult to cut materials, as well as of new coatings for tools, fast and more efficient machine-tools. The use of High Speed Milling has demonstrate to be of great efficiency for the production of moulds and dies with complex forms, leading to a competitive advantage for companies. However, milling complex form still presents several bottle necks in the production line. After the roughing operations, besides the stock removal left for the finishing operations, an extra volume of unwanted material remains on the workpiece. This material is related to the roughing strategy in $2 \frac{1}{2}$ axes, to the degree of curvature of the surface and the geometry of the cutting tool. Since the distribution of that material is not uniform, it affects the product quality, especially when one of the requirements is a high dimensional precision. The present work aims at identifying the most important characteristics necessaries to obtain a good high superficial quality despite of the tool flexion during cutting. The tool length and its diameter are considered as well as the cutting strategy to remove the stock and its excess. The highest roughness values occurred with the largest in-balance length, independently on the surface inclination. It was also verified that for some cases upward cutting has produced smaller roughness being compared to the downward strategy. However, on surfaces with little horizontal inclination and with abrupt variations of stock removal the downward cutting can produce better result than upward cutting.

Keywords: High Speed Milling; Die and Moulds; Roughness; Quality Superficial; Remaining Stock Removal; Volume not material uniform. 


\section{LISTA DE ILUSTRAÇÕES}

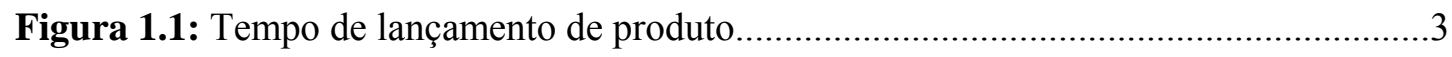

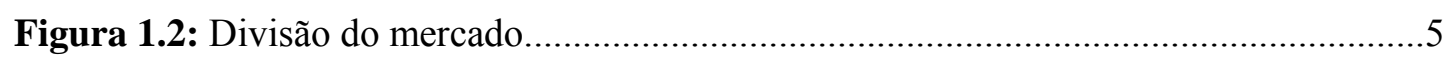

Figura 1.3: Distribuição de faturamento dos serviços..........................................................

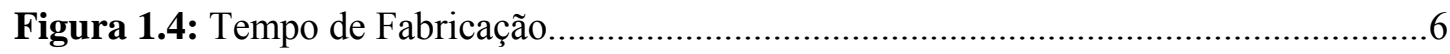

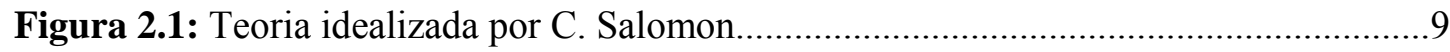

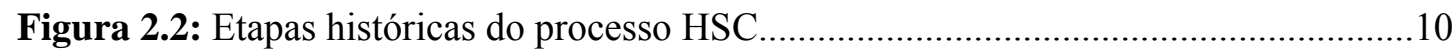

Figura 2.3: Temperatura versus velocidade de corte........................................................13

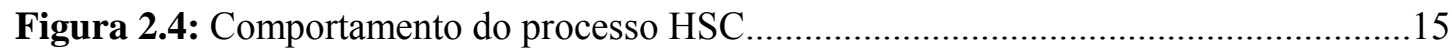

Figura 2.5: Faixas de velocidades de corte para diferentes materiais................................16

Figura 2.6: Velocidades de corte convencional e HSC .......................................................16

Figura 2.7: Racionalização do Processo de Fabricação de uma Matriz...............................19

Figura 2.8: Redução do ciclo de fabricação de moldes.......................................................21

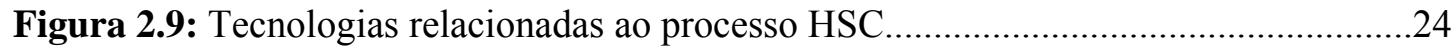

Figura 2.10: Componentes de uma máquina-ferramenta HSC .........................................26

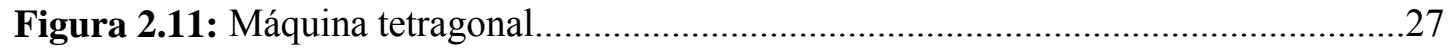

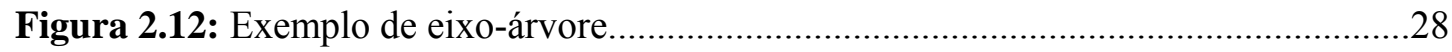

Figura 2.13: Comparação de esferas de material cerâmico e convencional.........................29

Figura 2.14: Comparação entre motores rotativos e lineares..............................................30

Figura 2.15: Problemas da utilização de um cone ISO em alta rotação...............................34

Figura 2.16: Cone HSK em destaque entre cones ISO..................................................... 34

Figura 2.17: Fixação por interferência e fixação hidro-mecânica........................................35

Figura 2.18: Sentido de corte - Fresamento tangencial.................................................. 40

Figura 2.19: Sentido de corte - Fresamento frontal.......................................................... 41

Figura 2.20: Espessura máxima dos cavacos $\operatorname{com}\left(\mathrm{V}_{\mathrm{c}}\right)$ recomendada..............................42

Figura 2.21: Descendente com grande espessura de cavaco e com $\left(\mathrm{V}_{\mathrm{c}}\right)$ muito baixa..........43

Figura 2.22: Desbaste com ferramentas de topo reto e esférico.........................................44

Figura 2.23: Geometria do processo com fresa de topo esférico........................................45

Figura 2.24: Geometria do processo com fresa de topo esférico.......................................45

Figura 2.25: Geometria do processo com fresa de topo esférico........................................46

Figura 2.26: Geometria do processo com fresa de topo esférico......................................46

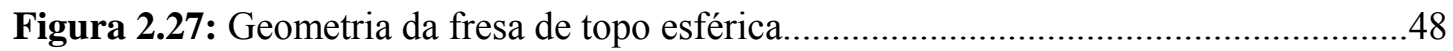


Figura 2.28: Características de um processo de usinagem estável.....................................49

Figura 2.29: Características de um processo de usinagem não estável..............................50

Figura 2.30: Representação da haste da ferramenta como um sistema engastado..............51

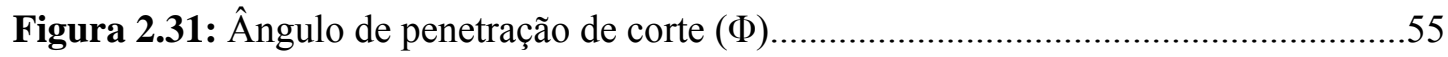

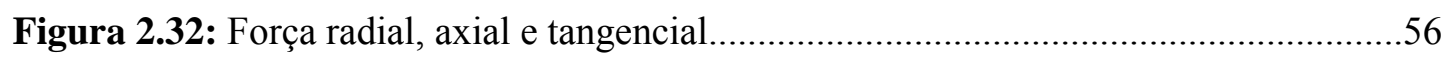

Figura 2.33: Representação simplificada das forças de corte.............................................57

Figura 2.34: Influência do pré-acabamento no resultado final............................................61

Figura 2.35: Variação do volume de material após a operação de desbaste........................62

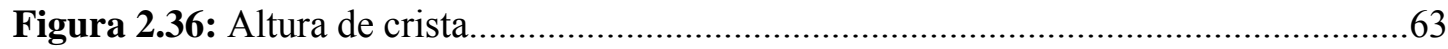

Figura 2.37: Representação trigonométrica para cálculo da altura de crista.......................64

Figura 2.38: Rugosidade de uma superfície plana após usinagem.....................................65

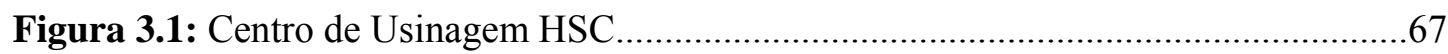

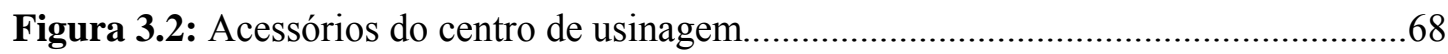

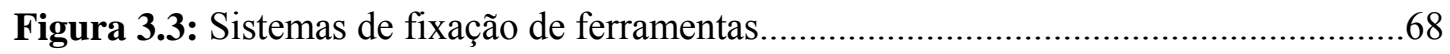

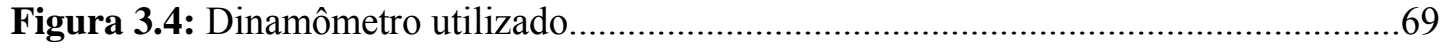

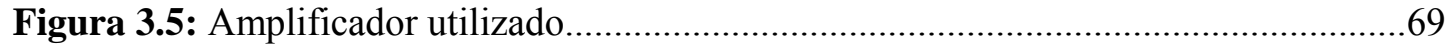

Figura 3.6: Sistema de aquisição e tratamento de sinais.................................................... 70

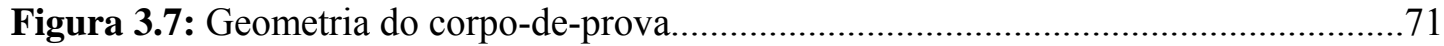

Figura 3.8: Aspectos gerais das ferramentas utilizadas nos testes....................................72

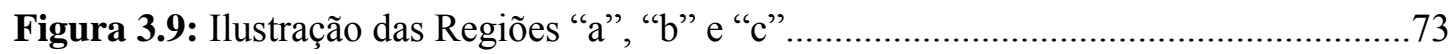

Figura 3.10: Estratégia e posição do corpo-de-prova em relação ao dinamômetro.............74

Figura 3.11: Esquema do método experimental utilizado para estimativa da rigidez..........75

Figura 3.12: Esquema de alinhamento e de medição das regiões “a, b e c".........................76

Figura 4.1: Superfícies com diferentes inclinações e com brusca transição.........................77

Figura 4.2: Corpo-de-prova após as usinagem de acabamento.........................................78

Figura 4.3: Características geométricas do sobremetal na Região "c"..............................78

Figura 4.4: Contato da ferramenta em função do sentido de corte......................................79

Figura 4.5: Rugosidade Ra para a fresa esférica de ø 12 mm............................................81

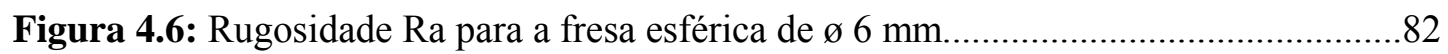

Figura 4.7: Rugosidade Ra para a fresa esférica de ø $6 \mathrm{~mm}$, balanço de $45 \mathrm{~mm}$.................83

Figura 4.8: Contato entre a ferramenta e as superfícies usinadas......................................83

Figura 4.9: Ferramenta lascada por instabilidade no processo........................................84

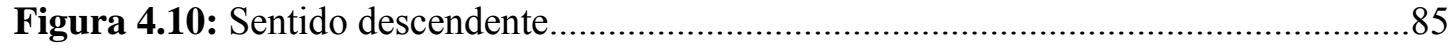

Figura 4.11: Erro de forma da região "a" da superfície usinada.........................................86 


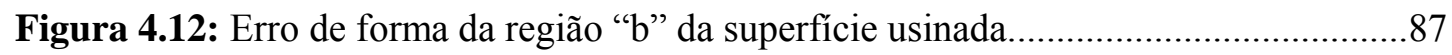

Figura 4.13: Erro de forma da região "c" da superfície usinada........................................87

Figura 4.14: Aspecto visual das superfícies obtidas com fresa $\varnothing 6 \mathrm{~mm}$.............................8

Figura 4.15: Gráfico das forças de usinagem para a ferramenta de $6 \mathrm{~mm}$ de diâmetro.......89

Figura 4.16: Gráfico das forças de usinagem para a ferramenta de $12 \mathrm{~mm}$ de diâmetro....89

Figura 4.17: Vibração do dinamômetro/peça e a ação de cada aresta de corte....................90

Figura 4.18: Resultado da rigidez da fresa de $6 \mathrm{~mm}$ obtida experimental.........................91 


\section{LISTA DE TABELAS}

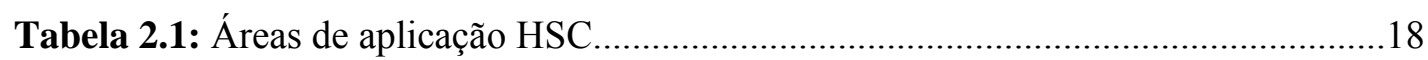

Tabela 3.1: Detalhes das ferramentas utilizadas para desbaste e acabamento....................72

Tabela 3.2: Parâmetros de corte utilizados no desbaste....................................................73

Tabela 3.3: Dados e parâmetros utilizados nas operações de acabamento.........................74

Tabela 3.4: Valores máximo e mínimo para a velocidade de corte..................................74

Tabela 4.1: Material remanescente em função das superfícies do corpo-de-prova...........80 


\section{LISTA DAS NOTAÇÕES E SÍMBOLOS}

\begin{tabular}{|c|c|}
\hline$A_{c}$ & Altura de crista $[\mathrm{mm}]$ \\
\hline $\mathrm{f}_{\mathrm{z}}$ & Avanço por aresta $[\mathrm{mm} /$ aresta $]$ \\
\hline Dg max & Diâmetro efetivo de corte (ferramenta de ponta esférica) [mm] \\
\hline$a_{e}$ & Profundidade Lateral de Corte $[\mathrm{mm}]$ \\
\hline$a_{p}$ & Profundidade de corte $[\mathrm{mm}]$ \\
\hline $\mathrm{V}_{\mathrm{c}}$ & Velocidade de corte $[\mathrm{m} / \mathrm{min}]$ \\
\hline $\mathrm{V}_{\mathrm{f}}$ & Velocidade de avanço $[\mathrm{mm} / \mathrm{min}]$ \\
\hline $\mathrm{V}_{\mathrm{ce}}$ & Velocidade efetiva de corte $[\mathrm{m} / \mathrm{min}]$ \\
\hline $\mathrm{E}$ & Módulo de elasticidade \\
\hline I & Momento de inércia \\
\hline $\mathrm{F}$ & Força na extremidade do cilindro \\
\hline $\mathrm{K}$ & Módulo de elasticidade \\
\hline h & Espessura do cavaco não deformado \\
\hline h' & Espessura do cavaco deformado \\
\hline hm & Espessura média do cavaco \\
\hline $\mathrm{b}$ & Largura do cavaco \\
\hline De & Diâmetro efetivo \\
\hline Dn & Diâmetro nominal \\
\hline $\mathrm{D}$ & Diâmetro \\
\hline $\mathrm{Fu}$ & Força de usinagem \\
\hline $\mathrm{Fc}$ & Força de corte \\
\hline Fr & Força radial \\
\hline Fn & Força normal \\
\hline $\mathrm{Ft}$ & Força tangencial \\
\hline Fat & Força ativa \\
\hline FT & Força de atrito na superfície de saída da ferramenta \\
\hline FT' & Força de atrito na superfície de folga da ferramenta \\
\hline Ff & Força de avanço \\
\hline Fé & Força efetiva \\
\hline Fap & Força de apoio \\
\hline $\mathrm{Fp}$ & Força passiva \\
\hline $\mathrm{Fa}$ & Força axial \\
\hline
\end{tabular}




$\begin{array}{ll}\text { R } & \text { Raio da ferramenta } \\ \psi \text { o } & \text { Ângulo de engajamento } \\ \text { Xo } & \text { Ângulo de posição } \\ \text { Icp } & \text { Comprimento de corte } \\ \text { ho } & \text { Espessura de usinagem instantânea } \\ \delta & \text { Flexão da ferramenta } \\ \Phi & \text { Ângulo de atuação da aresta em um ponto específico do corte } \\ \Phi_{\mathrm{t}} & \text { Ângulo de atuação da aresta no corte } \\ \gamma & \text { Ângulo de saída da ferramenta } \\ \mu & \text { Coeficiente de atrito } \\ \text { Ks } & \text { Pressão especifica } \\ \mathrm{x} & \text { Ângulo de penetração da aresta no sentido axial } \\ \mathrm{K}_{\mathrm{c} 1.1} & \text { Força específica de corte - Kienzle } \\ \text { Pc } & \text { Potência de corte } \\ \mathrm{L} & \text { Comprimento de balanço da ferramenta }\end{array}$




\section{LISTA DE ABREVIAÇÕES E SIGLAS}

$\begin{array}{ll}\text { CIM } & \text { Computer Integrated Manufacturing } \\ \text { CAD } & \text { Computer Aided Design } \\ \text { CAE } & \text { Computer Aided Engineering } \\ \text { CAM } & \text { Computer Aided Manufacturing } \\ \text { CNC } & \text { Comando Numérico Computadorizado } \\ \text { NC } & \text { Numerical Control } \\ \text { HSC } & \text { High Speed Cutting } \\ \text { HSM } & \text { High Speed Machining } \\ \text { EDM } & \text { Electrical Discharge Machining } \\ \text { PTW } & \text { Instituto de Técnicas de Produção e Máquinas Ferramentas } \\ \text { OPF } & \text { da Universidade Técnica de Darmstadt (Alemanha) } \\ & \text { Laboratório para Otimização de Processos de Fabricação. } \\ & \text { Escola de Engenharia de São Carlos }\end{array}$




\section{Introdução}

A aceleração do desenvolvimento tecnológico e a adoção de modernos processos de produção industrial são fenômenos que veêm se difundindo mundialmente, através do processo de globalização da economia mundial. Os reflexos desse processo mundial já são sentidos no Brasil, obrigando as indústrias nacionais a adaptarem-se às novas exigências do mercado mundial.

$\mathrm{O}$ desenvolvimento tecnológico aliado à alta competitividade do mercado, impulsiona o setor industrial, para a utilização intensiva de tecnologias ligadas à eletrônica e à informática. Nota-se uma ampla e crescente utilização do computador, nas diversas fases de fabricação de produtos, iniciando no projeto (Computer Aided Design - CAD), finalizando na manufatura (Computer Aided Manufacturing - CAM). Além disso, uma aplicação constante no controle de processos e na automação industrial (com a utilização de sensores, atuadores e Controler Logical Programer - CLP), a utilização de máquinas automatizadas (Comando Numérico Computadorizado - CNC), os braços mecânicos programáveis (robôs) e a integração do sistema de manufatura (Computer Integrated Manufacturing - CIM). Dessa forma, a automação industrial é um processo irreversível, tornando-se ferramenta imprescindível na busca da qualidade, produtividade e competitividade.

Considerando-se a rapidez com que as mudanças ocorrem na atualidade, as organizações são obrigadas a fabricar produtos com qualidade, baixo custo, buscando sempre a contínua satisfação de seus clientes. Ter rapidez na tomada de decisões e ser capaz de adequar-se continuamente às novas realidades devem ser as práticas fundamentais de empresas que têm como objetivo manter-se competitivas no mercado, o qual não possui fronteira nacional.

A própria popularização da internet com sua conectividade global, aliada aos avanços da tecnologia de informação, tem contribuindo para uma maior integração entre fornecedores e clientes, visando por sua vez, uma maior rapidez nos fluxos de informações entre as organizações, AGOSTINHO (1996) e LACERDA (2001).

A competitividade nas últimas décadas aumentou constantemente e, nas décadas de 50 e 60 , os esforços eram concentrados na redução de custos. Na década de 70 , as atenções estavam voltadas para a qualidade de produtos. Atualmente, os fatores de flexibilidade e o tempo de resposta inicialmente empregados nas décadas de 80 e 90 passaram a ser 
obrigações, onde a integração dos Sistemas de Manufatura tornou-se um grande diferencial competitivo, auxiliando a adaptação às novas realidades e ao aproveitamento de novas oportunidades.

A capacidade de manter-se competitivo está diretamente relacionada a diversos atributos, dentre os quais se destacam liderança, inovação e capacidade de resposta. Entretanto, todos dependem diretamente da capacidade de integração dos diversos componentes estruturais da organização, tantos em relação às inter-relações internas e externas. $O$ atributo liderança envolve uma série de sub-atributos, tais como foco no consumidor, qualidade, planejamento, competências centrais, melhoria contínua e acompanhamento de desempenho. A inovação é uma combinação de criatividade e geração de novas idéias, tanto para atrair clientes ou para melhorar o negócio, o que é diretamente dependente da habilidade de implementação. O terceiro atributo necessário à competitividade numa organização é a sua capacidade de resposta aos estímulos externos, caracterizado pela busca efetiva de feedback dos clientes e dos fornecedores, além da habilidade de tornar-se uma empresa de ciclo rápido. Estes são os elementos principais e imprescindíveis para uma efetiva capacidade de resposta. Isto por sua vez, tem como principais sub-atributos a excelência nos processos de negócio, a integração de estratégias, a adoção de tecnologia comprovada, a conexão direta com clientes e fornecedores e a capacidade de adaptação.

Nesta breve visão de padrões de competitividade e de Sistemas de Manufatura, pode-se observar a importância da integração interna da organização, além da sua integração com clientes e a cadeia de fornecedores. A empresa deve estar bem estruturada e integrada com as demais empresas que formam a cadeia logística global para conseguir atingir o sucesso, AGOSTINHO (1996).

Velocidade e integração são os fatores cruciais para o sucesso de organizações que atuam em um ambiente de concorrência acirrada, capaz de sustentar as vendas em especial por possibilitar o rápido atendimento às demandas do mercado, num momento em que existe uma diminuição do tempo entre o lançamento de um produto e outro em alguns setores da indústria.

Para que se possa extrair o máximo neste tipo de investimento é necessário compreender a aplicação de ferramentas e os fenômenos envolvidos no seu uso econômico. É preciso ter uma visão do todo, pois são muitas as variáveis que poderão interferir no sucesso do investimento. Começando por máquinas, software, ferramentas de corte e sistemas de fixação, fluidos de corte, material da peça até a habilidade técnica da equipe de trabalho, tudo deve estar em harmonia com os objetivos de custos e produtividade da empresa. 
A eficácia do chão-de-fábrica é parte fundamental na cadeia de fabricação, pois pode-se fabricar qualquer item, em qualquer quantidade, dentro de qualquer prazo, com a melhor qualidade, pelo melhor custo, devido a um diferencial de competitividade.

Segundo Ovtcharova (2002) nesta competição global o sucesso ou não de uma organização está relacionado com tempo de lançamento de um novo produto no mercado, atrasar o tempo de lançamento pode representar uma perda do retorno planejado, sem considerar que os recursos foram mal direcionados, além de prejudicar toda cadeia de desenvolvimento, conforme figura 1.1.

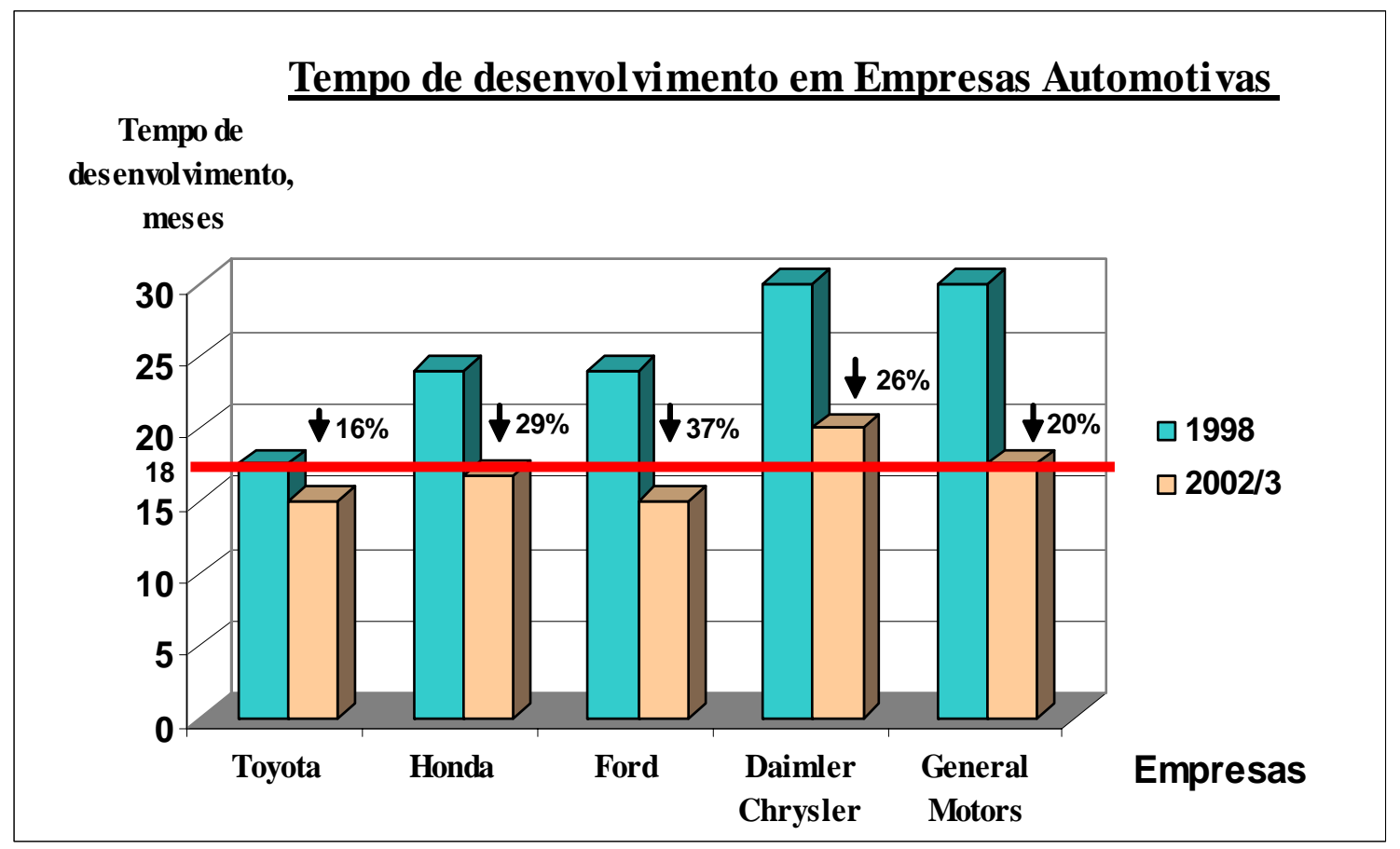

Figura 1.1 - Tempo de lançamento de produto (Adaptado de Ovtcharova, 2002).

Assim, pode-se afirmar que a otimização da cadeia produtiva de moldes e matrizes influenciará na diminuição do tempo total de lançamento de novos produtos, APQP (1995); OVTCHAROVA (2002); e URBANSKI (2000).

A otimização da manufatura de um produto é um dos objetivos da indústria de bens de consumo, principalmente na indústria metal-mecânica de ferramentaria. Otimizar significa, em um primeiro momento, reduzir os tempos de fabricação dos diferentes produtos, tempos de processamento e tempos improdutivos, preparação de máquinas e dispositivos, etc. 
No setor de ferramentaria o mais importante é trabalhar em condições operacionais ideais, pois o lote de fabricação é geralmente unitário o que, por sua vez, implica na alocação de todos os custos de produção em apenas um único produto.

Neste contexto a usinagem com altas velocidades de corte denominada como High Speed Cutting é considerada extremamente promissora, devido aos benefícios propiciados, em termos de redução de custos, tempos de fabricação, lead-times, melhoria da qualidade superficial e dimensional, redução das forças de corte proporcional ao aumento da velocidade de corte e melhor dissipação do calor do processo de corte, OLIVEIRA (2003).

Apesar do nome sugerir um tipo de usinagem em que se obtêm peças acabadas em tempos menores, a situação não é bem esta, mesmo operando em altíssimas velocidades às vezes se aplica avanços mínimos por rotação e por este motivo nem sempre os ganhos em tempo unitário são significantes. $\mathrm{Na}$ verdade as melhorias obtidas estão mais relacionadas com a qualidade superficial da peça usinada e a eliminação de etapas nos processos de acabamento, MARCONDES (2003).

O interesse pelo uso desta técnica de usinagem tem aumentado, não apenas em empresas do ramo aeronáutico, mas também automobilístico e eletro-eletrônico apresentando uma aplicação mais precisa no setor de matrizarias.

Atualmente, a principal aplicação de altas velocidades de corte está nas operações de fresamento, envolvendo desbaste e acabamento de materiais não ferrosos, visando altas taxas de remoção de material, aplicada na indústria aeronáutica, aeroespacial e automobilística. A pesquisa realizada pelo Institute for Prodution Engineering and Machine Tools (PTW) da Universidade Técnica de Darmstadt na Alemanha mostra que a tecnologia de usinagem com altas velocidades de corte também pode ser aplicada para operações de torneamento, fresamento e furação, SCHUTZER (1999).

De acordo com FALLBOHMER (1996) e LIMA (1994), desde a abertura do mercado no início da década de 90, as indústrias locais vêem sofrendo forte concorrência de indústrias estrangeiras em seus vários segmentos. No Brasil, as ferramentarias nacionais não seriam exceções, estando por sua vez em desvantagem tecnológica e produtiva em relação à indústria estrangeira. Assim, o desenvolvimento tecnológico tem sua razão relacionada à necessidade de sobrevivência num quadro de extrema competição. Atualmente, os maiores fornecedores mundiais de ferramentas são os EUA seguidos pelo Japão e Alemanha, contudo esses líderes de mercado enfrentam concorrência cada vez maior da França, Itália, Península Ibérica e dos Tigres Asiáticos, que possuem como principal 
vantagem os custos menores de mão-de-obra. Este é um fator de grande peso, num setor em que as operações de acabamento requerem um grande percentual de polimento manual. A indústria automobilística é a principal cliente do setor de moldes e matrizes, mais de $80 \%$ do faturamento encontra-se no setor de veículos automotivos, seguidos pelos setores de eletrônicos e eletrodomésticos, vide figura 1.2.

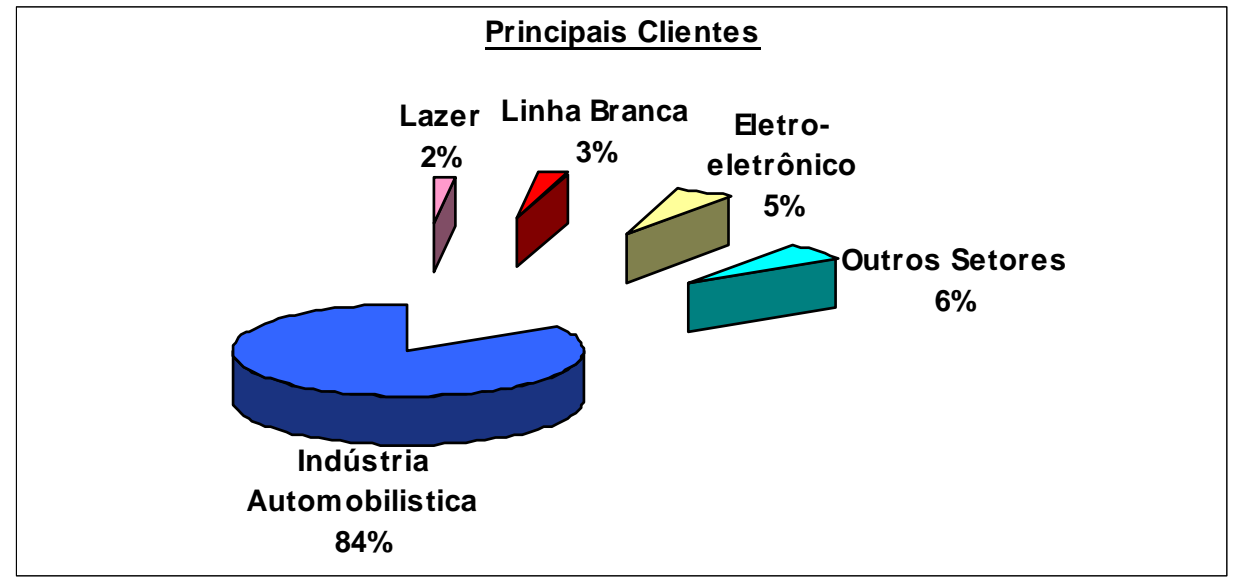

Figura 1.2 - Divisão do mercado (Adaptado de FALLBOHMER, 1996).

O maior faturamento do setor de matrizaria corresponde aos grupos de moldagem de plásticos (moldes de injeção, sopro), isto ocorre devido ao maior número de produtos no mercado. No caso de matrizes de estampagem a alta percentagem no faturamento é explicada pelo alto preço das matrizes, figura 1.3.

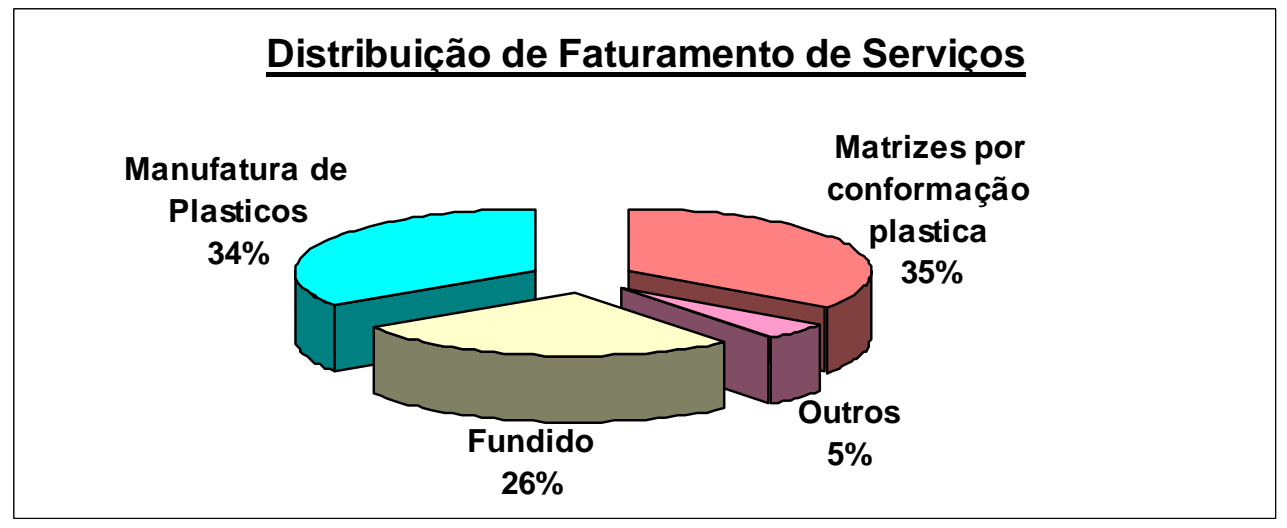

Figura 1.3 - Distribuição de faturamento (Adaptado de FALLBOHMER, 1996).

Segundo Gomes (2001) os Japoneses estão na frente neste mercado apresentando-se como os que fabricam mais ferramentas por ano, além de possuírem um menor tempo de 
fabricação, com um prazo de entrega médio de um molde de injeção por volta de 5 a 10 semanas. Na Alemanha e EUA, esse tempo está em torno de 10 a 20 semanas, enquanto no Brasil varia de 20 a 25 semanas.

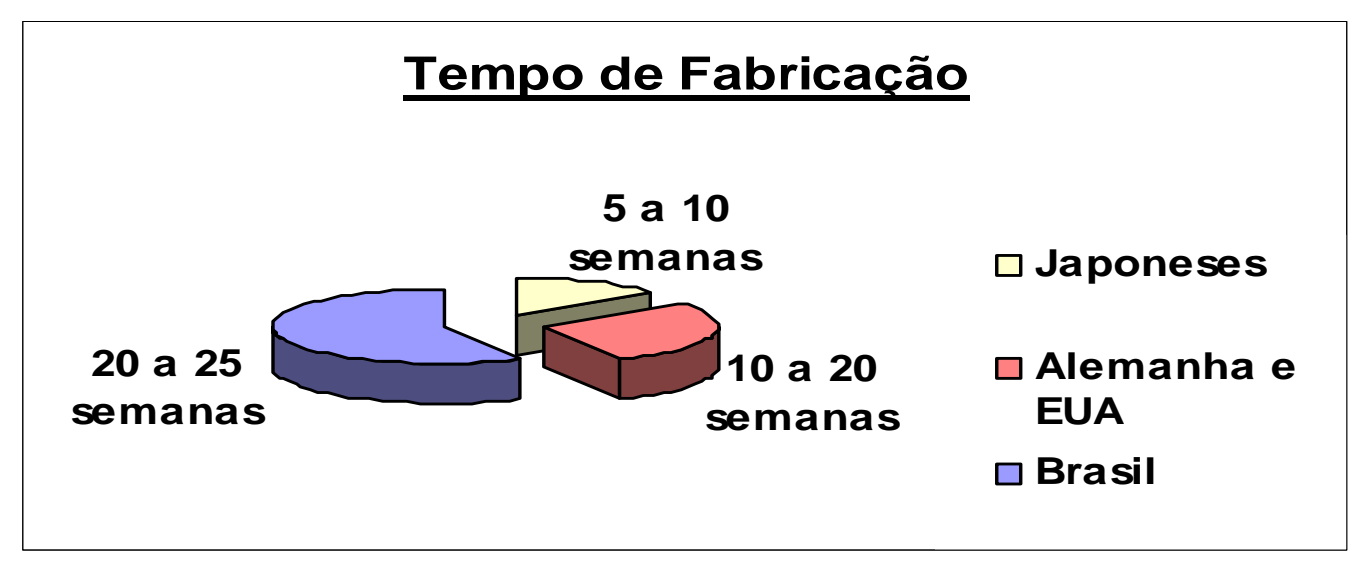

Figura 1.4 - Tempo de Fabricação (Adaptado de GOMES, 2001).

O desenvolvimento da Tecnologia HSC pelas indústrias de forma individual torna-se inviável, pois não se trata de se possuir um eixo-árvore e servo motor trabalhando em altíssima velocidade, mas sim de uma nova concepção do processo de manufatura, envolvendo toda a cadeia produtiva. Todos os fatores que influenciam no processo de usinagem devem ser cuidadosamente estudados para se obter uma aplicação eficiente e segura da tecnologia.

Para se atingir altas velocidades de corte e avanço principalmente para regiões complexas, limitações tecnológicas impedem a efetiva usinagem em HSC com precisão, que por sua vez compromete tanto a velocidade de trabalho do processo, como a precisão de contorno e qualidade superficial.

Na usinagem de moldes e matrizes contendo formas complexas, as operações de desbaste são, normalmente, realizadas em $2 \frac{1}{2}$ eixos, iniciando-se por um bloco prismático de matéria-prima. Nesta operação, um sobremetal é programado para ser removido posteriormente nas operações de acabamento. Embora este sobremetal seja, considerado, pelo sistema CAM, como sendo um perfil homogêneo, paralelo ao contorno final, um excedente de material não pode ser removido por limitações geométricas de contato, entre a ferramenta de corte e a superfície usinada. Este excedente de material se altera em função de três fatores: profundidade de usinagem $\left(a_{p}\right)$; grau de curvatura ou inclinação da superfície e também devido à geometria da ferramenta de corte SOUZA (2001). Embora os sistemas CAM atuais empreguem algoritmos sofisticados para identificar estas regiões, 
com a finalidade de minimizar o problema, este é um fato que sempre ocorre nesta seqüência de fabricação.

Grandes alterações no volume de material a ser removido durante a usinagem, em virtude destas transições topográficas em forma de escada, pode acarretar instabilidade no processo, principalmente quando se aplica usinagem em altas velocidades GOMES (2003).

\subsection{Objetivos}

Este trabalho objetiva estudar os problemas causados pelo excesso de sobremetal comumente deixado pela operação de desbaste. Um modelo de corpo-de-prova, com 3 diferentes inclinações, foi elaborado simulando situações com significativas variações do sobremetal excedente. A qualidade superficial será analisada em função da flexão de ferramentas de diferentes diâmetros causadas pelo excedente de sobremetal, assim como a retilineidade da superfície fresada. Também são considerados o comprimento em balanço da ferramenta e sua trajetória.

\subsection{Estrutura da Dissertação}

A estrutura deste trabalho está dividido em 6 capítulos:

$\checkmark$ Capítulo 1: Introdução com o intuito de situar o leitor dentro do panorama mundial em que se encontra a tecnologia HSC, apresenta também a estrutura da dissertação bem como uma breve descrição dos capítulos que compõem o documento.

$\checkmark$ Capítulo 2: Revisão bibliográfica do assunto contribuindo para o estudo da HSC, com tópicos que tratam do processo de usinagem, histórico e tecnologia HSC, suas aplicações, vantagens e limitações, ferramentas, máquinas operatrizes, eficiência, flexão da ferramenta, mecanismo de formação de cavaco, força e temperatura de corte. 
$\checkmark$ Capítulo 3: Procedimento experimental, destacando-se os dados utilizados nos ensaios como a máquina-ferramenta, as ferramentas, sistemas de fixação, corpo-de-prova, sistemas de aquisição de dados, equipamentos de medição e análise, planejamento do experimento e metodologias aplicados na execução do ensaio.

$\checkmark$ Capítulo 4: Resultados e discussões apresentados com uma análise dos resultados focando a qualidade superficial, a exatidão dimensional da superfície usinada e a flexão da ferramenta.

$\checkmark$ Capítulo 5: Conclusões pertinentes ao trabalho e as sugestões para futuros trabalhos.

$\checkmark$ Capítulo 6: Bibliografia.

$\checkmark$ Capítulo 7: Apêndices. 


\section{Revisão Bibliográfica}

\subsection{Breve Histórico da Usinagem com Altas Velocidades de Corte}

A tecnologia de usinagem com altas velocidades de corte já vem sendo desenvolvida há cerca de 70 anos. O método desenvolvido por C. Salomon mostrou uma série de limitações em termos de máquinas. Para poder realizar seus experimentos Salomon utilizou-se de uma serra circular de grande diâmetro. Mesmo com baixa rotação, o equipamento permitia uma velocidade periférica bastante alta, os ensaios foram realizados com materiais ferrosos e não ferrosos.

Com este experimento Salomon pôde observar que ao aumentar a velocidade de corte um aumento da temperatura era correspondente (Velocidade de corte no ponto "a" da figura 2.1), sendo que a partir de um determinado ponto as temperaturas caiam (Velocidade de corte no ponto "b" da figura 2.1). Assim, aumentando-se a velocidade de corte a temperatura diminuíam conjuntamente com as forças de corte o que veio a se tornar uma das principais características do processo HSC.

Com o aumento da velocidade de avanço e alta remoção de material o aquecimento da peça pode ser minimizado, pois grande parcela do calor gerada durante o processo de corte é dissipada juntamente com o cavaco, CEBALO (1999).

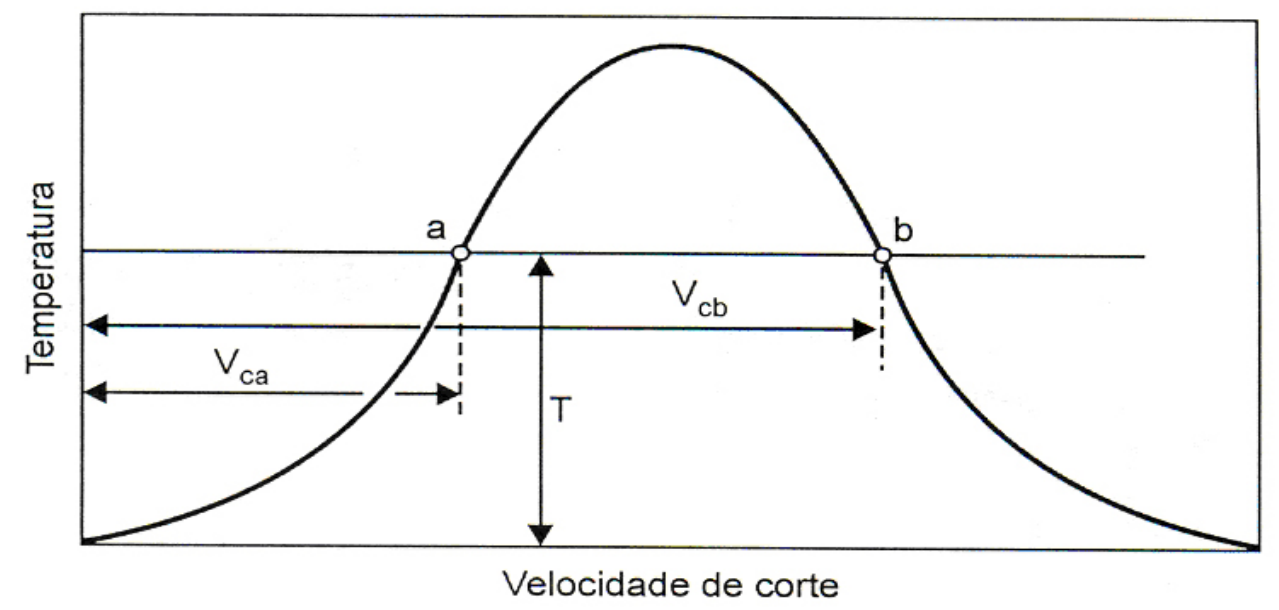

Figura 2.1 - Teoria idealizada por C. Salomon (MACHADO e BACCI, 2003). 
Infelizmente o uso prático destes estudos foi muito limitado em função da própria utilização de ferramentas de grande diâmetro, como no caso da serra circular utilizada por Salomon.

O método de Salomon ficou adormecido por vários anos porém, após a Segunda Guerra as pesquisas foram retomadas com a realização de ensaios balísticos, figura 2.2, pois não havia máquinas-ferramentas que permitissem as velocidades de cortes necessárias (SCHUTZER e SCHULZ, 2003).

Diversos estudos realizados na década de 60 nos Estados Unidos mostraram que a produtividade aumenta significativamente e os custos de produção podem ser reduzidos, se os problemas com o intenso desgaste das ferramentas e as vibrações nas máquinas trabalhando a altas velocidades pudessem ser solucionados, VAUGHN (1958).

Mc Gee apresentou na década de 70 resultados bastante promissores no aumento da produtividade e redução de custos na usinagem de alumínio com velocidade de corte de $5.500 \mathrm{~m} / \mathrm{min}$. As pesquisas visando o desenvolvimento tecnológico do processo com fins industriais só tiveram início nos anos 80 na PTW, da Alemanha com o patrocínio do Ministério de Ciência e Tecnologia da Alemanha.

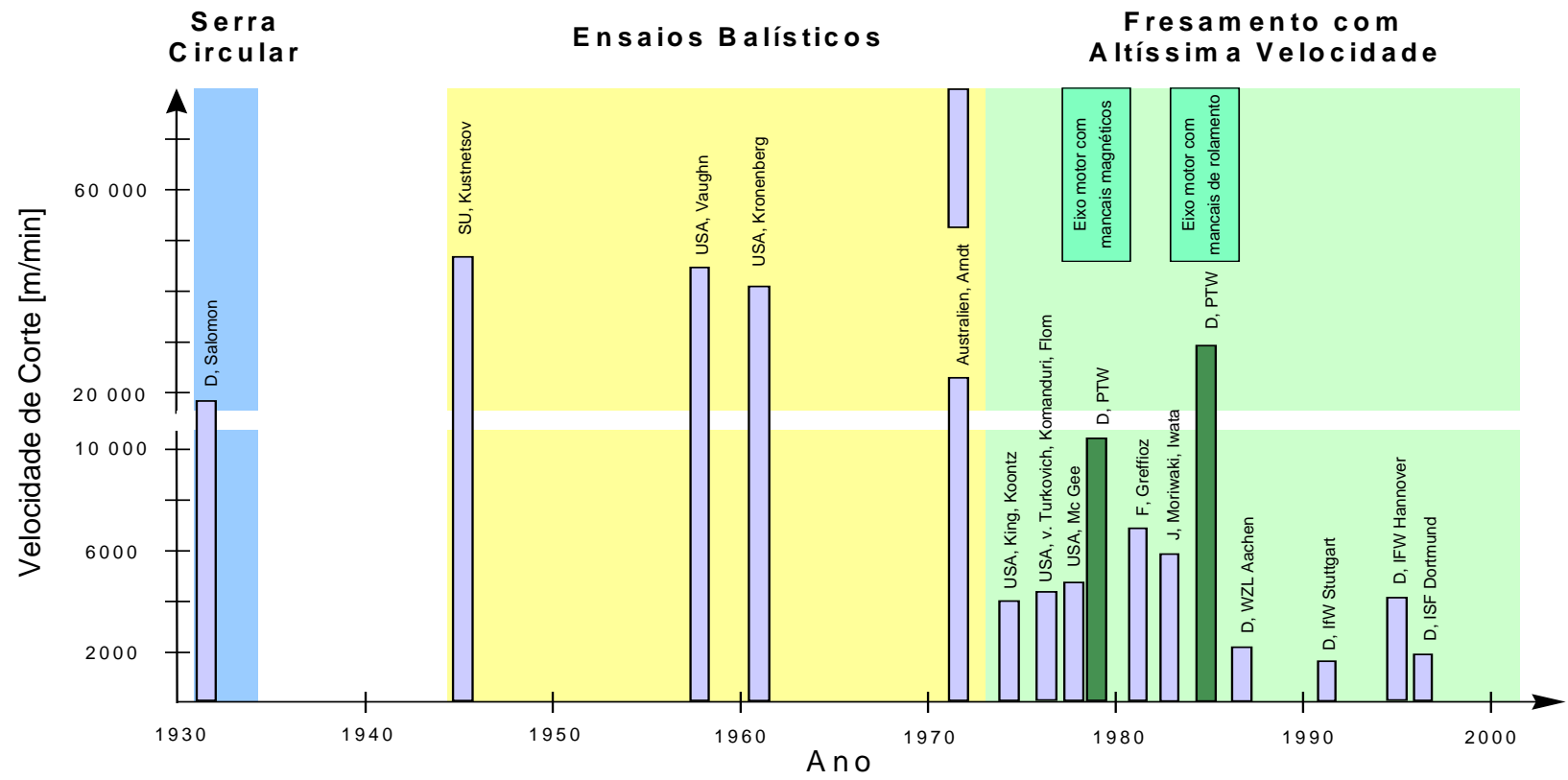

Figura 2.2 - Etapas históricas do processo HSC (SCHUTZER e SCHULZ, 2003). 
Foram iniciados projetos com o objetivo de desenvolver máquinas-ferramentas, componentes e acessórios (eixo-motor de alta rotação, acionamento, ferramental, dispositivos de fixação, $\mathrm{CNC}$, etc). Só com a conclusão desses projetos, no início da década de 90, é que a usinagem HSC se tornou efetivamente um processo industrial, SOUZA (2001).

\subsection{Conceito da Usinagem em Altas Velocidades}

A usinagem HSC é atualmente a mais importante tecnologia de usinagem em desenvolvimento e implantação, é utilizada em processos de fresamento, furação, torneamento e também retificação. Apresenta a possibilidade de trabalhar com velocidades de corte cinco a dez vezes maiores do que as normalmente utilizadas, utilizando avanços e profundidades de corte muito menor do que aquelas adotadas em usinagem convencionais.

Embora possa ser utilizada em operações de desbaste, a sua aplicação é principalmente indicada para semi-acabamento e acabamento.

Inicialmente, pode parecer estranho falar de um processo de alta produtividade com avanços por dente $\left(f_{z}\right.$ até $\left.0,25 \mathrm{~mm}\right)$ e profundidades de corte $\left(a_{p}\right.$ entre 0,01 a $\left.0,5 \mathrm{~mm}\right)$ tão reduzidas, porém devido às altas velocidades de corte, é possível atingir velocidades de avanço de até 30 metros por minuto, OLIVEIRA (2003).

Normalmente, vários fatores interferem no processo de usinagem, no caso de altas velocidades essa interferência é ainda maior. A usinagem HSC é na verdade uma tecnologia não convencional em que fatores como máquina, ferramenta de corte, material e forma da peça a ser usinada, além do próprio processo a ser elaborado interage entre si de uma forma bem mais crítica do que no processo convencional, (SANDVIK, 1999).

A usinagem HSC pode ser definida como o uso de velocidades de eixos-árvore e taxas de avanço mais elevadas para uma remoção mais rápida de material, sem o comprometimento da precisão ou qualidade, normalmente quando as taxas de avanço da usinagem excedem freqüentemente os $5.000 \mathrm{~mm} / \mathrm{min}$.

A produção de peças com alta qualidade, utilizando a tecnologia HSC como método de usinagem, depende de todo o conjunto da máquina-ferramenta, ou seja, os componentes mecânicos da máquina, o hardware e o software que a controla. Estes recursos estão em 
constante desenvolvimento, pois trata-se de uma tecnologia nova e que está, cada vez mais, sendo explorada, MARINAC (2001).

Para obter maior velocidade de usinagem, é necessária uma CPU (Central Processing Unit) de $\mathrm{CNC}$ com processamento rápido, um conjunto de drives digitais entre outros itens sugeridos.

Para melhorar a precisão, utilizam-se formas mais suaves de aceleração, rapidez de respostas do sistema, componentes mecânicos e drives, além da utilização de funções específicas para a eliminação de erros. Programas elaborados com funções polinomiais ou splines, acelerações suaves e transição de velocidades suaves são itens necessários para atingir um alto grau de qualidade de acabamento de superfície usinada. Porém, alguns destes itens interferem entre si, fazendo com que a melhoria de um dos objetivos, signifique a piora de outro, MOREIRA (2002) e ARNONE (1998).

Ainda segundo os estudos iniciados por Salomon (1931), após uma determinada velocidade de corte as temperaturas de usinagem começavam a decrescer, ou seja, com o aumento da velocidade de avanço, espessuras pequenas e altas taxas de remoção, levavam à minimização do aquecimento da peça, pois uma grande parcela do calor gerado durante o processo de corte é dissipada juntamente com o cavaco.

De acordo com OLIVEIRA (2003), SANDVIK (1999), SCHULZ (1997), SCHUTZER e SCHULZ (2003), com o aumento da velocidade de corte, pôde-se obter um aumento no volume de material removido, uma redução das forças de corte e a melhoria da qualidade superficial. Porém, um fator negativo que o processo apresenta é uma redução da vida útil da ferramenta de corte.

Sabe-se, de fato, que a temperatura na aresta de corte tende a diminuir em certos níveis de velocidade de corte, níveis estes bem superiores aos dos processos convencionais, este fenômeno ocorre com maior intensidade em ligas de alumínio e metais não ferrosos e com menor intensidade em aços e ferros fundidos, em processos de corte interrompido, conforme observado na figura 2.3 . 


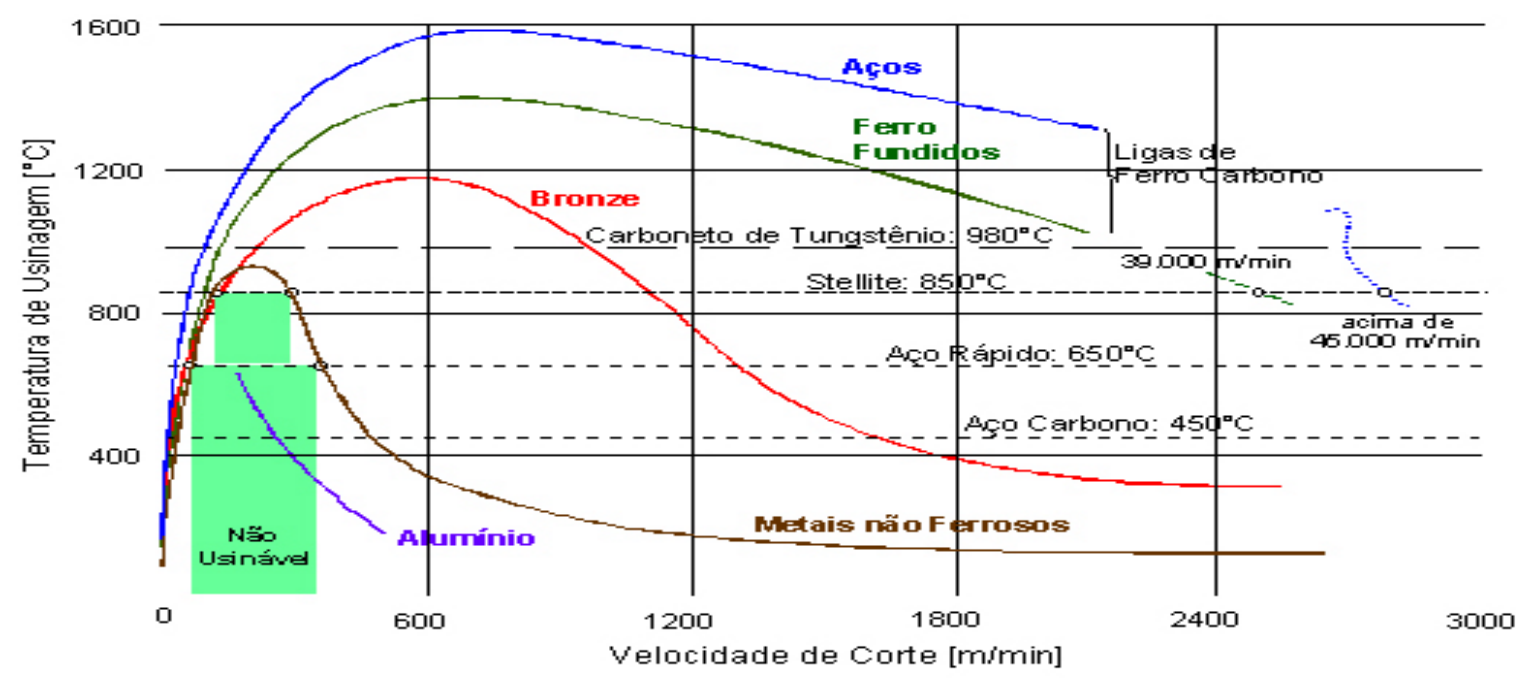

Figura 2.3 - Temperatura versus velocidade de corte (SCHUTZER e SCHULZ 2003).

A formação do cavaco também é diferente no processo de corte com altas velocidades, tendendo a uma forma de cavaco mais segmentada do que no processo convencional, mas este fato também não apresenta diferenças na pressão de corte que pudessem levar a uma menor temperatura na aresta de corte da ferramenta, OLIVEIRA (2003).

$\mathrm{O}$ processo de desgaste de uma ferramenta de corte tem como um dos fatores de influência o calor no processo de corte, o qual é gerado diretamente na aresta de corte na região de contato ferramenta-peça.

Uma boa parte da energia despendida no trabalho realizado pela ferramenta ao cortar o material é transformada em calor que por sua vez, tende a ser removido pelos cavacos em aproximadamente $80 \%$. Os $20 \%$ restantes vão para a peça, a ferramenta e o fluido de corte. A temperatura na região de contato ferramenta-peça pode atingir $1400^{\circ} \mathrm{C}$, sendo este o fator predominante para o referido desgaste da ferramenta, OLIVEIRA (2003).

A teoria do processo de formação de cavacos mostra que a força necessária é uma grandeza que depende da secção do material a ser removido e da pressão específica de corte. Sem entrar na questão de quanto o valor da pressão específica de corte difere na usinagem HSC em comparação a usinagem convencional, tem-se que quanto maior for a secção de material removida pela ferramenta no processo de corte, maior será a sua força de corte, maior o trabalho realizado e maior a energia despendida gerando por sua vez uma maior quantidade de calor.

$\mathrm{Na}$ usinagem em altas velocidades a ferramenta se desloca de forma muito rápida, porém removendo pequenas porções de material em cada passe realizado. Tem-se assim, altos 
valores de velocidade de corte e de avanço, porém baixos valores de profundidade de corte radiais e axiais, bem como baixas espessuras médias de cavaco.

Desta forma, tem-se uma situação em que com altas velocidades de corte existe uma tendência de aumento do calor gerado, com pequenos valores de profundidade de corte e avanço existe uma tendência à redução do calor gerado, levando a um nível térmico suportável pela aresta de corte da ferramenta. Isto explica por que até mesmo ferramentas usadas em processos convencionais podem ser utilizadas em HSC com bons resultados, OLIVEIRA (2003).

De fato, não se pode esperar que um processo HSC possa remover altas profundidades de corte em aços endurecidos. A aresta de corte não suportaria valores altos de pressão e calor gerados em tal situação. Altas remoções em usinagem HSC são possíveis em ligas de alumínio, alguns metais não-ferrosos e parcialmente em ferros fundidos, todos sem endurecimento. De uma forma não produtiva, aços temperados com durezas de até 63 HRC são usinados com ferramentas de metal duro já há muito tempo, o que não existia até alguns anos atrás eram máquinas-ferramentas capazes de altas velocidades de avanço.

Deve se observar que, em um processo de usinagem, não somente o calor e a abrasão geram desgaste da ferramenta mas também outros fatores iniciam, influenciam e intensificam o desgaste. No processo de fresamento, o sentido de corte da ferramenta é outro ponto importante para o desgaste, trabalhando-se no sentindo concordante, a ferramenta se beneficia da maior espessura de cavaco no início do corte e não sofre tensões de tração quando sai do material. Ferramentas de metal duro e outros materiais, como o PcBN, cerâmicas e diamante, não possuem altas resistências a tensões de tração e tendem a apresentar microlascas quando submetidas a estes processos de usinagem, OLIVEIRA (2003).

A ocorrência de vibrações durante a usinagem também pode causar danos à ferramenta, podendo ocasionar micro-lascas e gerar uma quebra da aresta de corte. As vibrações são comuns na usinagem de moldes e matrizes, nos quais o comprimento da ferramenta muitas vezes precisa ser longo para atingir a profundidade do perfil usinado. Controlar a flexão da ferramenta, através da otimização do sistema de fixação, estratégias de corte e sobremetal removido são ações que além de melhorar a vida da ferramenta ainda garantem uma boa qualidade dimensional e superficial na peça usinada, OLIVEIRA (2003).

De um modo geral, a usinagem HSC se caracteriza por um aumento no volume de material removido, redução das forças de corte na usinagem, melhor qualidade da 
superfície usinada e redução da vida útil da ferramenta de corte em função do aumento da velocidade de corte, conforme pode-se observar na figura 2.4 (SCHULZ, 1996).

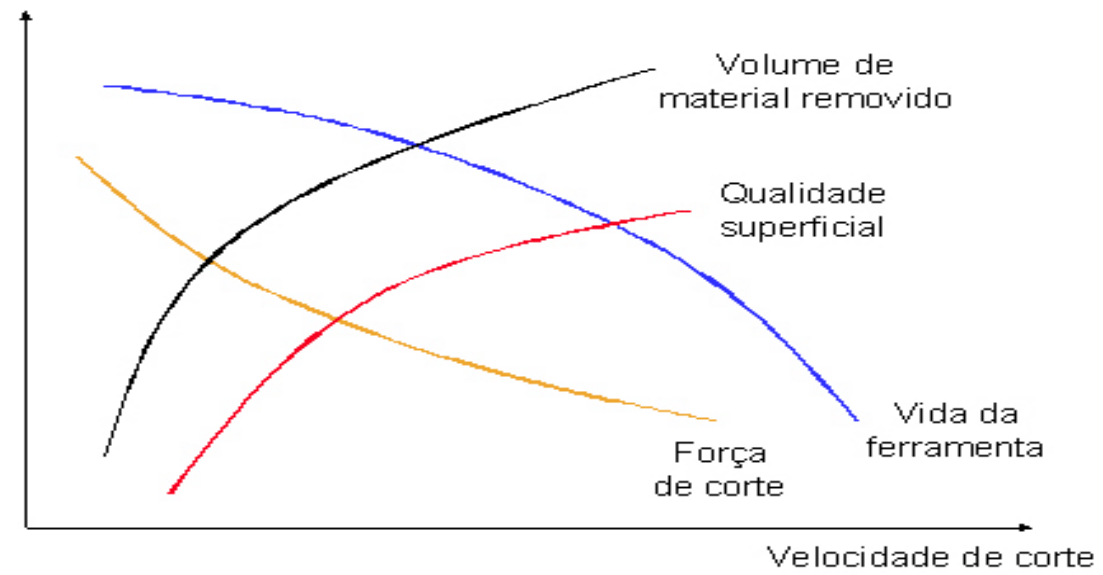

Figura 2.4 - Comportamento do processo HSC (SCHULZ, 1996).

A aceleração para movimentos e posicionamentos da máquina ferramenta, também é um fator importante a ser considerado, principalmente na usinagem de formas complexas, máquinas que trabalham com altas acelerações podem obter um ganho significativo em comparação às máquinas convencionais. As máquinas-ferramentas na faixa de transição para a usinagem HSC, atualmente podem trabalhar com acelerações da ordem de $10 \mathrm{~m} / \mathrm{s}^{2}$, máquinas com motores lineares trabalham hoje com acelerações da ordem de $30 \mathrm{~m} / \mathrm{s}^{2}$. Encontra-se no mercado eixos-árvore com rotação de até $100.000 \mathrm{rpm}$, embora seja mais comum a faixa de 15.000 a $40.000 \mathrm{rpm}$, GEIST (1999).

Na Figura 2.5 observa-se a faixa de valores que define a alta velocidade de corte para cada material especifico, SCHULZ (1996). 


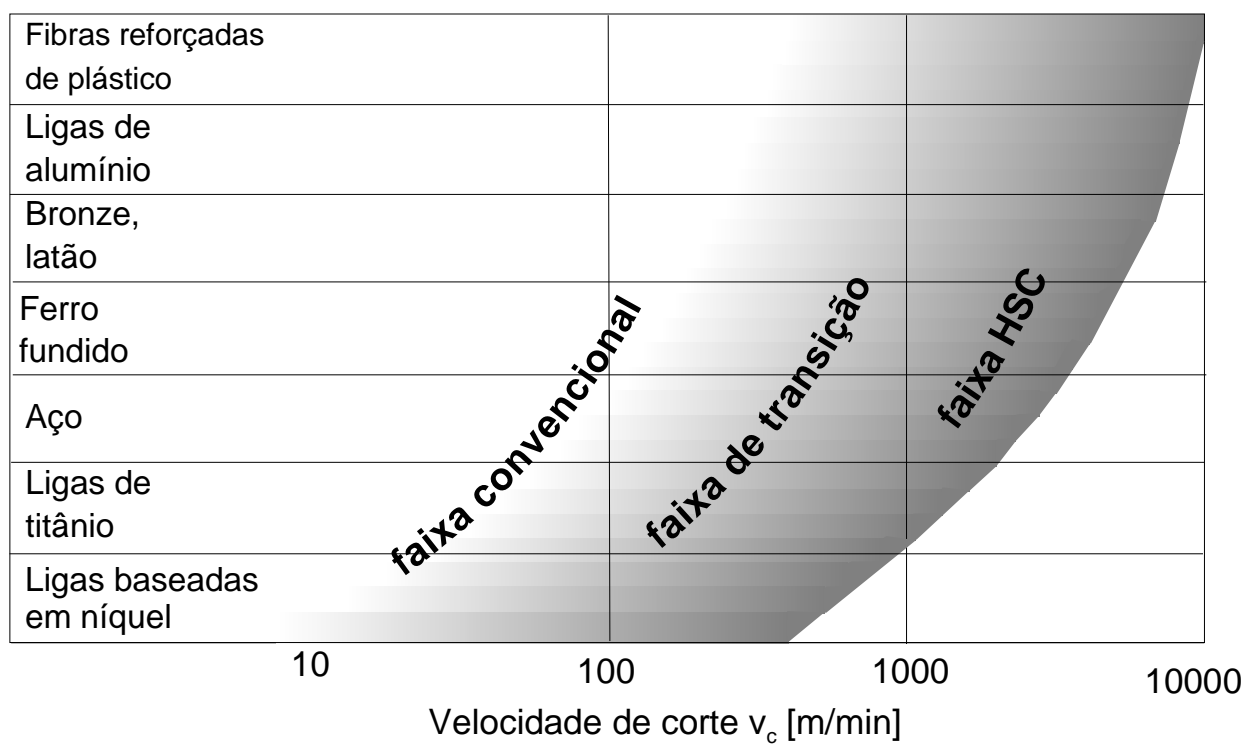

Figura 2.5 - Faixas de velocidades de corte para diferentes materiais (SCHULZ, 1996).

A velocidade de corte para HSC em operações de fresamento está na faixa de 10 vezes superior às velocidades convencionais, de acordo com o material a ser usinado, SCHULZ (1997). Segundo MULLER \& SOTO (1999) a faixa de velocidade de corte também esta relacionada à aplicação especifica. A Figura 2.6 ilustra as faixas de velocidades em função da operação de usinagem.

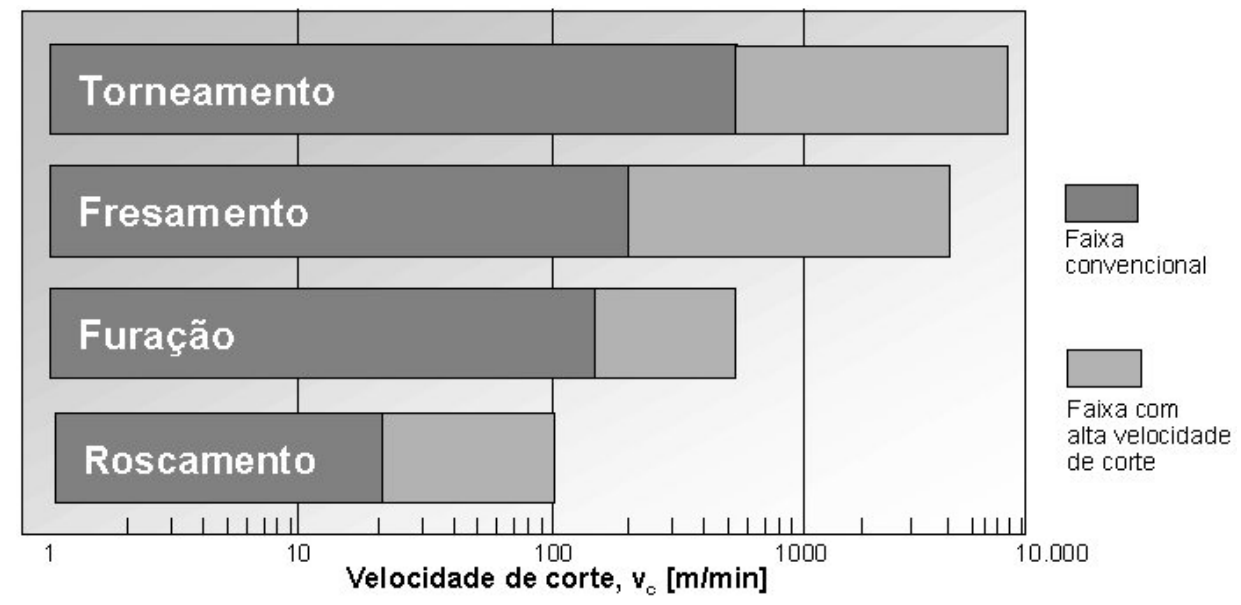

Figura 2.6 - Velocidades de corte convencional e HSC (MULLER \& SOTO, 1999). 


\subsection{Aplicações, Vantagens e Desvantagens da usinagem HSC.}

Atualmente a Tecnologia HSC vem sendo sofrendo grande desenvolvimento no processo de fresamento onde encontra sua maior utilização, mas pode ser aplicada também nos processos de torneamento, furação, roscamento, etc.

Para o fresamento, a tecnologia HSC está sendo desenvolvida para atender duas áreas da manufatura:

1. Operações de desbaste e acabamento de materiais não ferrosos, amplamente utilizados nos setores aeronáutico e aeroespacial;

2. Operações de pré-acabamento e acabamento de materiais ferrosos, envolvendo os fabricantes de moldes e matrizes e seus clientes da indústria automobilística, eletrodoméstica e bens de consumo.

A usinagem HSC oferece uma drástica redução dos tempos de manufatura, comparada aos processos convencionais. Para materiais não ferrosos tem-se uma economia de tempo e custos, obtendo maior precisão ao produto usinado, pois reduzem drasticamente os processos de acabamento manuais posteriores ao processo de usinagem, SCHULZ (1997). Esta redução é devida à alta qualidade do acabamento superficial conseguido com a utilização da tecnologia HSC.

A tabela 2.1 mostra os principais campos de aplicação e exemplos de processos de corte em que a usinagem HSC fornece vantagens especificas.

O objetivo da HSC não é apenas atingir velocidades de corte elevadas, mas principalmente obter a flexibilidade que a velocidade pode proporcionar, aumentando assim o tempo de resposta bem como a produtividade (MMS, 2003). 
Tabela 2.1 - Áreas de aplicação HSC (SCHULZ, 1997).

\begin{tabular}{l|l|l}
\hline \multicolumn{1}{c|}{ Vantagens HSC } & \multicolumn{1}{|c}{ Áreas de aplicação } & \multicolumn{1}{c}{ Exemplos } \\
\hline Grande remoção de material & $\begin{array}{l}\text { Ligas de metal } \\
\text { Ferro fundido }\end{array}$ & $\begin{array}{l}\text { Indústria aeroespacial } \\
\text { Indústria de moldes }\end{array}$ \\
\hline Alta qualidade de & $\begin{array}{l}\text { Usinagem de precisão } \\
\text { Peças especiais }\end{array}$ & $\begin{array}{l}\text { Indústria óptica } \\
\text { Mecânica fina }\end{array}$ \\
\hline Baixas forças de corte & $\begin{array}{l}\text { Peças com espessura fina de } \\
\text { parede }\end{array}$ & $\begin{array}{l}\text { Indústria aeroespacial } \\
\text { Indústria automobilística }\end{array}$ \\
\hline Alta freqüência de excitação & $\begin{array}{l}\text { Usinagens sem vibração em } \\
\text { peças de difícil manufatura }\end{array}$ & $\begin{array}{l}\text { Mecânica de precisão } \\
\text { Indústria óptica }\end{array}$ \\
\hline Dissipação de calor com o & Usinagem com baixas & $\begin{array}{l}\text { Mecanismos de precisão } \\
\text { Ligas de magnésio }\end{array}$ \\
cavaco & temperaturas de processo & \\
\hline
\end{tabular}

Segundo SANDVIK (1999) os fatores econômicos e técnicos que influenciaram o forte desenvolvimento da HSC são:

a) Sobrevivência - A sempre crescente competitividade entre os mercados estabelece novos padrões a todo instante. As exigências com relação a tempo e eficiência de custos são cada vez mais altas. Disso decorre a necessidade de desenvolvimentos de novos processos de produção e novas técnicas, incluindo HSC.

b) Materiais - Os vários segmentos da indústria em geral requerem novas soluções especialmente em termos de materiais:

- A indústria aeroespacial geralmente utiliza ligas resistentes ao calor e aços inoxidáveis.

- A indústria automotiva utiliza diferentes composições bimetálicas, ferro fundido compacto e um volume crescente de alumínio.

- A indústria de moldes e matrizes tem que enfrentar principalmente o problema de usinar aços-ferramenta com alta dureza, os quais exigem máximo desempenho da ferramenta durante todo o processo.

c) Qualidade - A usinagem HSC pode contribuir para a minimização do acabamento manual, especialmente importante em moldes, matrizes ou peças com uma geometria 
tridimensional complexa. Isso resulta em superfícies de alta qualidade superficial e dimensional, além de economia de custos de manufatura.

d) Processos - A usinagem HSC pode otimizar os tempos de produção, através de um menor número de set-up e fluxos simplificados quanto à logística. Um alvo típico, dentro da indústria de moldes e matriz é a usinagem completa de ferramentas de tamanho pequeno em material totalmente endurecido com um único set-up. Além disso, o longo tempo dos processos de eletroerosão também pode ser reduzido, ou eliminado, com a usinagem a altas velocidades. A figura 2.7 mostra as possíveis racionalizações no processo produtivo, onde:

a) Processo inicial: (1) blank macio, (2) desbaste, (3) semi-acabamento, (4) tratamento térmico, (5) eletroerosão, (6) acabamento das regiões de fácil acessibilidade, (7) acabamento manual.

b) Opção para o processo 1 : onde a etapa de eletroerosão foi substituída pelo acabamento da cavidade com HSM, assim sendo reduzindo uma etapa do processo.

c) Opção para o processo 2: (1) blank já recebeu o tratamento térmico e está com dureza final de utilização, (2) desbaste, (3) semi-acabamento, (4) acabamento final, todos realizados com uma única fixação, (5) acabamento manual reduzido ou mesmo eliminado.

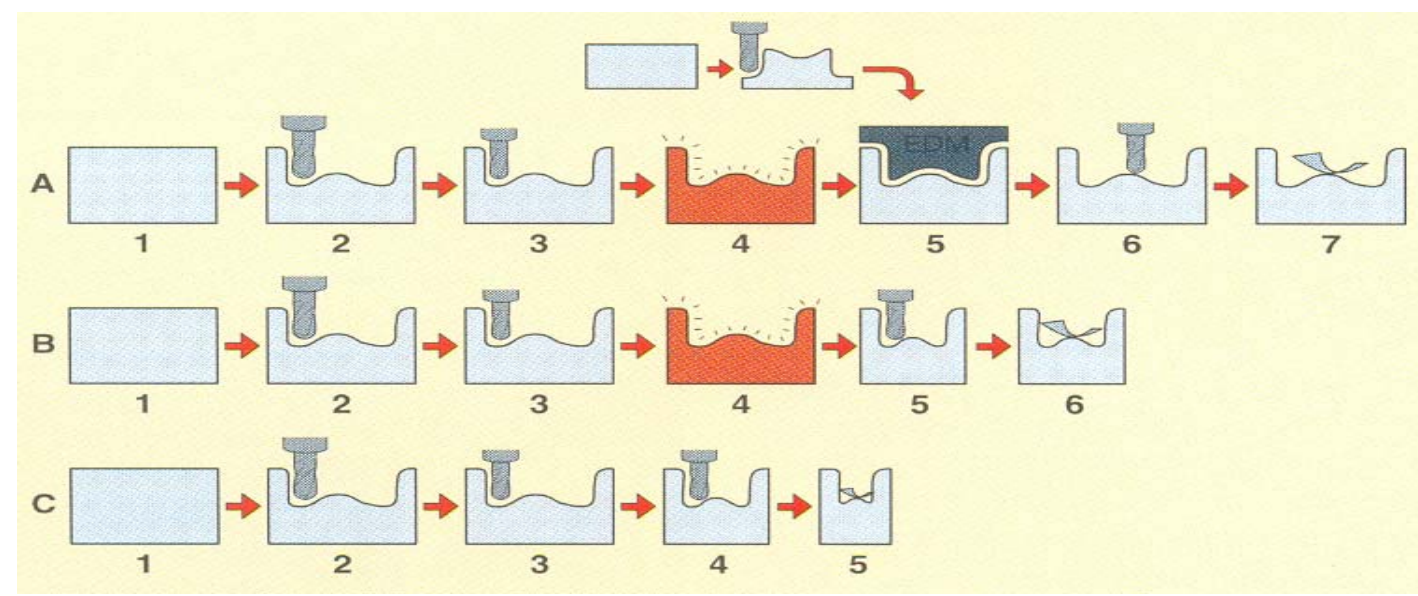

Figura 2.7 - Racionalização do Processo de Fabricação de uma Matriz (SANDVIK, 1999).

e) Desenho \& Desenvolvimento - Para se manter competitivo no mercado atual, uma das principais armas é a renovação constante dos produtos. $\mathrm{O}$ ciclo de vida médio para carros 
é de 4 anos, 1,5 anos para computadores e acessórios e 3 meses para telefones manuais (convencionais e não móveis ). Um dos pré-requisitos para o desenvolvimento rápido do produto, bem como de rápidas mudanças de desenho, é a técnica HSC.

f) Produtos complexos - Há um aumento de superfícies multifuncionais nas peças. Por exemplo, os novos desenhos de lâminas de turbinas, além de funções e características otimizadas, os desenhos anteriores possibilitavam polimento manual ou com robôs (manipuladores). As lâminas de turbinas com um desenho novo e mais sofisticado, devem ser acabadas via usinagem e preferivelmente por HSC.

h) Equipamentos de produção - $\mathrm{O}$ forte desenvolvimento de materiais de corte, sistemas de fixação, máquinas-ferramentas, controles e especialmente equipamentos CAD/CAM abriu possibilidades para os novos métodos e técnicas de produção.

As características mais relevantes do emprego e utilização da HSC estão nos aspectos econômicos e técnicos.

\section{Vantagens econômicas}

Conforme NOVASKI \& CORREAA (1998) dentre as principais vantagens econômicas proporcionadas pelo uso da HSC destacam-se as seguintes:

$\checkmark$ Aumento na produtividade;

$\checkmark$ Redução dos custos do processo de fabricação, custos de fabricação reduzidos devido a ciclos totais mais rápidos;

$\checkmark$ Maior flexibilidade na alocação de mão de obra;

$\checkmark$ Maior flexibilidade comercial, pois pedidos complexos podem ser atendidos em menor espaço de tempo.

Em uma empresa automobilística, foram realizados testes de fabricação para determinar as vantagens de se utilizar a tecnologia HSC na produção de ferramentas para estampagem de chapas metálicas, utilizando-se a matriz ilustrada na figura 2.8 como modelo, foram fabricadas duas destas ferramentas, uma pelo processo convencional utilizado pela empresa e a outra se aplicando a Tecnologia HSC. Neste estudo, comparouse a etapa de produção após as operações de desbaste, pois são nestas etapas que a tecnologia HSC se diferencia do processo convencional. As operações de desbaste normalmente são realizadas em uma fresadora convencional, por esta ser, em geral, mais 
robusta, uma vez que esta operação exige alta potência devido ao grande volume de material a ser removido neste processo, não exigindo alta precisão.

Portanto, observa-se na figura 2.8 uma redução de 52 horas do processo de manufatura convencional para o HSC. Esta redução na se deu pelo tempo de usinagem propriamente dito, mas nas etapas posteriores. No processo HSC inclui-se uma etapa adicional, o préacabamento elevando-se o tempo de usinagem, em contrapartida, eliminou-se o acabamento manual, reduziu-se drasticamente o polimento manual e as etapas de try-out, propiciando com isto, a redução do tempo de manufatura citada.

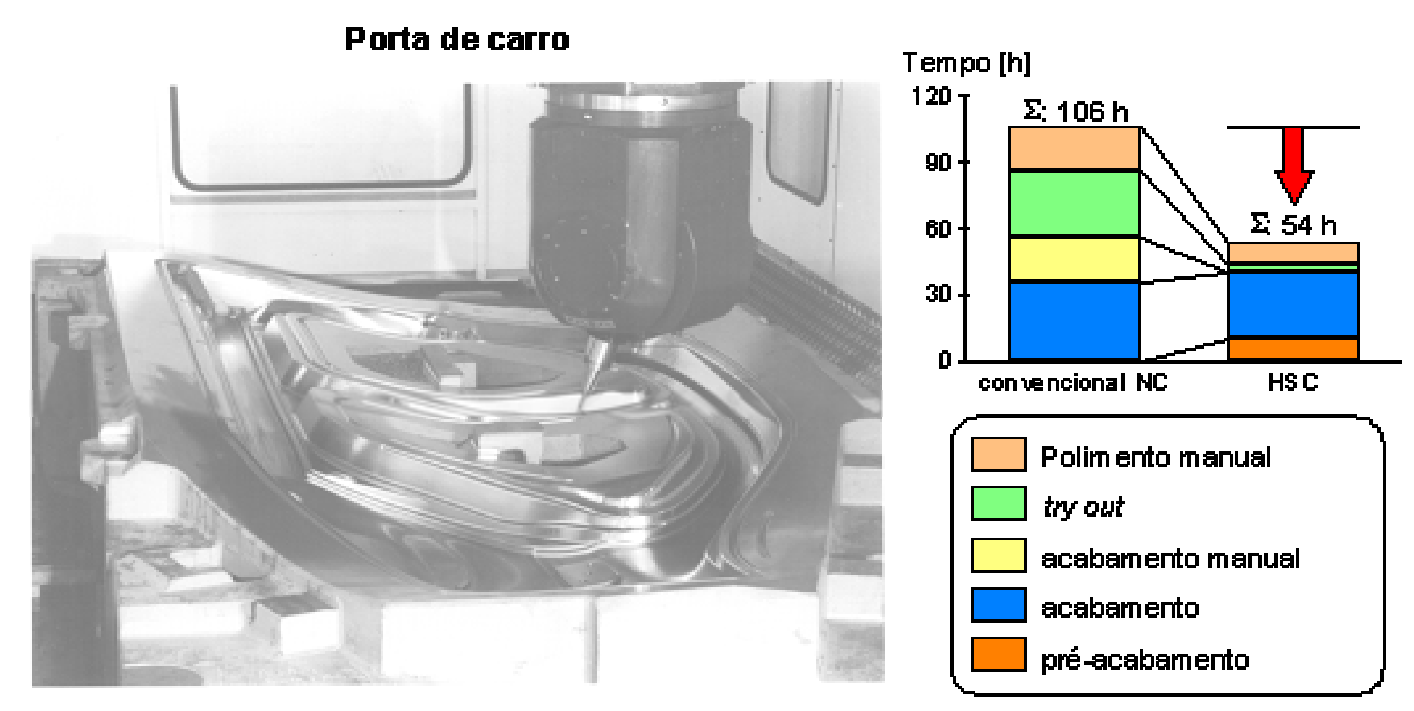

Figura 2.8 - Redução do ciclo de fabricação de moldes (FINZER, 1998).

\section{Vantagens Tecnológicas}

Segundo SCHULZ (1997), NOVASKI \& CORRÊA (1998), KIRSCHNIK (1997) e SCHULZ \& WURZ (1997), as vantagens de ordem tecnológica são:

$\checkmark$ Aumento da qualidade superficial, o que elimina muitos trabalhos posteriores;

$\checkmark$ Melhoria nos mecanismo de formação de cavaco;

$\checkmark$ Melhoria da exatidão dimensional;

$\checkmark$ Diminuição das forças de corte proporcional ao aumento das velocidades de corte;

$\checkmark$ Usinagem sem vibrações, pois as oscilações induzidas pelo corte da ferramenta são de alta freqüência;

$\checkmark$ Melhoria na dissipação do calor do processo, pois a maior parte da energia térmica gerada se concentra no cavaco, o que proporciona menor aquecimento da peça, especialmente no fresamento; 
$\checkmark$ Altas taxas de remoção de material;

$\checkmark$ Baixos tempos inativos.

No entanto a maior economia alcançada com a utilização de máquinas-ferramenta com alta velocidade, em comparação com máquinas convencionais, é a forte influência da escolha adequada da tecnologia de corte, dos avanços, das ferramentas e principalmente da estabilidade do processo.

\section{Desvantagens}

De acordo com o comentário de SCHULZ (1997), KIRSCHNIK (1997) e SCHULZ \& WURZ (1997) também existem desvantagens que precisam ser consideradas, tais como:

$\checkmark$ Alto nível de desgaste da ferramenta de corte;

$\checkmark$ Maior custo tanto para máquinas-ferramenta e ferramentas de corte;

$\checkmark$ Necessidade de alta precisão do balanceamento do ferramental;

$\checkmark$ Necessidade de fuso de alta velocidade, os quais são excessivamente caros e possuem baixa durabilidade, em torno de 5000 à 10000 hora na máxima velocidade de rotação.

$\checkmark$ Necessidade de sistemas de controle especiais;

$\checkmark$ Necessidade de otimização adequada dos parâmetros tecnológicos, os quais ainda não são totalmente dominados.

Devemos ressaltar que tais desvantagens devem-se ao fato de que HSC é uma tecnologia em desenvolvimento, e com os novos estudos em andamento permitiram a adequada otimização desta tecnologia.

\subsection{Manufatura de moldes e matrizes}

Normalmente o ciclo de desenvolvimento de um componente gerado por um molde ou matriz é bastante longo e requer a aplicação de várias áreas do conhecimento tecnológico. Este ciclo pode ser divido em três fases distintas: Projeto do Produto, projeto do molde e manufatura do molde.

Em geral, o lote de fabricação de uma ferramenta do tipo molde ou matriz é pequeno e muitas vezes unitário, são distintos para cada produto a ser fabricado. Isto implica na amortização dos custos de produção do setor diretamente sobre um único produto (um 
molde ou uma matriz), este fato associado à ineficiência atual de fabricação destes ferramentais enfatiza a necessidade de racionalização desta etapa produtiva.

Nos processos convencionais de fresamento de moldes e matrizes, as baixas velocidades de trabalho inviabilizam a obtenção de um acabamento superficial de boa qualidade, devido ao longo tempo necessário para tal fim.

O processo tradicional para manufatura de moldes e matriz envolve as seguintes etapas, SOUZA (2001):

$\checkmark$ Fresamento CNC de desbaste, partindo de um material em bruto: esta operação é executada em $2 \frac{1}{2} 2$ eixos, pois a ferramenta é posicionada em uma determinada altura em $\mathrm{Z}$ e depois executa movimentos em dois eixos para remoção de material deste nível. Quando a remoção de material do nível inicial é finalizada a ferramenta se posiciona em uma nova altura em $\mathrm{Z}$ (definida pela profundidade de corte), e remove o material deste plano, repetindo este processo até o fim. Normalmente, deixa-se um sobremetal para a operação final de acabamento;

$\checkmark$ Fresamento CNC para alívio de cantos e pré-acabamento: estas operações têm a finalidade de eliminar grandes volumes de material deixados pelo desbaste, devido à ineficiência do processo ou remover material em áreas onde a ferramenta de desbaste (devido ao diâmetro) é incapaz de alcançar;

$\checkmark$ Fresamento CNC de acabamento: esta é uma operação de fresamento e, 3 eixos, que visa remover as sobras de material deixadas pelas operações de desbaste;

$\checkmark$ Operações manuais de acabamento (polimento e retificação): são realizadas por um “artesão" e consomem um tempo relativamente longo utilizando instrumentos tais como: lixas, pedras, esmerilhadeiras manuais, etc. Este processo tem a finalidade de eliminar as imperfeições deixadas pelas operações anteriores de usinagem, influenciando de forma determinante os custos, tempos de produção e acarretando em imprecisões.

\subsection{Tecnologia da usinagem com alta velocidade de corte}

A implementação da tecnologia HSC em ambiente fabril ainda pode ser considerada um processo de risco, não apenas pelo alto investimento necessário, mas também porque esta tecnologia ainda se encontra em desenvolvimento. Também, deve-se considerar que a 
utilização eficiente da tecnologia HSC se difere drasticamente do processo convencional de usinagem CNC utilizado atualmente, envolvendo o estudo e a aplicação de outras tecnológicas relacionadas (SCHULZ, ABELE, SAHM, 2001).

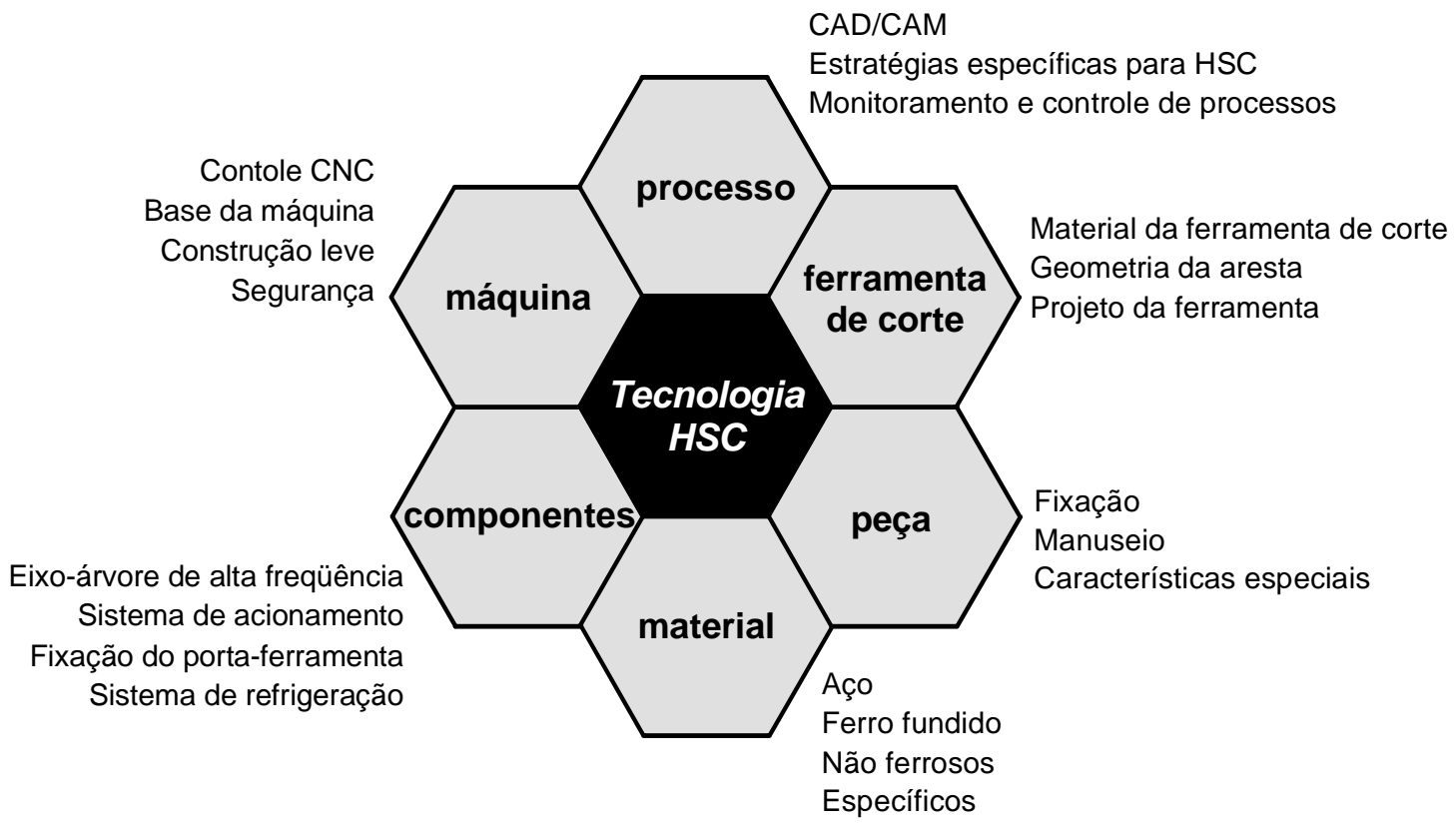

Figura 2.9 - Tecnologias relacionadas ao processo HSC (SCHULZ, 2001).

A figura 2.9 mostra as tecnologias correlatas que devem ser consideradas para se trabalhar de maneira eficiente em HSC, as principais tecnologias envolvem:

$\checkmark$ Construção da máquina-ferramenta: o conceito estrutural e o material utilizado na construção da base da máquina devem ser cautelosamente estudados, visando uma redução de peso dos componentes móveis para que a máquina possa atingir altas velocidades de avanço e suportar às altas taxas de acelerações com segurança, mantendo a precisão;

$\checkmark$ Ferramenta de corte: deve ser analisado o material, o revestimento e a geometria da ferramenta em cada situação especifica, para que a redução da vida útil da ferramenta devido o aumento da velocidade de corte, não torne o processo inviável. Além disso, deve-se analisar o sistema de fixação da ferramenta e o balanceamento de todo o sistema;

$\checkmark$ Comando numérico da máquina: este deve possuir alta capacidade de processamento para lidar com as altas velocidades de avanço e funções especiais que permitem a análise de blocos subseqüentes do programa $\mathrm{NC}$, detectando alterações bruscas de 
trajetória de ferramenta e reduzindo a velocidade para não causar desvio de contorno. Esta função é conhecida como "Look-ahead";

$\checkmark$ Programação NC: a programação deve ser realizada cautelosamente para evitar trajetórias de ferramenta com alterações bruscas e áreas que contenham diferentes volumes de material a ser removido.

Portanto, para justificar o alto investimento necessário, deve-se conhecer e utilizar corretamente todas as tecnologias que estão relacionadas com o processo HSC, buscando seus reais benefícios, tornando mais competitivos os setores que utilizam este processo de manufatura e os setores que estejam relacionados a estes dentro da cadeia produtiva, (SOUZA, 2001).

A exigência em relação aos equipamentos usados em usinagem a altas velocidades é extrema, o que por sua vez impulsiona o desenvolvimento.

A máquina, as ferramentas e os programas adequados para projeto e manufatura auxiliados por computador (CAD/CAM), são absolutamente essenciais para que a indústria possa utilizar a tecnologia HSC.

Todos esses componentes devem necessariamente atender a especificações mais rigorosas. A tecnologia de usinagem com alta velocidade envolve o uso de máquinasferramentas e ferramentas com modernos conceitos de projeto e fabricação.

Além dos componentes materiais citados acima, é imprescindível o conhecimento tecnológico o treinamento de mão-de-obra especializada para que todas as vantagens da tecnologia possam ser amplamente alcançadas.

\subsubsection{Máquinas-ferramentas}

A máquina-ferramenta adequada a usinagem HSC é constituída por uma série de componentes cuja finalidade é atender aos requisitos de alta velocidade, avanço rápido, elevada aceleração e maior precisão, figura 2.10. 


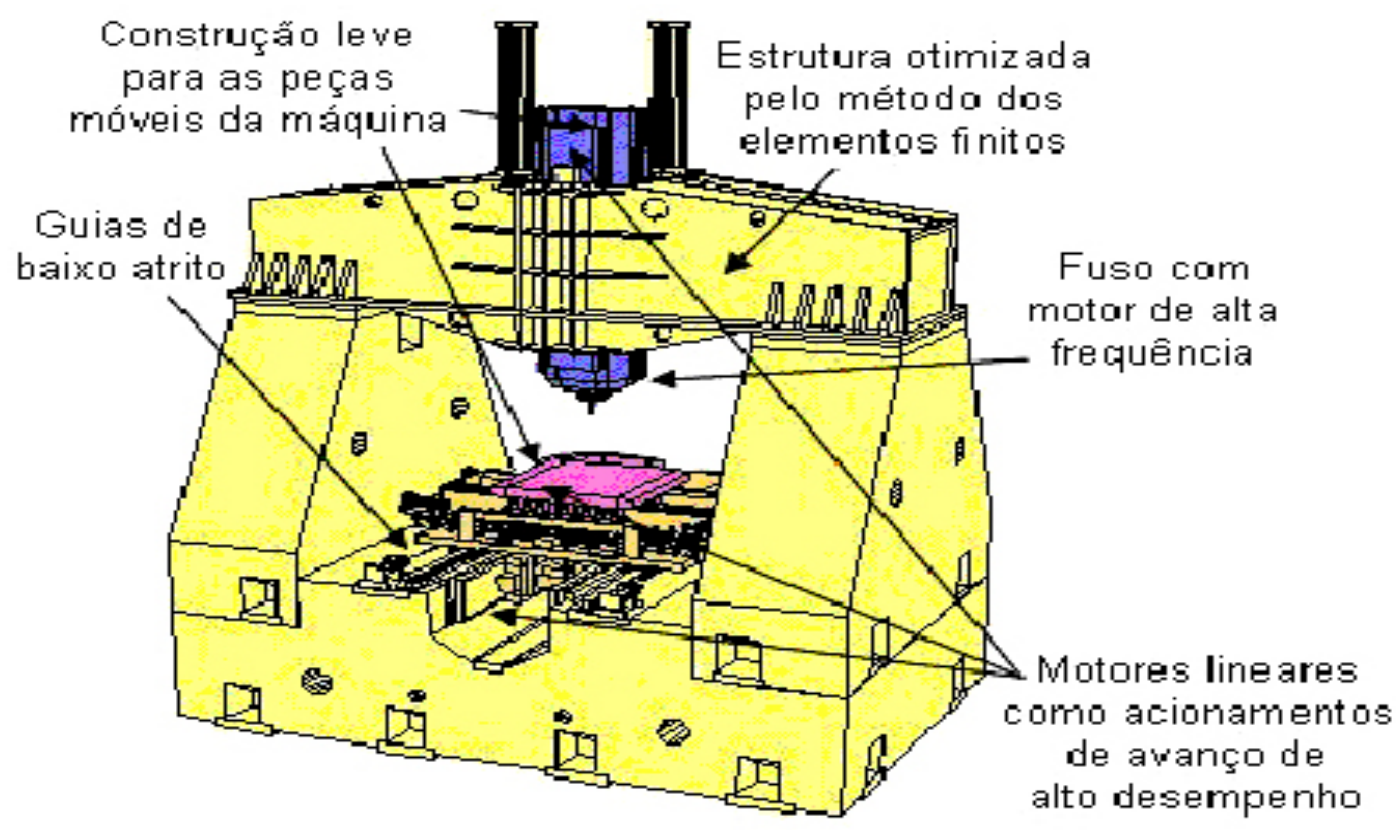

Figura 2.10 - Componentes de uma máquina-ferramenta HSC (SCHULZ \& WURZ, 1997).

Todas as partes móveis da máquina-ferramenta devem ser produzidas com peças de baixa densidade para a diminuição da inércia, para esta redução utiliza-se material apropriado para a construção, como as ligas de Alumínio e Titânio e ainda pela otimização da geometria das peças com a correta aplicação de programas de elementos finitos (SCHULZ \& WURZ, 1997).

Devido à necessidade de altas velocidades de avanço, são somente empregadas guias de baixo atrito, com mancais de elementos cerâmicos rolantes. Os motores de avanço devem demonstrar excelentes características dinâmicas com capacidade para gerar altos momentos em curtos períodos de tempo, o que por sua vez justifica a aplicação de motores lineares. A combinação de motores de torque direto e fuso é vantajosa, para proporcionar deslocamentos rápidos, com alto torque, dispensando trens de transmissão e acoplamentos (BEART, 1997; WALZ, 1996).

Para máquinas de alto desempenho, onde se esperam excitações de ondas mecânicas em freqüência e potências bem mais altas do que as normalmente observadas, as propriedades de amortecimento da estrutura da máquina são muito relevantes. Portanto a estrutura de uma máquina para trabalhar em rotações compatíveis com os eixos-árvore disponíveis deve ser adequadamente projetada em suas formas ou utilizar materiais com melhores propriedades de amortecimento. Em geral a base da máquina é de concreto 
polimérico, o que garante um componente para a absorção em altas solicitações bastante favorável, o seu efeito de amortecimento estrutural e aproximadamente 10 vezes maior do que o ferro fundido ou de construções de aço soldadas, reduz os problemas de vibração (SCHULZ, 1999).

As características térmicas da estrutura também são responsáveis pela estabilidade dimensional da máquina, as máquinas nas quais se pretendem obter componentes com tolerâncias da ordem de poucos micrômetros devem ser capazes de produzir nessas tolerâncias repetidamente, COELHO (2002).

Para isto tem-se observado algumas soluções:

$\checkmark$ Projeto de estruturas simétricas que minimizam os efeitos das variações térmicas, como exemplo tem-se a máquina tetragonal na qual a estrutura é formada por tetraedro que minimiza os efeitos de variações térmicas, vide Figura 2.11.

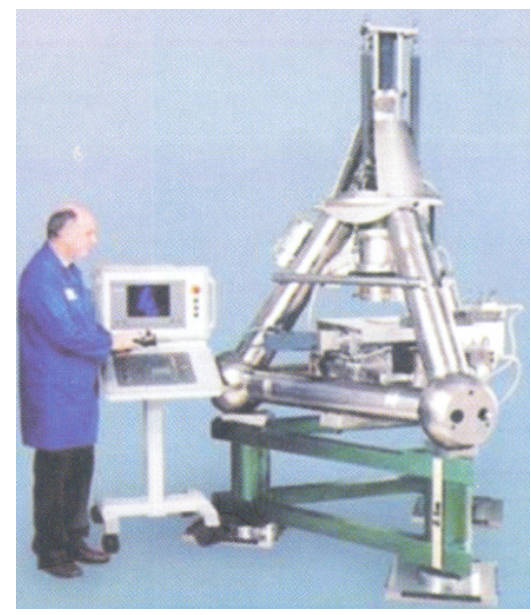

Figura 2.11 - Máquina tetragonal (COELHO, 2002).

$\checkmark$ Compensação térmica por resfriamento contínuo da estrutura ou por diferenças nos deslocamentos comandados. A compensação térmica por resfriamento da estrutura é uma solução já comumente empregada em retificadoras, o fluido de refrigeração do processo de corte passa pela estrutura buscando estabilizar a temperatura. Esse sistema sem nenhuma sofisticação pode minimizar o efeito das variações dimensionais decorrentes da temperatura. Em projetos mais cuidadosos pode haver um resfriamento bem mais controlado e levar a resultados melhores, a compensação térmica por diferenças em deslocamentos nos eixos mostra-se bem mais complexa, uma vez que pontos estratégicos da máquina deveriam ter sua temperatura medida e a correspondente diferença dimensional ser compensada. Neste caso, calibrações 
prévias são necessárias e as diferenças devem ser armazenadas em memória para compensação.

$\checkmark$ O projeto com materiais de baixo coeficiente de dilatação térmica pode minimizar o problema, com valores aceitáveis dentro das variações térmicas previstas, o uso de granito sintético que possui baixo coeficiente de dilatação térmica em relação ao aço e ao ferro fundido.

Os rolamentos de esferas de cerâmicas estão sendo amplamente empregados em mancais para eixo-árvore (figura 2.12).

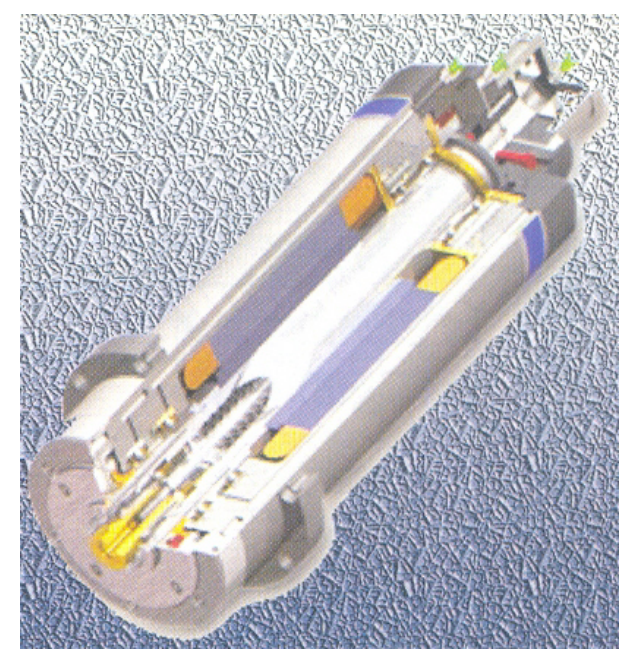

Figura 2.12 - Exemplo de eixo-árvore com mancais contendo rolamento de esferas de cerâmica (COELHO, 2002).

De acordo com POPOLI (2000) as esferas cerâmicas têm 60 \% menos massa do que as de aços, isto é significativo, pois quando um rolamento de esferas esta operando particularmente a altas rotações, as forças centrífugas empurram as esferas para a pista externa proporcionando uma deformação no formato da esfera. As esferas de cerâmica, com menos massa, não são afetadas a altas velocidades em relação a esferas de aço, na realidade o uso de esferas de cerâmicas permitem uma velocidade até $30 \%$ mais alta em relação das esferas de aço, sem sacrificar a sua vida. Nos rolamentos de esferas de cerâmica, mesmo à medida que aumentam as velocidades de operação às esferas, estas sempre operam mais frias do que as de aço convencionais, isto ocorre devido a circularidade quase perfeita das esferas de cerâmica. Com a formação de calor sendo reduzida, a vida do lubrificante é prolongada, conforme ilustrada a figura 2.13. Os rolamentos de cerâmica operam em níveis de vibração muito mais baixos e apresentam maior rigidez. 
Embora os rolamentos de esferas de cerâmicas apresentem vantagem em relação à potência disponível para a usinagem e a diminuição do desgaste nos mancais, o custo pode ainda ser outro fator decisivo para o emprego.

Sendo assim, os eixos-árvore aptos a trabalhar em processos com alta velocidade de corte devem ser capazes de manter altas rotações e dispor de altos valores de torque, para poderem usinar uma diversidade maior de materiais, desde a grafite cuja força de corte é muito baixa, até aço temperado com os mais altos valores de força de corte.

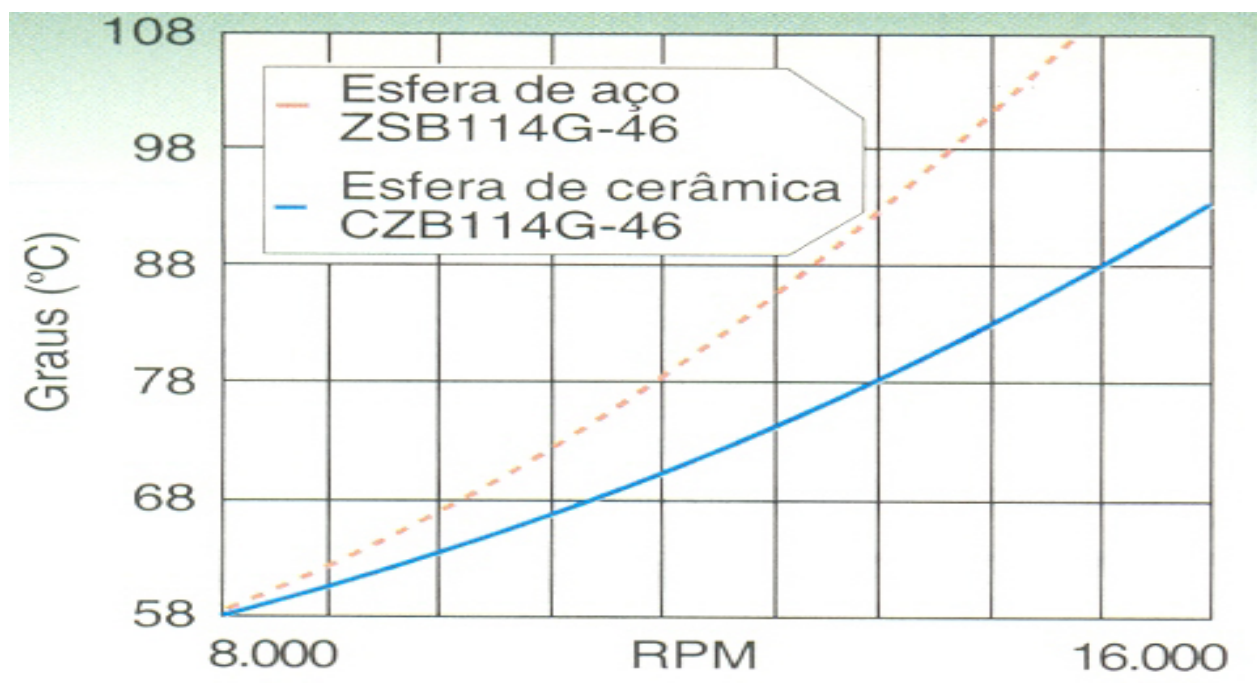

Figura 2.13 - Comparação de esferas de material cerâmico e convencional (POPOLI, 2000).

Os acionamentos dos motores de avanço devem apresentar boas características dinâmicas, isto é, "loops" de controle com menores constantes de tempo e motores que possam gerar altos momentos por curtos períodos de tempo. É possível a obtenção do mais alto desempenho pela introdução de acionamentos com motores lineares, evitando os elementos de acionamento convencionais (SCHULZ \& WURZ, 1997).

Segundo FURUKAWAY e MORONUKI (1987), as máquinas operatrizes atuais são capazes de atingir exatidões de ordem de $0,005 \mathrm{~mm}$, devido principalmente a melhorias nos métodos de projeto, avanços nas tecnologias e nos materiais empregados. Por exemplo, o uso de guias lineares nos eixos das máquinas teve como resultado uma grande diminuição do atrito, eliminando problemas como deformações geradas nas guias convencionais. 
Isto é garantido por uma malha de controle de posição que utiliza réguas óticas, que inclui todo o sistema mecânico de avanço para a obtenção do controle. Assim a régua óptica detecta os erros mecânicos ocorridos durante o movimento e esses são compensados pelo CNC (MMS, 2003).

Com o aumento das rotações do eixo-árvore, o balanceamento insuficiente provoca problemas dinâmicos em níveis cada vez maiores, como a influência de massas desbalanceadas aumenta na razão da velocidade ao quadrado, o método clássico de balancear separadamente cada parte, antes da montagem, não é mais suficiente para o corte com alta velocidade. Uma abordagem promissora é integrar um sistema de balanceamento no eixo-árvore, como o utilizado para os de retificação, WECK (1999).

Os acionamentos convencionais de avanço consistem de um motor de acionamento e elementos de transmissão, a exemplo de fusos de esferas recirculantes, cremalheiras ou correias dentadas, que convertem movimento rotativo em linear. Estes elementos de transmissão são os atuais fatores limitantes para o sistema de acionamento no que se refere à velocidade, carga sobre a rigidez, distâncias de deslocamento e dinâmica, pois a distorção ou folga do fuso de esferas, do redutor ou do acoplamento afetam a resposta do sistema.

Devido à transmissão de movimento do acionamento de parafuso, a aceleração do fuso de esferas recirculantes é relativamente independente do tamanho das massas em movimento linear, a potência de aceleração é comandada fundamentalmente pelos movimentos de inércia dos fusos e do motor e pelo passo do fuso. O comportamento de motor linear é completamente diferente, ver figura 2.14 (MMS, 2003).

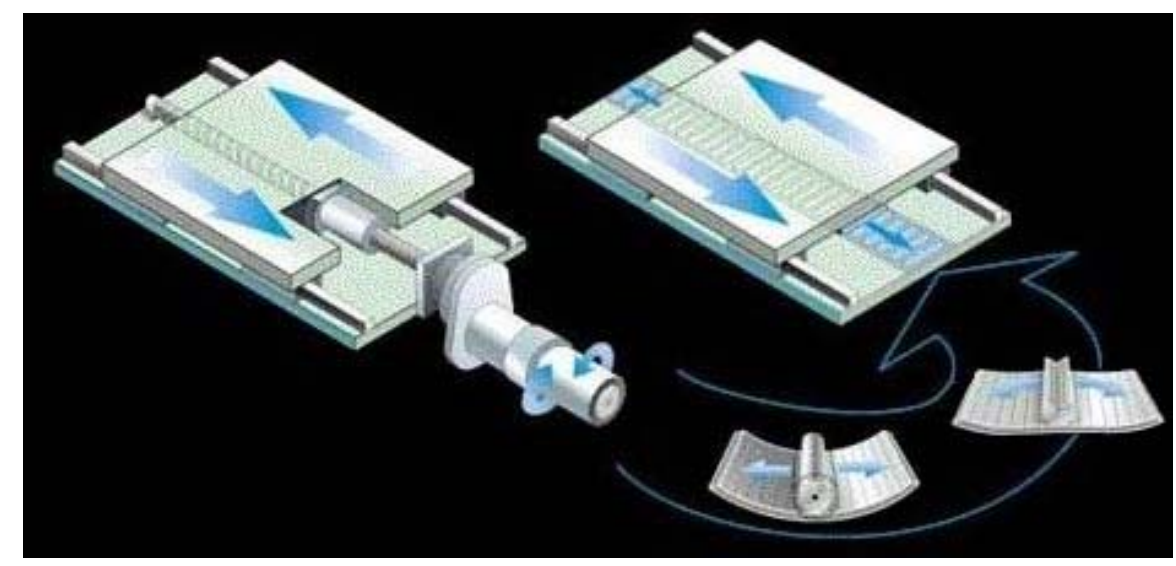

Figura 2.14 - Comparação entre motores rotativos e lineares (MMS, 2003). 
A sua potência de aceleração é inversamente proporcional à massa em movimento linear, este comportamento tem um efeito direto sobre o comportamento operacional deste tipo de conceito de avanço, se um eixo acionado por um motor linear é concebido para atingir altas acelerações, o fator chave é que os componentes da máquina sejam de construção leve. Todas as opções concebíveis de projeto e conceito devem ser exploradas, se a intenção for movimentar peças de massas diferentes com o auxílio de um motor linear, deve-se lembrar que o comportamento da aceleração do eixo irá variar com a massa da peça. Esta mudança de comportamento deve ser levada em consideração na programação $\mathrm{CN}$, pois de outra forma a máquina será incapaz de proporcionar as precisões de manufatura requeridas. Assim sendo, o acionamento linear direto é mais adequado para eixos de avanço, nos quais as massas permanecem quase totalmente constantes (WECK, 1999).

As vantagens do sistema de motor linear sobre o sistema de motor rotativo são maior velocidade devido à maior eficiência, maior exatidão com maior rigidez, livre de manutenção, curso ilimitado, guias múltiplas em pistas simples, compatíveis com sala limpa e vácuo, operação silenciosa e menor quantidades de peças.

Em contrapartida, as desvantagens são; eixo vertical com necessidade de contrapeso, variações de carga de difícil regulagem, estrutura magnética aberta proporcionando alta atração magnética e custo relativamente mais alto.

Sua estrutura é constituída de duas partes principais: a parte móvel, onde a bobina está instalada, e a placa magnética fixa. Um magneto permanente de alto desempenho é usado para a obtenção da máxima força por unidade de área. A folga do motor está próxima de 1,0 mm e sua tolerância não é tão rígida, o que facilita sua instalação na máquina. O tubo de resfriamento está encaixado na parte móvel de forma a remover efetivamente o calor (SOGABE, 1996).

Segundo ARNONE (1998) as principais desvantagens da utilização de motores lineares são:

Estrutura magnética aberta propiciando alta atração magnética;

$\checkmark$ Geração de grande quantidade de calor que deve ser removido do motor;

$\checkmark$ Além de seu elevado custo; 


\subsubsection{Considerações sobre Ferramentas de corte}

Em usinagem com alta velocidade de corte o desgaste da ferramenta de corte pode ser o fator limitante. Atualmente muitos centros de usinagem apresentam velocidades superiores às utilizadas pelas ferramentas sem que estas quebrem ou tenham desgaste excessivo. Num processo otimizado para usinagem com alta velocidade, a ferramenta provavelmente determinará a velocidade em processo. Os esforços para a otimização do processo HSC devem incluir, principalmente, estudos sobre as estratégias de usinagem que reduzam o desgaste da ferramenta de corte, tornado o processo viável e eficiente. Os dois principais mecanismos de desgaste associados com a usinagem com alta velocidade são desgaste por dissolução química e o desgaste de difusão limitada. Em essência o material da ferramenta dissolve-se dentro do fluxo do cavaco, devido a isto, o material da ferramenta que é mais resistente à dissolução exibe o menor desgaste. Em relação ao desgaste de difusão limitada, quando a velocidade de corte é aumentada à temperatura de corte se eleva a um nível no qual a aderência do material do cavaco ocorre em todo lugar sobre a superfície da ferramenta. Esta camada de material aderente torna-se saturada com os constituintes da ferramenta e serve como uma camada de difusão limite, reduzindo a taxa de transporte do material da ferramenta dentro do cavaco e conseqüentemente a taxa de desgaste. O fenômeno de desgaste crescente de difusão limitada, e a redução drástica observada no desgaste ocorrem com o aumento da velocidade. Por causa do aumento exponencial da difusidade com a temperatura, um aumento adicional na velocidade de corte além da velocidade para o mínimo desgaste produz um aumento rápido na taxa de desgaste (FLOW e KOMANDURI, 1989).

A consideração dos mecanismos de desgaste dos materiais das ferramentas durante a usinagem com alta velocidade sugere três possibilidades para o desenvolvimento da ferramenta:

$\checkmark$ Escolha de um material de ferramenta que seja tão estável quimicamente com relação à peça, de forma que a dissolução química da ferramenta não ocorra significantemente, até o ponto de fusão da peça;

$\checkmark$ Promova a transição para o regime de desgaste de difusão;

Fundamentalmente o material da ferramenta adequada para as operações de HSC deve combinar elevada dureza a quente, alto nível de tenacidade e baixa afinidade química com o material submetido à usinagem. 
Segundo a MMS (2003) a razão para isto é que na usinagem com alta velocidade freqüentemente há impacto, vibração e mudanças de temperatura que são prejudiciais a altas velocidades de corte. Uma ferramenta com boa tenacidade possui menos propensão ao lascamento ou à ruptura como resultados destes impactos.

\subsubsection{Interface eixo-árvore da máquina, porta-ferramenta e a ferramenta de corte.}

No sistema composto por eixo-árvore, porta-ferramenta e ferramenta, o porta-ferramenta é a ligação que tem maior efeito sobre a concentricidade e o equilíbrio do conjunto. Quando o eixo-árvore aumenta a velocidade a escolha da porta-ferramenta tem maior impacto sobre a eficiência do processo (MMS, 2003).

A interface máquina-ferramenta/peça é onde ocorre a maior concentração de esforços entre a peça e a máquina, segundo (SCHULZ, 1997) e (BECK, 1998) deve garantir:

$\checkmark$ Troca rápida e automática de ferramentas e funções de alto desempenho;

$\checkmark$ Alta precisão de troca e repetição;

$\checkmark$ Mínimos erros de balanceamento;

$\checkmark$ Alta concentricidade, boa tolerância de desvio radial de giro e elevada precisão de posicionamento;

$\checkmark$ Influência reduzida da força centrífuga em função das pequenas dimensões radiais e das massas;

$\checkmark$ Rigidez e requisitos gerais de corte, transmissão de torque, por exemplo.

Um porta-ferramenta muito utilizado em máquinas-ferramenta $\mathrm{CNC}$ é cone ISO, porém a força centrifuga de um eixo-árvore a alta velocidade pode causar um retração cone ISO (MMS, 2003).

Ao utilizar um cone ISO, cujo sistema de tração e realizado pelo centro do eixo-árvore da máquina, as deformações têm efeitos acentuados devido à falta de contato entre o cone ISO e a face do eixo-árvore da máquina, fazendo com que o cone seja puxado para dentro do eixo-árvore (CAVIOCHIOLLI, 2003), conforme ilustrado na figura 2.15. 


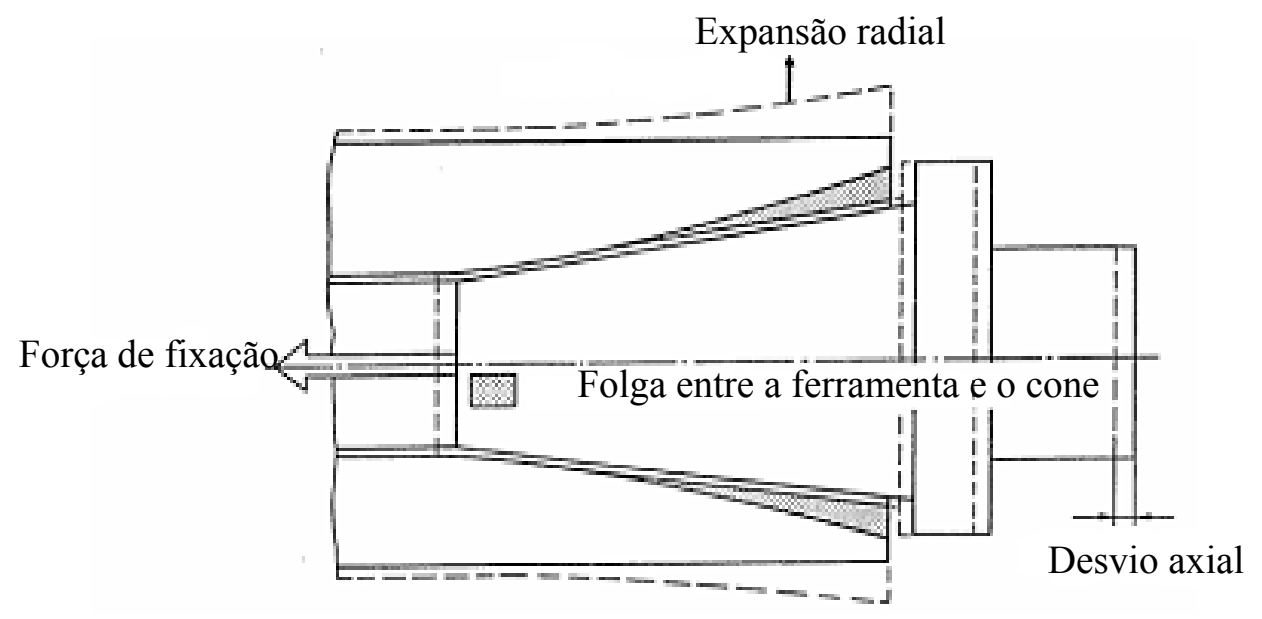

Figura 2.15 - Problemas da utilização de um cone ISO em alta rotação (CAVIOCHIOLLI, 2003).

Uma boa conexão entre a ferramenta e máquina-ferramenta é o cone de haste vazada HSK, figura 2.16, que foi projetada visando a usinagem com alta velocidade, este sistema já provou, em testes, suportar até quatro vezes o esforço gerado na usinagem. Desta maneira, está atendida também a característica de segurança (BECK, 1998).

A haste cônica vazada HSK tem alta rigidez, por outro lado a forma desta hasta não é simétrica e têm sido verificados problemas com o seu balanceamento (WATANABE, 1996).

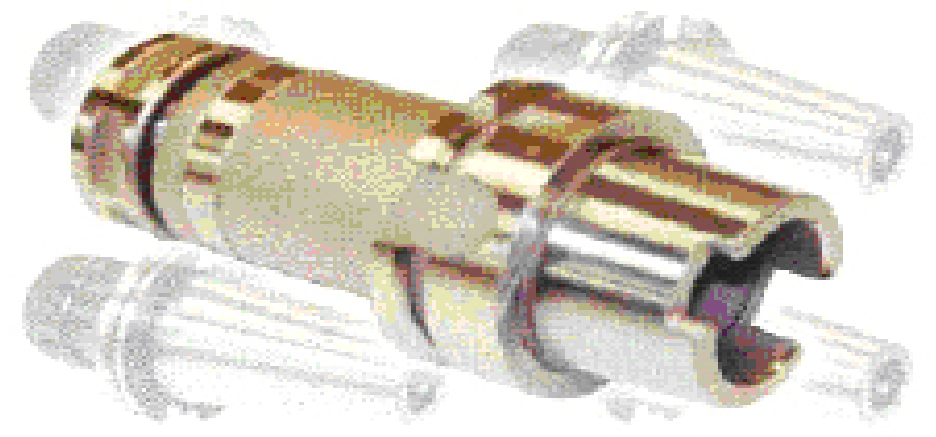

Figura 2.16 - Cone HSK em destaque entre cones ISO (MMS, 2003).

O desbalanceamento da ferramenta produzirá uma vibração a uma freqüência igual à rotação do fuso. Se a quantidade de desbalanceamento for pequena, esta vibração também 
será pequena. $\mathrm{O}$ peso não tem que ser simétrico para reduzir a força centrífuga, mas apenas balanceado. $\mathrm{O}$ balanceamento de um peso pode ser feito por qualquer contra-peso que tenha o mesmo produto de massa vezes o raio (MMS, 2003).

A fixação por porta-pinças demonstra alguns problemas quanto à precisão de fixação e baixa resistência quanto a forças radias (SANDVIK, 1999). Para operações de alta precisão e de alta rotação, dois sistemas de fixação foram desenvolvidos (CAVIOCHIOLLI, 2003):

$\checkmark \mathrm{Na}$ fixação por interferência térmica, o mandril é aquecido e depois de dilatado, a ferramenta é posicionada fixando-se ao mandril após o resfriamento. Este sistema demonstra grande precisão e balanceamento. Em contra partida, representa um alto investimento, pois não possibilita a utilização de pinças e, portanto, para cada diâmetro de ferramenta deverá haver um respectivo mandril.

$\checkmark$ Na fixação hidro-mecânica, fixa-se a ferramenta através da contração de sua parede interna, provocada pelo movimento de um mecanismo mecânico existente dentro do mandril, que por sua vez, é acionado hidraulicamente.

A figura 2.17 ilustra estes dois mecanismos de fixação de ferramentas adequados para usinagem em alta velocidade e alta precisão.
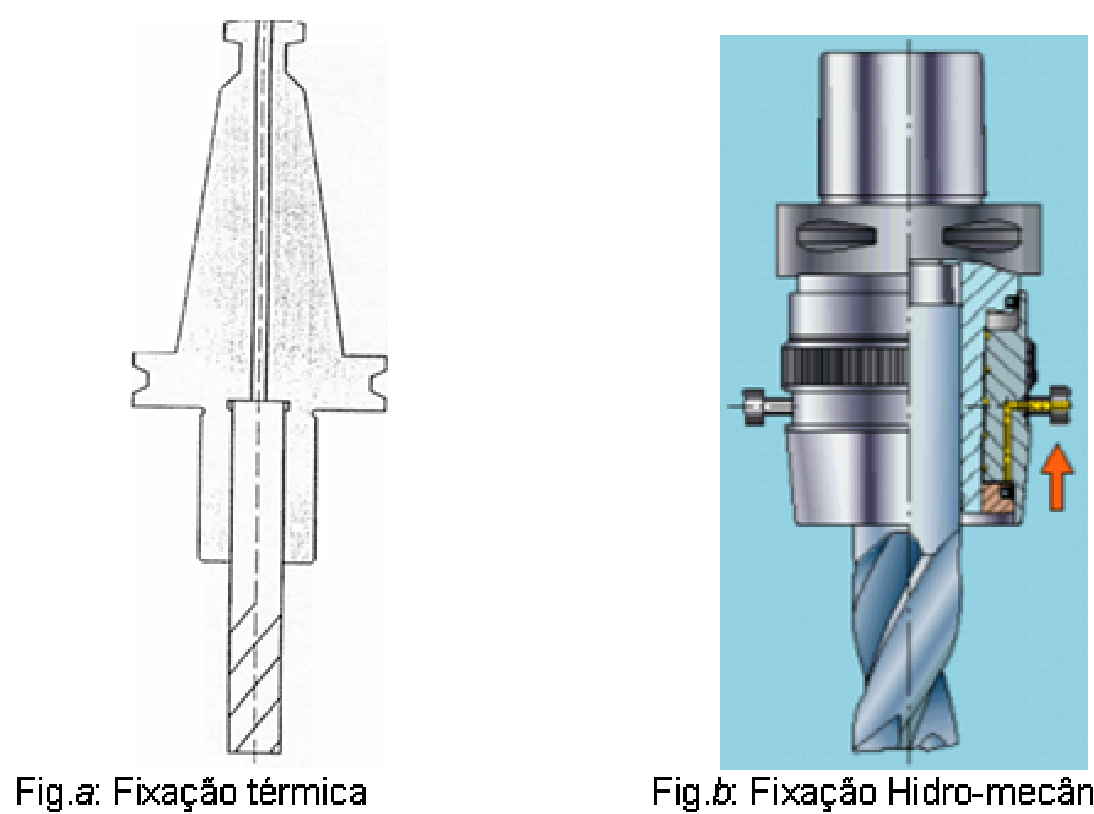

Figura 2.17 - Fixação por interferência e fixação hidro-mecânica (CHRISTOFFEL, 2001). 
O desbalanceamento da ferramenta de corte pode prejudicar o acabamento superficial e a máquina, em conseqüência da solicitação dinâmica nos mancais do eixo-árvore. As forças ocasionadas pelo desbalanceamento dependem da classe de desbalanceamento da ferramenta, de acordo com a equação abaixo.

$$
F_{\text {Desbal. }}=G \times \operatorname{massa} \times \frac{n}{9549}
$$

Onde:

$\mathrm{G}$ - classe de balanceamento da ferramenta $[\mathrm{mm} / \mathrm{s}]$;

Massa - massa da ferramenta em [kg];

$\mathrm{n}$ - rotação da ferramenta [RPM];

\subsubsection{Considerações sobre CNC}

Para que as vantagens da tecnologia a altas velocidades possam ser alcançadas, os comandos numéricos presentes nas máquinas devem possuir características técnicas de alto nível. Um dos primeiros requisitos é a velocidade de processamento de bloco, programas CNC para fresamento de superfícies complexas geralmente consistem de uma longa seqüência de comandos de interpolações, que por sua vez determinam à posição da ponta da ferramenta. Neste caso o tempo de processamento de bloco pode representar uma limitação à velocidade de avanço (MOREIRA, 2002).

A capacidade de interpolação simultânea de até cinco eixos é outro recurso importante para a usinagem de superfícies complexas, torna-se necessário que uma fresa de topo possa trabalhar com ângulos de até $90^{\circ}$ e perpendicularmente à superfície gerada, o que só é possível em máquinas com capacidade de movimentação em cinco eixos, movendose a mesa onde fixa-se a peça, ou o eixo-árvore. Nestes casos, o $\mathrm{CNC}$ deve garantir que a velocidade de avanço seja mantida na ponta da ferramenta, com recursos mais sofisticados que permitam ainda que se modifique a inclinação da fresa em relação à 
superfície que está sendo gerada durante a interpolação. Os acionamentos da máquinaferramenta para aplicações a altas velocidades devem também ser atualizados com a tecnologia de controle digital.

Esses novos desenvolvimentos permitem que as máquinas apresentem melhor desempenho dinâmico, uma vez que o seu ajuste é facilitado e há redução dos erros de arraste e melhor precisão de posicionamento a alta velocidades.

Os comandos devem também ser capazes de incorporar novas trajetórias de interpolação, além da linear e circular, interpolações por curvas splines são cada vez mais requisitadas para as chamadas superfícies complexas, as quais exigem curvas diferentes de retas ou circunferências. Os comandos mais modernos devem incorporar ainda controle de aceleração, para evitar os solavancos pela suavização da variação da velocidade de avanço, esse recurso permite à máquina uma transição mais suave entre mudanças bruscas de direção no fresamento de superfícies complexas (SOUZA, 2001).

Os comandos destinados a altas velocidades devem ter a função "look ahead”, que permite uma previsão de mudanças de direção e, conseqüentemente, a suavização do movimento, para que a ferramenta possa descrever com maior fidelidade a trajetória comandada, esta função possibilita a usinagem a velocidades médias de avanço superiores às proporcionadas por máquinas convencionais.

Desta nova geração de CNC exige-se ainda que, além da desaceleração do movimento de avanço dos eixos, seja também reduzida a rotação do eixo-árvore. Dessa forma, pode-se manter constante a espessura do cavaco formado no fresamento, sendo essa espessura fundamental para manter as forças de corte constantes e, conseqüentemente a solicitação dinâmica na ferramenta, permitindo manter maior precisão dimensional na peça (MOREIRA, 2002; GEIST, 1999; KIRSCHNIK, 1997).

Como as máquinas HSC empregadas na usinagem de superfícies complexas devem conter programas longos o que, por sua vez, requerem dos CNC alta capacidade de memória e altas taxas de transferências de dados, a transferência pode envolver o acesso ao disco rígido e esse pode ser um ponto crítico para a manutenção das altas velocidades. A transferência dos programas da estação CAM para a máquina também deve ser rápida, para que o set-up da máquina seja agilizado, atualmente isso é feito com placas ethernet e redes padrão TCP/IP (HELLENO, 2003; MOREIRA, 2002). 


\subsection{Operações de fresamento CNC}

O número de eixos no fresamento se refere ao número de graus de liberdade de uma máquina NC em posicionar ferramentas de corte, (CAVALHEIRO, 1998):

- 2 eixos: ferramentas se movimentam apenas nas direções X e Y, permite apenas aplicações planares.

- $2 \frac{1}{2}$ eixos: adiciona usinagem no eixo $Z$, o qual pode ser posicionado, mas não pode ser usado em movimentos simultâneos com os eixos $\mathrm{X}$ e Y, é utilizado para posicionar a ferramenta em níveis de profundidade de corte. Em princípio é possível utilizar usinagem $2 \frac{1}{2}$ eixos para fabricar peças tridimensionais.

- 3 eixos: movimenta os eixos X, Y e Z simultaneamente durante a usinagem, permite a interpolação linear utilizando os três eixos simultaneamente, interpolações circulares podem ser realizadas apenas em duas dimensões.

- 4 eixos: adiciona-se às características de usinagem tridimensional, acrescenta-se respectivamente, um ou dois eixos de rotação controláveis, permite posicionamento da ferramenta através da rotação da mesa da máquina em torno de um eixo perpendicular à mesa.

- 4 eixos simultâneos: como descrito acima, mas com o quarto eixo utilizado também para movimentos de corte, simultaneamente aos outros 3.

- 5 eixos: permite a movimentação básica em torno dos três eixos mais dois eixos de movimento simultâneo, paralelos ou em torno de X, Y ou Z.

O fresamento tridimensional é o processo mais utilizado pelo setor de matrizaria, é nesta faixa que se encontra a maior gama de aplicações de máquinas-ferramentas para trabalhar em HSC. Isto se deve aos fatores técnicos de programação NC (incluindo a verificação de colisões entre a ferramenta, peça e dispositivo de fixação) e os custos envolvidos para a usinagem 4D ou 5D, estas técnicas são basicamente utilizadas quando não existe outra alternativa viável. 


\subsection{Aspectos Gerais do Fresamento}

De acordo com FERRARESI (1977), CAVALHEIRO (1998) e SANDVIK (1999) o processo de fresamento é semelhante a outros processos de usinagem, como o torneamento, furação e retificação. No fresamento a retirada de material é promovida pelo movimento relativo entre a ferramenta e a peça. O movimento de corte, obtido pela rotação da ferramenta e pelo avanço, pode ser normal ou oblíquo à direção do eixo de rotação, o avanço é dado pelo deslocamento da fresa, da mesa e em algumas vezes de ambos.

O fresamento é o processo mais utilizado na confecção de cavidades, mesmo sendo um dos mais complexos dentro os processos de usinagem. Isto se deve à grande variedade de ferramentas e máquinas e às altas taxas de remoção de material.

No fresamento a aresta de corte da ferramenta penetra na peça, removendo uma porção de material, sendo que existem duas diferenças básicas na formação do cavaco em relação, por exemplo, ao torneamento ou à furação.

1- O fresamento consiste de corte interrompido, onde cada gume de corte ou faca atua durante um tempo inferior ou igual à metade do tempo gasto para completar uma revolução.

2- A espessura do cavaco varia constantemente ao longo do corte, devido ao movimento de rotação da fresa e avanço da peça.

Com a descontinuidade na remoção de material a cada rotação da fresa, as formas do primeiro e último contato entre a ferramenta e a peça são de fundamental importância no desgaste e lascamento da ferramenta, com isto as solicitações térmicas e dinâmicas alternantes no gume da fresa, podem levar à formação de fissuras e à quebra do gume por fadiga. Portanto, os materiais para a confecção de fresas devem ter alta tenacidade, elevada resistência a solicitações térmica e alta resistência de gume, o material que propicia maior produtividade na usinagem de aços é o metal-duro, devido a boas características de tenacidade e resistência de gume, apesar do aço rápido ainda ter grande aplicação. A cerâmica tem limitações quanto à resistência a solicitações térmicas, embora 
seja mais resistente ao desgaste e a altas temperaturas que o metal-duro e o aço rápido, sua aplicação mais freqüente na usinagem fina de ferro fundido.

Tem se ainda o Nitreto Cúbico de Boro (CBN), com a aplicação crescente no fresamento em altíssima velocidade e o diamante policristalino (PVD), empregado na usinagem de ligas de alumínio e materiais sintéticos.

\subsubsection{Sentido de corte}

Segundo CAVALHEIRO (1998) e SANDVIK (1999) algumas estratégias apresentam a possibilidade do fresamento somente no sentido discordante, concordante ou ainda utilizando os dois, para otimizar a usinagem em relação ao tempo, figura 2.18. Porém, a usinagem somente é totalmente concordante ou totalmente discordante se a ferramenta penetra lateralmente no material com a metade ou menos do seu diâmetro, pois ao contrário existem os dois tipos de corte, observamos assim, que este parâmetro realmente especifica a posição da ferramenta em relação ao material removido.

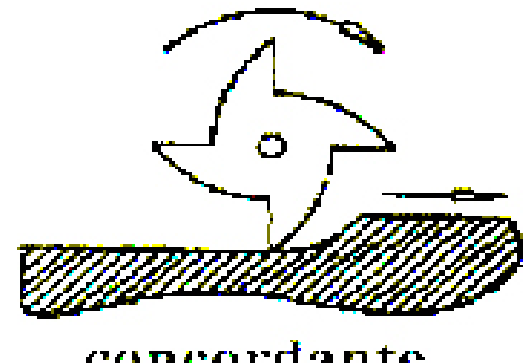

consordante

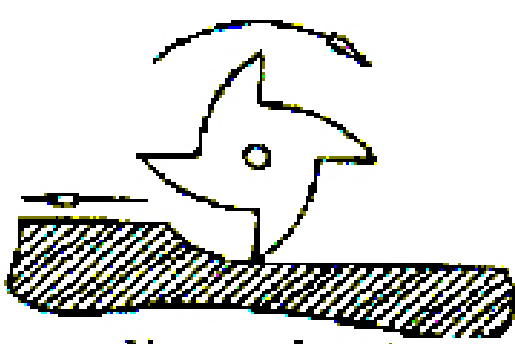

diseordante

Figura 2.18 - Sentido de corte - Fresamento Tangencial: Fresa de topo com quatro gumes cortando o material à direita, ou seja, no sentido concordante (sentido de avanço) e com material à esquerda ou no sentido discordante (contrário ao avanço), as setas retas mostram o sentido do movimento da ferramenta em relação à peça (CAVALHEIRO, 1998). 
A combinação dos movimentos de corte e avanço define o sentido de corte, considerando que o deslocamento é realizado pela mesa onde é fixada a peça, o sentido de corte pode ser: concordante, quando o sentido da velocidade de corte $\left(\mathrm{V}_{\mathrm{c}}\right)$ é o mesmo da velocidade de avanço $\left(\mathrm{V}_{\mathrm{f}}\right)$ e discordante, quando o sentido da $\mathrm{V}_{\mathrm{c}}$ é oposto ao sentido da $\mathrm{V}_{\mathrm{f}}$. Outra forma de saber qual o sentido de corte é pela espessura inicial e final do cavaco.

No fresamento concordante, o corte inicia com a espessura máxima (valor do avanço por dente) e termina com espessura teoricamente zero, no sentido discordante, a espessura inicial é zero e a final, máxima. Dependendo da posição da ferramenta em relação à peça, pode-se ter, também, os dois sentidos simultaneamente, vide figura 2.19.

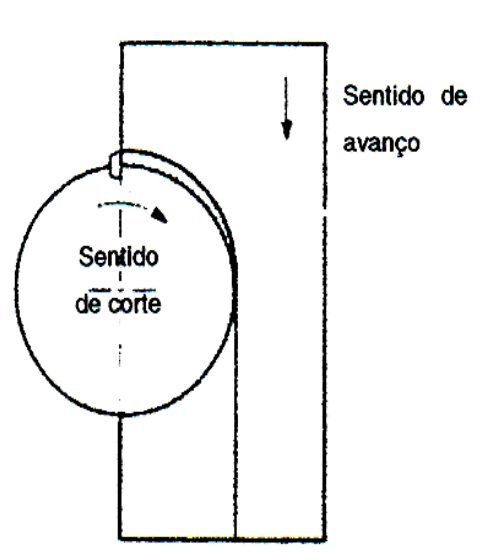

Fresamento concordante

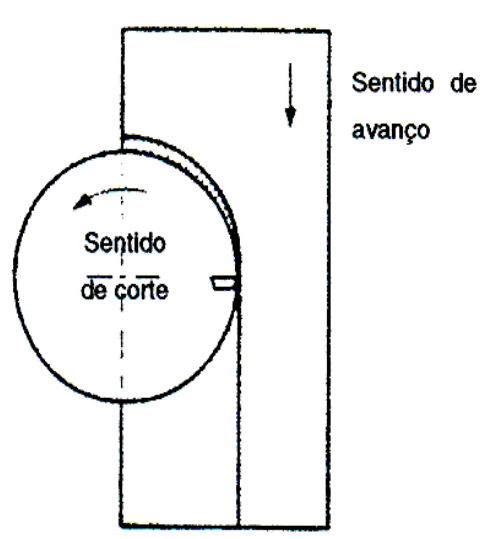

Fresamento discordante

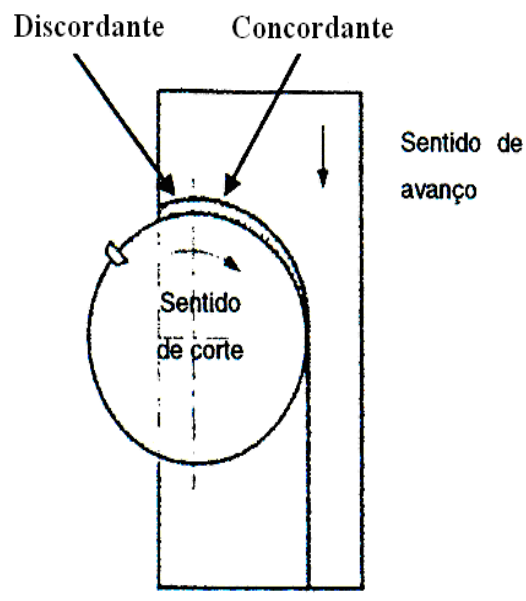

Fresamento concordante $\theta$ discordante

Figura 2.19 - Sentido de corte - Fresamento Frontal.

Porém, são muito comuns as usinagens de acabamento utilizando os dois sentidos de corte, pois para a remoção de sobremetais muito pequenos os efeitos prejudiciais da usinagem discordante são menos pronunciados. Além disso, no caso da usinagem completamente concordante, a ferramenta teria de retrair-se, movimentar-se para o início do próximo deslocamento e novamente descer sobre a peça, o que aumenta o tempo de usinagem (ainda que esses movimentos sejam em programação de avanços rápidos).

Entretanto, em alguns casos, é aconselhável utilizar o fresamento discordante, principalmente quando houver folgas na máquina-ferramenta, no fresamento periférico em acabamento de materiais temperados, onde o fresamento discordante consegue melhores tolerâncias de perpendicularidade da parede fresada, e os degraus entre os 
passes são menores ou inexistentes isto se deve, principalmente, à direção das forças de corte. Quando se tem uma aresta de corte muito viva em ação, as forças de corte tendem a puxar a fresa em direção ao material, no fresamento discordante esta tendência é menor. Um aspecto que devemos considerar, é que no fresamento concordante a aresta de corte é exposta principalmente a tensões de compressão, as quais são bem suportadas pelo metal duro, situação que é contrária no fresamento discordante, onde a aresta de corte é submetida a tensões de tração para as quais o metal duro não apresenta boa resistência.

\subsubsection{Usinagem Ascendente e Descendente}

Conforme SARAIVA (2000) e SANDVIK (1999) deve-se optar pela usinagem de baixo para cima (ascendente) conforme ilustrado na figura 2.20, dessa forma a espessura de cavaco tem um valor máximo com uma velocidade de corte mais favorável.

Quando a fresa usina de cima para baixo (descendente) há amassamento de material, por que a velocidade de corte é menor no centro da ferramenta.

O amassamento ocorre com maior intensidade em planos com inclinações menores, devido ao contato da parte central da fresa com a peçam causando picos que aumentam a rugosidade.

Durante a usinagem descendente, temos uma espessura de cavaco grande sendo gerada em uma região próxima ao centro da ferramenta, onde se tem baixa velocidade de corte. Há o risco constante de lascamento da ferramenta conforme a indicado na figura 2.21.

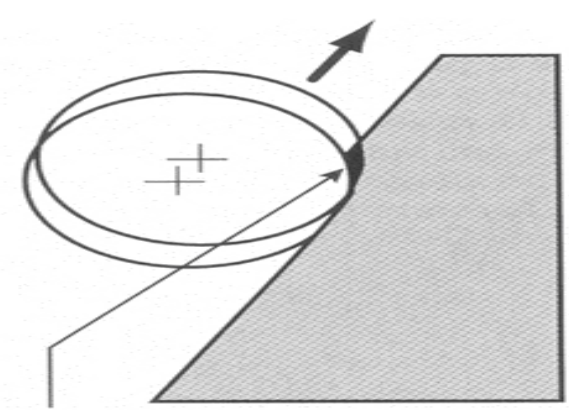

Figura 2.20 - Espessura máxima dos cavacos com $\left(\mathrm{V}_{\mathrm{c}}\right)$ recomendada, SANDVIK (1999). 


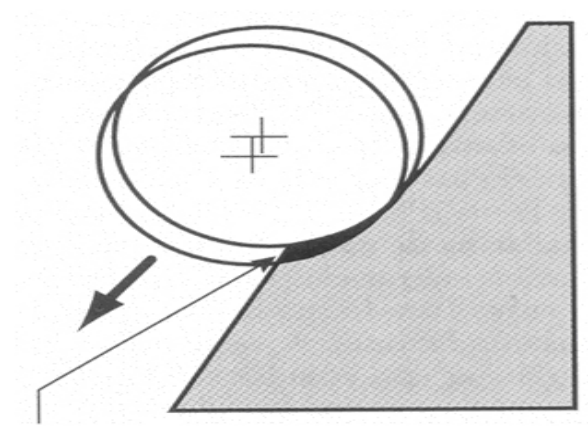

Figura 2.21 - Descendente com grande espessura de cavaco e com $\left(\mathrm{V}_{\mathrm{c}}\right)$ muito baixa, SANDVIK (1999).

\subsubsection{Volume constante de sobremetal}

O desbaste de cavidades efetuado com uma fresa de topo reto apresenta o inconveniente de formar uma superfície com degraus em forma de escada com variação brusca de sobremetal que deve ser removido na operação posterior de pré-acabamento. Isso, naturalmente gera forças de corte variáveis e deflexão da ferramenta.

O resultado é um volume de material não-uniforme de sobremetal para o acabamento, o que influirá na precisão geométrica e no acabamento da superfície. Com a utilização de ferramentas de topo esférico ou toroidais, a transição entre os passes torna-se mais suave e o volume de sobremetal irregular é menor, o que por sua vez gerará menos deflexão e forças de corte constantes SANDVIK (1999).

A Figura 2.22 (a) ilustra o contorno de uma peça com diferentes graus de curvatura, e o bloco prismático de matéria prima, para sua fabricação. A Figura 2.22 (b) ilustra o material restante da operação de desbaste utilizando uma ferramenta de topo reto. Observa-se que são evidentes as transições bruscas de sobremetal em forma de escada. A Figura 2.22 (c) mostra o desbaste nas mesmas condições de usinagem, mas utilizando uma ferramenta de topo esférico, observa-se transições suaves de sobremetal remanescente. 


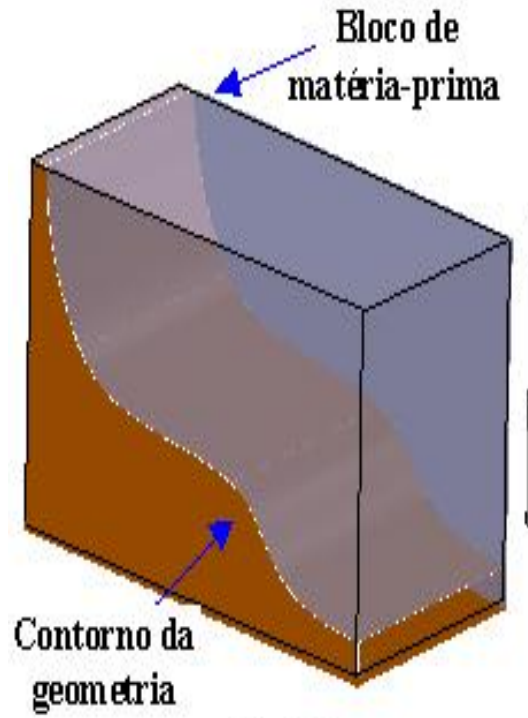

Fig. (a)

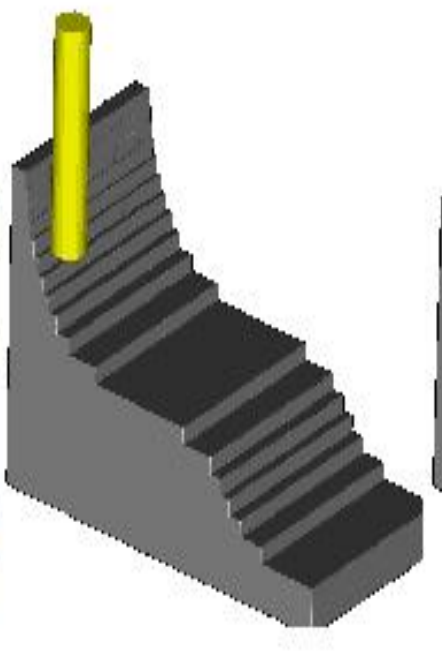

Fig. (b)

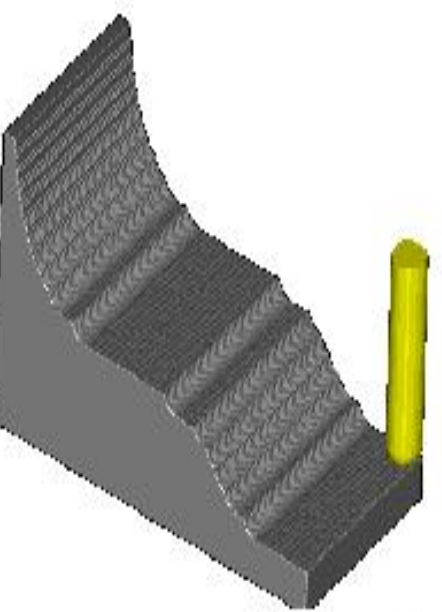

Fig. (c)

Figura 2.22 - Desbaste com ferramentas de topo reto e esférico (SOUZA, 2004).

Conforme GOMES (2001) esta variação na quantidade de sobremetal em forma de escada a ser removido na operação de acabamento é prejudicial ao processo, principalmente em altas velocidades de corte. Esta transição topográfica pode provocar oscilações da força, diminuindo a vida da ferramenta e deflexões na ferramenta para a operação posterior de pré-acabamento ou acabamento, que invariavelmente influenciaram na precisão geométrica e acabamento da peça. Com a utilização de ferramentas de topo esférico ou toroidais, a transição entre os passes é menos pronunciada e o volume de sobremetal é menor.

\subsubsection{Geometria do processo de fresamento com uma fresa de topo esférico $2 \frac{1}{2} 2$ eixos.}

As condições de contato da aresta de corte modificam-se continuamente nas fresas de topo esférico em função da geometria. A rotação constante promove uma variação da velocidade de corte que oscila de zero no centro da ferramenta a um valor máximo no diâmetro efetivo. Na usinagem de um plano perpendicular ao eixo da ferramenta, 
independente da profundidade de usinagem $\left(\mathrm{a}_{\mathrm{p}}\right)$ ou da largura de corte $\left(\mathrm{a}_{\mathrm{e}}\right)$, a extremidade da ferramenta se mantém em contato com a superfície e nesta região a velocidade de corte é zero.

A espessura (h) e a largura (b) do cavaco variam em função da profundidade de usinagem $\left(a_{p}\right)$, reduzindo as tensões no gume da ferramenta, permitindo, deste modo o emprego de maiores velocidades de avanço GOMES (2001).

Os detalhes da geometria de contato da fresa de topo esférico com material da peça plana, perpendicular ao eixo da ferramenta são demonstrados nas figuras 2.23, 2.24, 2.25, 2.26 juntamente com os principais parâmetros de usinagem.

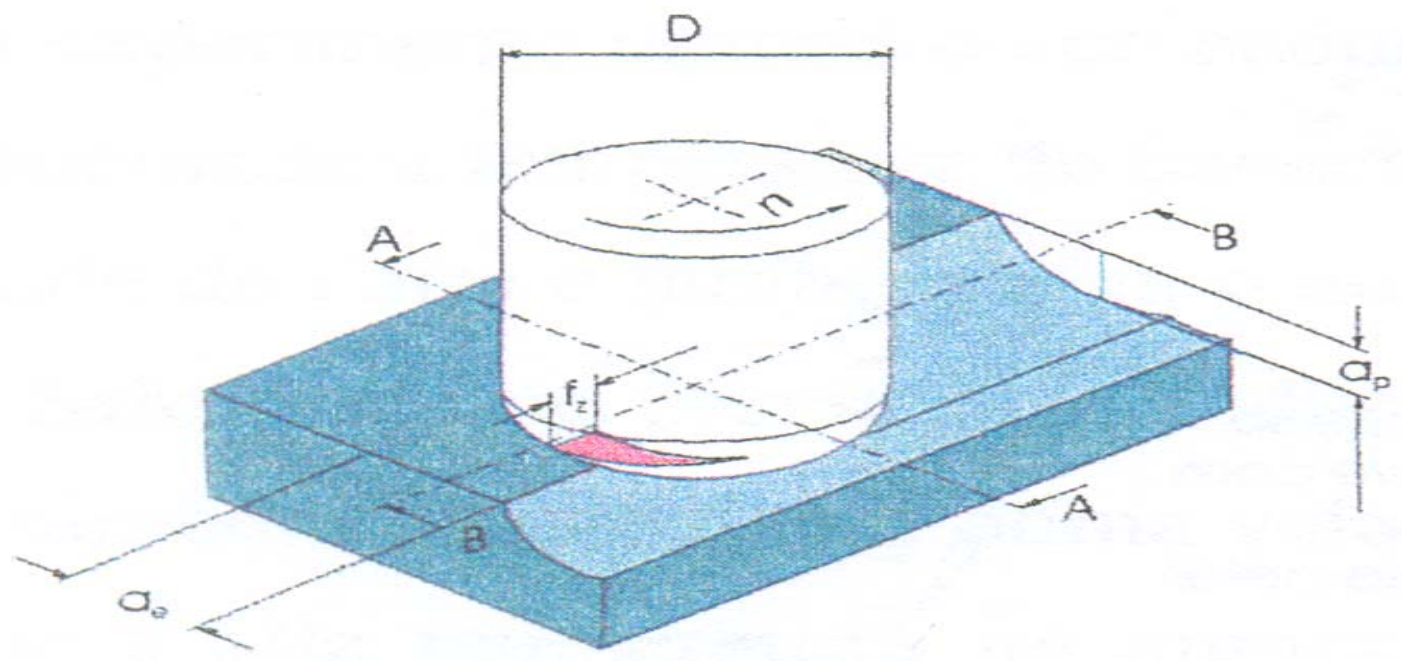

Figura 2.23 - Geometria do processo com fresa de topo esférico (GOMES, 2001).

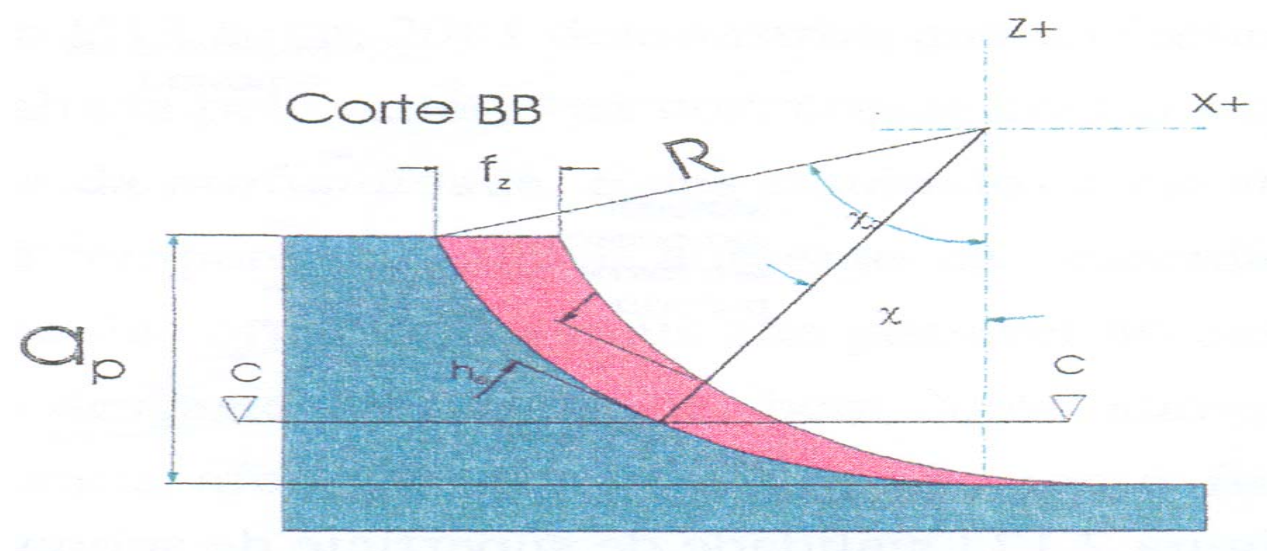

Figura 2.24 - Geometria do processo com fresa de topo esférico (GOMES, 2001). 


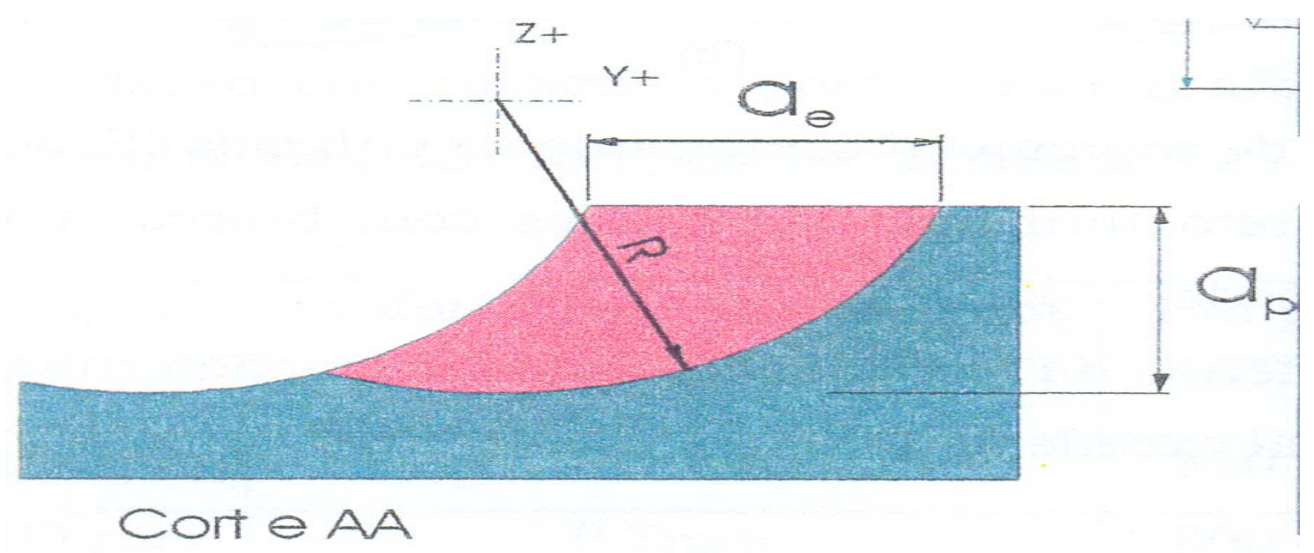

Figura 2.25 - Geometria do processo com fresa de topo esférico (GOMES, 2001).

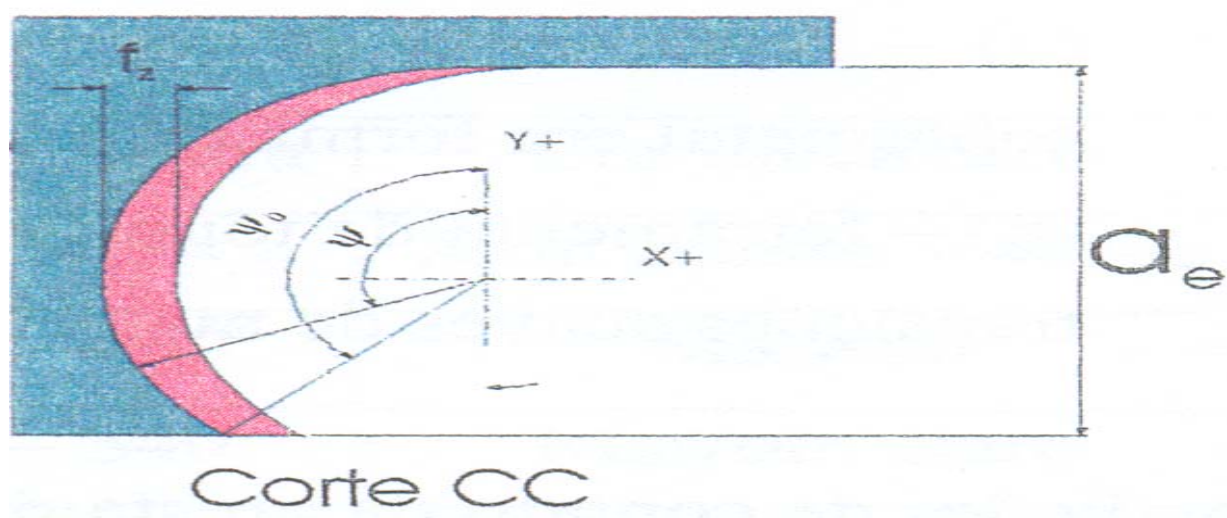

Figura 2.26 - Geometria do processo com fresa de topo esférico (GOMES, 2001).

O ângulo de engajamento total da ferramenta no corte $(\psi$ o $)$ pode ser determinado por:

$$
\psi_{0}=\arccos \left(1-\frac{2 \times a_{e}}{D \times \operatorname{sen} \chi}\right)
$$

O valor do ângulo de posição tem seu valor máximo na superfície da peça e é definido pela expressão:

$$
\chi_{0}=\arccos \left(1-2 \times \frac{a p}{D}\right)
$$


Observando a equação 2.2 podemos afirmar que o ângulo de engajamento total tem o seu valor mínimo quando o ângulo de posição tem o seu valor máximo. O produto D.sen $\chi$ identifica o diâmetro da fresa de ponta esférica que está em contato com a superfície da peça que está sendo usinada. Este diâmetro é também conhecido como diâmetro efetivo e é nele que é calculada a velocidade de corte. Quando o valor da penetração de trabalho “a”" é menor que o diâmetro efetivo, o valor do ângulo de engajamento é menor que $180^{\circ}$ na superfície da peça. O valor limite do ângulo de engajamento é de $180^{\circ}$ e ele ocorre na superfície da peça quando o valor de "ae" é igual ao diâmetro efetivo ou dentro da peça quando o valor do ângulo de posição assume um valor tal que a razão ae/D.sen $\chi$ torna-se unitária. Por limitação física, quando ae/D.sen $\chi$ é maior que a unidade o ângulo de engajamento é de $180^{\circ}$.

O fresamento concordante é aquele em que no movimento de corte o ângulo começa com o valor máximo $\psi$ o e vai decrescendo até o valor nulo (o sentido do movimento de avanço concorda com o movimento rotativo da fresa) e o fresamento discordante (o sentido do movimento de avanço é contrário ao movimento rotativo da fresa) é aquele em que o ângulo de engajamento do dente cresce do valor zero até o máximo \%o (DINIZ, 2000).

Para fresas de topo esférico, o comprimento de corte (lcp) corresponde a:

$$
l_{c p}=\psi_{0} \times \frac{D}{2} \times \operatorname{sen} \chi
$$

A espessura de usinagem instantânea (ho) é função do avanço por dente, do ângulo de posição e do ângulo de engajamento:

$$
h_{0}(\psi, \chi)=f_{z} \times \operatorname{sen} \psi \times \operatorname{sen} \chi
$$

E seu valor é determinado pela seguinte aproximação:

$$
h_{m}=\frac{2 \times f_{z} \times a_{e}}{\psi_{0} \times D \times \operatorname{sen} \chi}
$$


A velocidade de corte $\left(\mathrm{V}_{\mathrm{c}}\right)$ é uma função do ângulo de posição $(\chi)$, e seu valor máximo é a velocidade de corte efetiva $\left(\mathrm{V}_{\text {ce }}\right)$ que pode ser expressa pela próxima equação:

$$
V_{c e}=\pi \times D \times n \times \operatorname{sen} \chi_{0} / 1000
$$

A análise acima foi desenvolvida para as passadas no primeiro nível da profundidade, quando toda a superfície está plana, perpendicular ao eixo da ferramenta. Do segundo nível de profundidade em diante, a profundidade de usinagem oscila entre o valor de ap fixado e o valor de ap mais a altura de crista da passada anterior. Assim fica claro que a velocidade efetiva máxima não será mais a mesma, o ângulo máximo de posição também não será mais o mesmo, ambos sofrerão um pequeno acréscimo.

A geometria da fresa de topo esférica, figura 2.27 proporciona o corte de material em qualquer inclinação da superfície entre $0^{\circ}$ e $90^{\circ}$ com relação ao plano normal ao eixo da ferramenta, na usinagem em 3 eixos várias partes do gume efetuam o corte, podendo mudar conforme a trajetória da fresa sobre a cavidade. Dependendo da forma e inclinação da superfície, cada ponto da fresa em contato com a peça está submetido a diferentes condições de corte. Contudo, a região central da ferramenta é a mais crítica, onde a velocidade de corte é muito pequena, resultando no amassamento do material e num acabamento superficial ruim conforme já mencionado nos capítulos anteriores.

Embora existam fresas de ponta esférica com insertos intercambiáveis que cumprem a mesma função das interiças, com as vantagens de melhor desempenho, facilidade de reparo em caso de quebra das pastilhas e desvantagens de alto investimento inicial, geralmente são empregadas fresas interiças na operação de acabamento das cavidades.
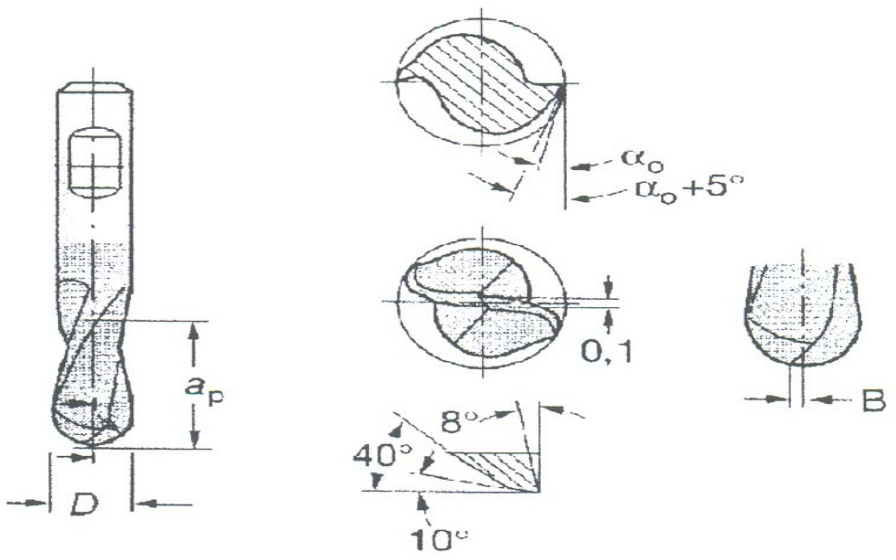

Figura 2.27 - Geometria da fresa de topo esférica. 


\subsubsection{Considerações sobre o cavaco gerado durante o fresamento.}

As características físicas dos cavacos gerados durante as operações de usinagem, sua forma, volume e cor refletem diretamente nas características do processo de usinagem que os gerou, como apresentado por diversas fontes (TRENT e WRIGHT, 2000; MACHADO e SILVA, 1999). Pequenas modificações observadas nos cavacos podem refletir a qualidade superficial gerada pela usinagem, assim como alterações na vida da ferramenta de corte e desvio dimensional. Este fato tem maior ênfase quando se trabalha em altas velocidades de usinagem, onde pequenas distorções do cavaco ideal tem maior relevância na estabilidade do processo, devido às altas velocidades de corte. Nos estudos realizados NING et al (2001), verificou-se o comportamento da usinagem em alta velocidade através dos cavacos gerados durante os experimentos. Utilizou-se material endurecido (H13 - 55 HRc) empregando uma ferramenta de ponta esférica para a usinagem. Entretanto, este estudo foi realizado apenas para usinagem plana, considerando o eixo da ferramenta de corte perpendicular a superfície usinada. Entre os resultados, o autor apresentou diferentes formas de cavaco, que estão relacionadas à estabilidade da usinagem. A figura $2.28 a$ apresenta a foto de um cavaco gerado por uma usinagem considerada estável pelo autor, devido à qualidade superficial obtida. $\mathrm{O}$ cavaco é enrolado possuindo forma próxima a um cone. A figura $2.28 b$ apresenta um esboço de atuação da ferramenta durante o corte estável.

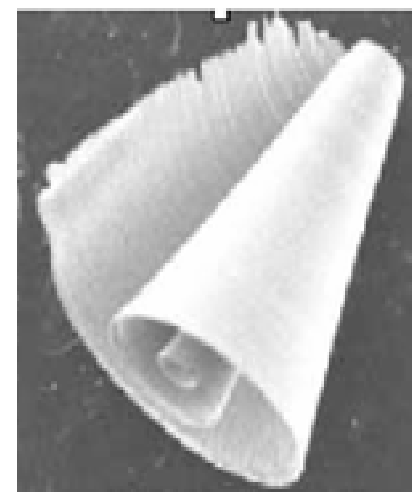

Fig. a: Cavaco cốtico

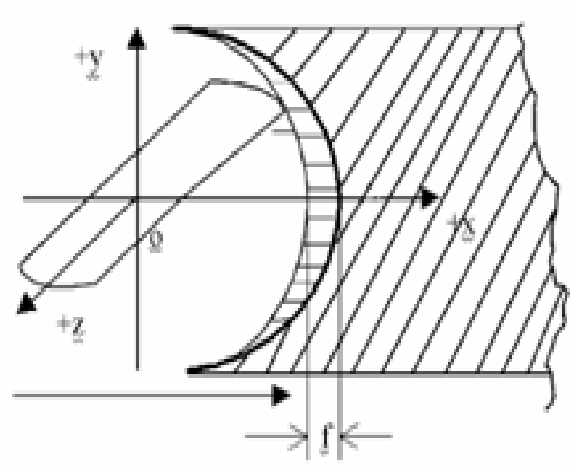

Fig. b: Processo de cotte estável

Figura 2.28 - Características de um processo de usinagem estável (NING, 2001). 
Atribuindo parâmetros de corte mais severos, o autor obteve um processo de corte considerado não-estável, resultando em uma qualidade superficial de baixa qualidade e alterações no mecanismo de geração dos cavacos. Nesta condição de usinagem verificaram-se acentuadas vibrações auto-excitadas (vibrações tipo chatter), repercutindo na forma do cavaco, como ilustrado pela figura 2.29a. O cavaco é do tipo agulha, proveniente da vibração da ferramenta (e/ou da peça) durante a atuação de uma aresta de corte (figura 2.29b). Neste caso, mais de um cavaco é gerado durante a atuação de cada aresta. Este fato ocorre devido às oscilações entre a ferramenta e a peça. No corte estável a atuação de cada aresta gera um único cavaco.

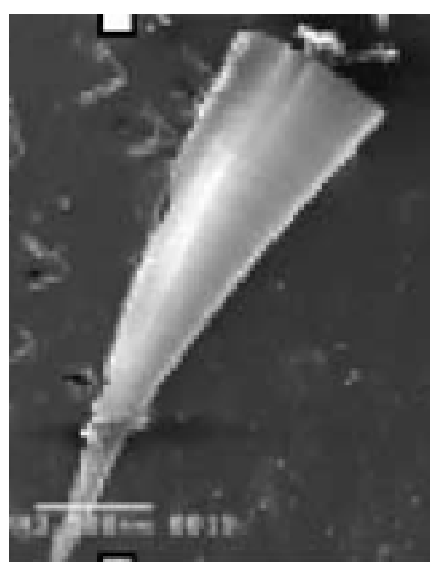

Fig. a: Cavaco agulha

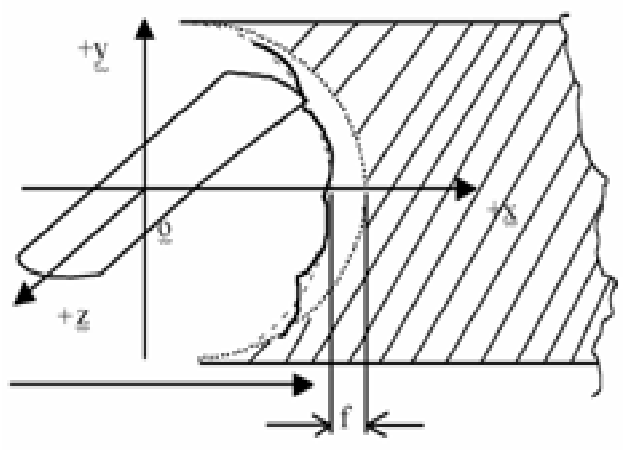

Fig. b: Processo de cotte näo-estavel

Figura 2.29 - Características de um processo de usinagem não estável (NING, 2001).

\subsection{Análise da flexão sobre o erro dimensional}

Diversos fatores como o material da ferramenta, a rigidez da interface ferramenta/portaferramenta e a conexão com o eixo árvore têm um impacto na propriedade dinâmica da ferramenta de corte. O erro dimensional produzido na superfície da peça ocorre, fundamentalmente pelo deslocamento da haste da ferramenta, no caso de corte concordante, no momento da entrada do gume na peça, a maior espessura de usinagem (h) provoca uma retração da haste da ferramenta de corte, provocando o erro dimensional da peça. Para a representação do desvio da haste da ferramenta, pode-se considerar 
aproximadamente a rigidez da ferramenta de ponta esférica como uma viga engastada, com uma força (F) agindo na ponta, assim sua flexão é representada pela figura 2.30.

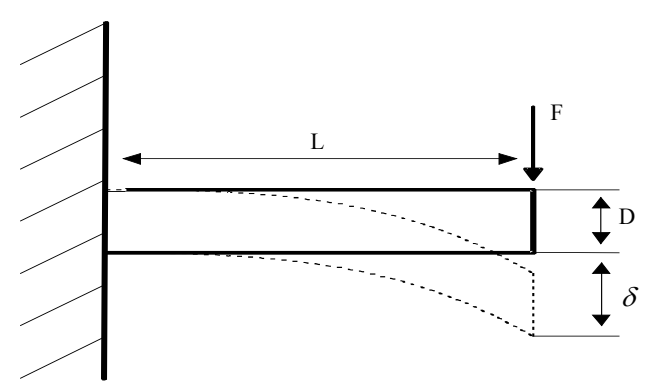

Figura 2.30 - Representação da haste da ferramenta como um sistema engastado.

A equação 2.8 fornece a flexão para um sistema engastado, quando submetida a uma força na sua extremidade:

$\delta=\frac{F \times L^{3}}{3 \times E \times I}$

Onde:

$\delta=$ Flexão da ferramenta, [mm];

$\mathrm{L}=$ É o comprimento em balanço, $[\mathrm{mm}]$;

$\mathrm{F}=$ Força na extremidade do cilindro, $[\mathrm{N}]$;

$\mathrm{E}=$ Módulo de elasticidade do material, $\left[\mathrm{N} / \mathrm{mm}^{2}\right]$;

$\mathrm{I}=$ Momento de inércia da seção transversal, $\left[\mathrm{mm}^{4}\right]$;

O momento de inércia da seção transversal de um cilindro é dado pela equação 2.9.

$I=\frac{\pi \times D^{4}}{64}$

Onde:

$\mathrm{D}=$ diâmetro da seção transversal, [mm]; 
Pela combinação de ambas as equações fica evidente que o comprimento da ferramenta (L) tem fator exponencial 3 e o diâmetro (D) tem fator exponencial 4, que por sua vez influenciam diretamente no desvio da haste da ferramenta.

Ou seja, o desvio será tanto maior quanto maior for o comprimento da haste e quanto menor for o diâmetro da ferramenta de corte, conforme a equação 2.10 .

$$
\delta=K \times \frac{I^{3}}{D_{c}^{4}}
$$

Deve-se, portanto usar a ferramenta de maior diâmetro possível com montagem mais curta possível, mas isto restringe a usinagem HSC quando se tenta usinar cavidades estreitas e profundas.

Como o metal-duro apresenta um módulo de elasticidade maior do que o aço-rápido (210 $\mathrm{kN} / \mathrm{mm}^{2}$ do aço-rápido contra $360 \mathrm{kN} / \mathrm{mm}^{2}$ do metal duro), as ferramentas com hastes de metal-duro apresentam um menor desvio.

Reduzir as vibrações no corte, o que conduz a menores erros de forma na peça, pode ser feito através da diminuição do comprimento em balanço da fresa conforme citado acima, por outro lado à combinação da geometria da ferramenta, com condições de corte apropriadas, permitem manter estes erros dentro de limites aceitáveis.

\subsection{Aspectos básicos da força de corte}

O conhecimento da força de corte é de grande importância no projeto dos elementos de máquinas-ferramentas, como os acionamentos, guias, mancais, sistemas de fixação das ferramentas e dispositivos de fixação das peças, na determinação dos parâmetros de corte para o planejamento dos processos de usinagem. Portanto a força de corte é utilizada para estimar a maior parcela da potência requerida na usinagem, de acordo com a equação 2.11 .

$$
P_{c}=\frac{F_{c} \times V_{c}}{60000}[w]
$$


Onde:

Pc: potência de corte $(\mathrm{W})$

$\mathrm{Fc}$ : força de corte $(\mathrm{N})$

Vc: velocidade de corte $(\mathrm{m} / \mathrm{min})$

A força de corte representa a única parcela que contribui para o cálculo da potência. A força de usinagem, por sua é a soma vetorial de três parcelas principais: a força de corte, a força de avanço e a força passiva (FERRARESI, 1977).

De acordo com FERRARESI (1977) e DINIZ et al. (2000), as forças atuantes no processo podem ser classificadas em força ativa $(\mathrm{Ft})$ e força passiva $(\mathrm{Fp})$.

a) A força ativa (Ft): é a componente de $\mathrm{Fu}$ atuando no plano de trabalho, e que contribui para potência de usinagem. A força ativa pode ser decomposta ainda nas seguintes componentes:

FT': Força de atrito entre a peça e a superfície de folga da ferramenta;

FT : Força de atrito entre o cavaco e a superfície de saída da ferramenta;

Ff : Força de avanço, é a projeção de Fu sobre a direção de avanço;

Fc : Força de corte, é a projeção de Fu sobre a direção de corte;

Fap : Força de apoio, é a projeção de Fu sobre a direção perpendicular à direção de avanço, situada no plano de trabalho;

Fe : Força efetiva, é a projeção de Fu sobre a direção efetiva de corte;

Fn : Força de compressão, é a projeção de Fu sobre a direção perpendicular à superfície principal de corte;

b) A força passiva (Fp): é a componente de $\mathrm{Fu}$ atuando em um plano perpendicular ao plano de trabalho, e não contribui parra a potência de usinagem, apenas para a deflexão da elástica da peça e da ferramenta, por isso é responsável pela dificuldade de obtenção de tolerâncias de forma e dimensão apertadas DINIZ at al (2000). Assim, a força de usinagem pode ser expressa pela equação 2.12 .

$$
F_{u}=\sqrt{F_{p}^{2}+F_{t}^{2}}
$$


A força de usinagem corresponde também ao vetor formado pelas componentes de forças obtidas pelo dinamômetro (Fx,Fy,Fz), de acordo com a equação 2.13, conforme LIMA et al. (2003).

$F_{u}=\sqrt{F x^{2}+F y^{2}+F z^{2}}$

Por diferentes modelos, pode-se estimar o valor da força de corte utilizando à pressão especifica e a área de seção de corte, o método de Kienzle é bastante utilizado para esta estimativa. Este método permite a aplicação em diferentes processos de usinagem, para isso é necessário considerar a correlação entre a pressão específica e a área da seção transversal do cavaco, conforme a Equação 2.14.

$F_{c}=K_{s} \times A$

Onde:

Ks: pressão específica de corte, $\left[\mathrm{N} / \mathrm{mm}^{2}\right]$;

A: Área da seção transversal do cavaco não deformado, $\left[\mathrm{mm}^{2}\right]$.

O valor do parâmetro Ks depende do material da peça a ser usinada, da geometria e do material da ferramenta de corte, o Ks também pode ser entendida como sendo a energia necessária para remover uma unidade volumétrica de cavaco da peça. Tabelas com valores de Ks podem ser encontradas na literatura, baseadas em diferentes teorias para a determinação deste parâmetro. A principal teoria para determinação do Ks foi proposta por Kienzle, conforme a equação 2.15.

$$
K_{S}=K_{S_{I}} \times h^{2}
$$

Onde:

$\mathrm{Ks}_{1}$ e Z são constantes que dependem do material da peça e da ferramenta. 
O modelo utilizado por Gomes (2001) para definir a força de corte (Fc) em operações de fresamento com ferramentas de topo plana, envolve grandezas experimentais, como força específica de corte definida por Kienzle (Kc1.1) e o coeficiente de Kienzle (1-mc), além da profundidade de corte (ap), do número de arestas atuantes no corte (Z) e a espessura média do cavaco (hm), de acordo com a equação (2.16).

$F_{c}=a p \times Z \times h_{m}^{(1-m c)} \times K_{c 1-1}$

A espessura média do cavaco $(\mathrm{hm})$ é definida em função do ângulo de penetração no corte (Ф) do avanço por aresta (fz), da espessura de corte (ae) e do diâmetro da ferramenta (d), conforme ilustra a figura 2.31 .

A espessura média do cavaco $(\mathrm{hm})$ pode ser calculada pela equação 2.17:

$h_{m}=f_{z} \times a_{e} \times \frac{360^{\circ}}{(\phi \times \pi \times D)}$

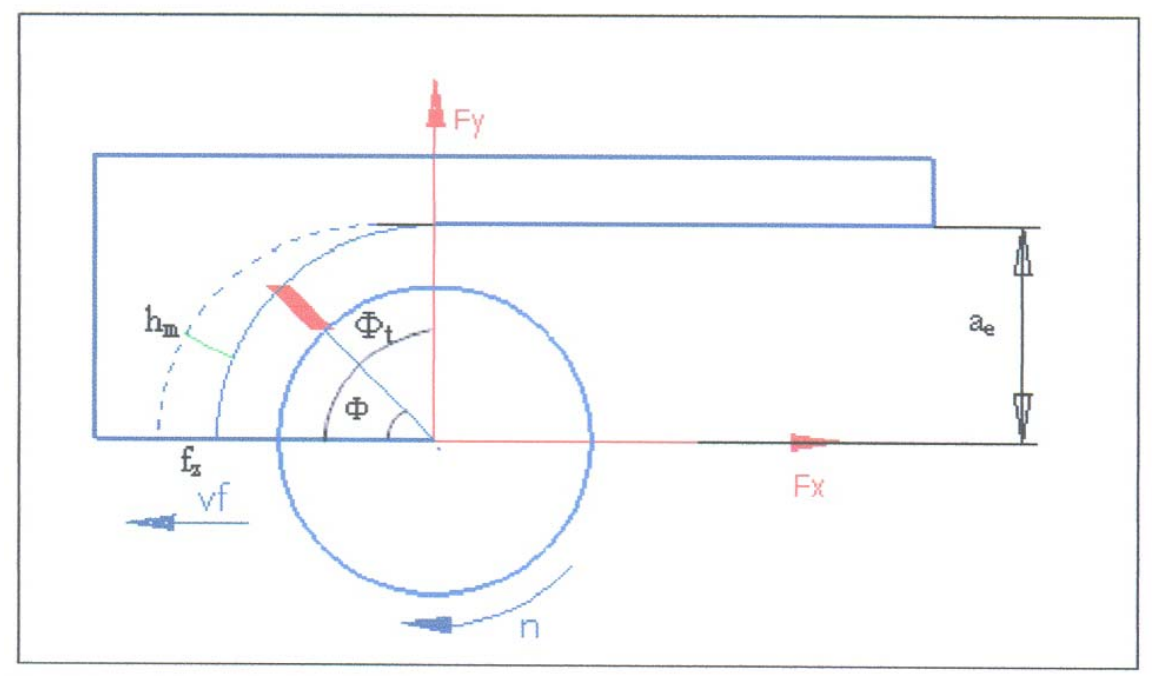

Figura 2.31 - Ângulo de penetração de corte (Ф) (Souza, 2004).

$\mathrm{Na}$ análise por LIMA et al. (2003), ainda considerando uma ferramenta de topo plana, o modelo para estimar a força de corte envolve as componentes radiais $(\mathrm{Fr})$, tangenciais $(\mathrm{Ft})$ e axiais $(\mathrm{Fa})$ da força de usinagem, em função da espessura média do cavaco $(\mathrm{hm})$, profundidade de corte (ap), dos coeficientes de força de corte que contribuem para a ação 
do corte (Ktc, Krc e Kac) e a constante para forças residuais (Kte, Kre e Kae) nas direções tangenciais, radiais e axiais. Segundo o autor, estes coeficientes foram obtidos experimentalmente para um determinado par ferramenta/peça.

$F_{t}(\phi)=K_{t c} \times a p \times h_{m}(\phi)+k_{t e}(\phi)$

$F_{r}(\phi)=K_{r c} \times a p \times h_{m}(\phi)+K_{r e}(\phi)$

$F_{A}(\phi)=K_{a c} \times a p \times h_{m}(\phi)+K_{a e}(\phi)$

Utilizando a figura 2.32, as componentes de corte nas direções X, Y, Z podem ser determinadas, desta forma pode-se obter:

$$
\begin{aligned}
& F_{x}(\phi)=-F_{t} \times \cos (\phi)-F_{r} \operatorname{sen}(\phi) \\
& F_{y}(\phi)=F_{t} \times \operatorname{sen}(\phi)-F_{r} \cos (\phi) \\
& F_{z}(\phi)=F_{a}
\end{aligned}
$$

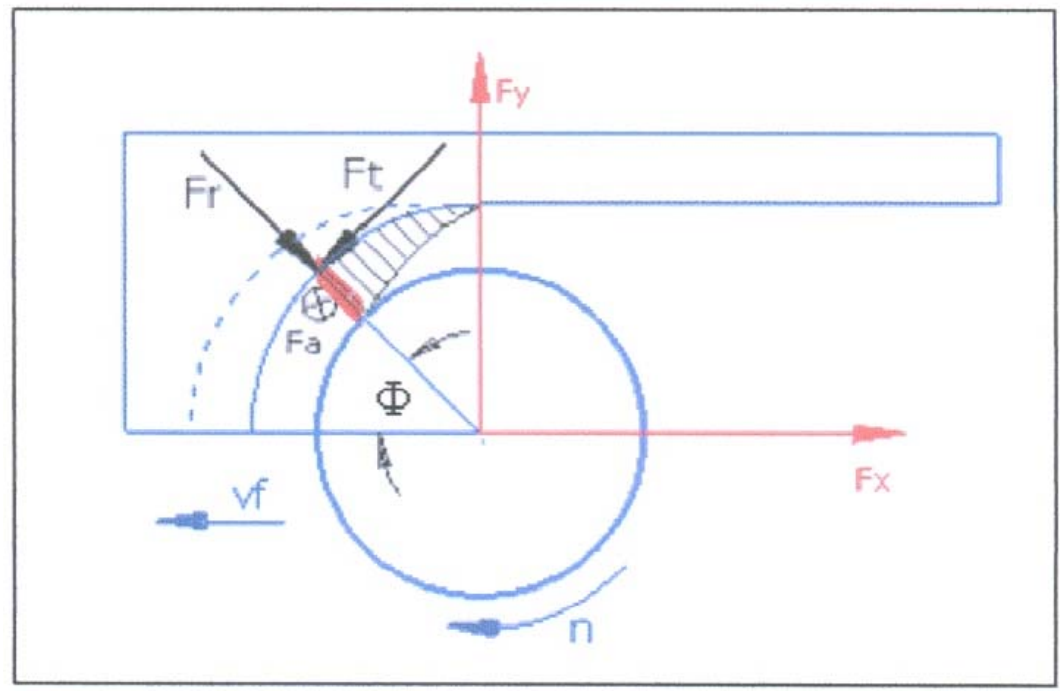

Figura 2.32 - Força radial, axial e tangencial (Souza, 2004). 
Neste trabalho realizado por LIMA et al. (2003) foram desconsideradas as forças de atrito. NEVES (2003) realizou uma análise sobre as forças nas operações de fresamento em uma superfície plana, utilizando ferramentas de ponta esférica. Um modelo matemático simplificado das forças atuantes na aresta de corte foi empregado, considerando o sentido concordante de usinagem, como ilustra a figura 2.33.

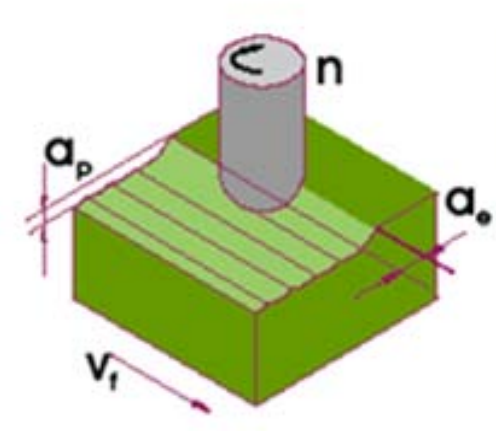

Fig. a

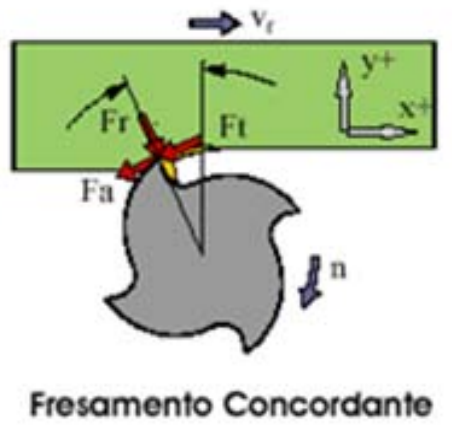

Fig. $b$

Figura 2.33 - Representação simplificada das forças de corte, NEVES (2003).

A Figura 2.33(a) mostra um corte feito num plano paralelo ao de trabalho, no diâmetro efetivo. Nesta vista, notam-se a componente radial (Fr) e tangencial (Ft) atuando na aresta de corte da ferramenta. Neste modelo, a força de atrito Fa entre a superfície de folga da ferramenta e a superfície usinada foi considerada, e esta representada como uma força que se opõe à rotação e segundo os autores deste trabalho, o erro desta aproximação não é representativo. A força instantânea Fy no sentido concordante, obtida pelo dinamômetro, é a soma das projeções sobre o eixo $\mathrm{Y}$ das componentes radiais, tangenciais mais a força de atrito. A força de atrito pode ser determinada em função da força radial e do coeficiente de atrito $\mu$, Portanto a força Fy pode ser expressa pela equação 2.24.

$$
F y=-F \operatorname{sen} \phi-F r(\cos \phi+\mu \operatorname{sen} \phi)
$$

Considerando a força de avanço para a obtenção da componente Fx, a mesma análise pode ser feita, equação 2.25 .

$$
F X=-F t \times \cos \phi+F r(\operatorname{sen} \phi+\mu \cos \phi)
$$


Entretanto, NEVES (2003) considerou apenas a força de atrito entre a peça e a superfície de folga da ferramenta de corte. Segundo BLACK (1989) esta componente da força de atrito não é representativa, frente ao atrito causado pela superfície de saída da ferramenta e o cavaco. Outro fato observado é que embora tenha sido considerada nesta análise, uma

ferramenta de ponta esférica, com a aproximação realizada pelos autores para definir o ponto de contato da ferramenta com a peça, o modelo passa a ter característica de uma fresa de topo reto, reduzindo-se apenas o diâmetro nominal da ferramenta.

$\mathrm{Na}$ literatura pesquisada sobre o estudo de força de usinagem no fresamento, observam-se simplificações nos modelos propostos. Em geral, estas simplificações podem ocorrer quanto às características intrínsecas do processo, e/ou quanto ao próprio processo de usinagem. Em operações de fresamento são atribuídas simplificações geométricas na ferramenta/peça. Observam-se poucos trabalhos envolvendo forças de corte, para operações de fresamento com ferramentas de ponta esféricas.

Para o caso de uma ferramenta com múltiplas arestas de corte, ponta esférica e ângulo de hélice as condições de entrada e saída das arestas no processo de corte, requerem expressões de força que considerem os diferentes pontos de contato de cada aresta, e sua posição no momento do corte, o que torna o estudo mais complexo.

Com a velocidade de corte e diâmetro efetivo da ferramenta variando ao longo da aresta, a força de corte e todos os outros parâmetros tecnológicos variam por conseqüência. Assim sendo, a análise das forças de corte se distinguem drasticamente entre operações de fresamento com ferramentas de topo em comparação com as ferramentas de ponta esférica, onde as variações das forças estão relacionadas com a posição e contato da aresta de corte.

\subsubsection{Comportamento da força com alta velocidade}

Segundo FLOW \& KOMANDURI (1989), a força de corte diminui com o aumento da velocidade de corte até um valor mínimo, o qual é atingida a uma determinada velocidade, além desta velocidade característica a força tende a aumentar lentamente. 
Por exemplo, a força para o aço AISI 4340 contínua a diminuir com o aumento da velocidade até cerca de $1500 \mathrm{~m} / \mathrm{min}$, onde a força começa a aumentar com a velocidade. Similarmente ao aço AISI 4340, o alumínio 6061-T6 exibe uma redução inicial na força com o aumento da velocidade até aproximadamente $3000 \mathrm{~m} / \mathrm{mim}$, além do qual a força aumenta levemente.

Em contraste aos resultados encontrados com o aço AISI 4340 e o alumínio, a força de corte para o titânio é relativamente invariável com a velocidade. Na prática, a velocidade de corte máxima para o alumínio não parece ser limitada pelo desgaste da ferramenta de corte, nesse caso os fatores de controle são a velocidade do eixo-árvore e a potência. Altas taxas de avanço e profundidade de corte adequada devem ser otimizadas para conseguir obter altas taxas de remoção de material. Dependendo dos tipos de corte reto ou de contorno, a velocidade de resposta da máquina-ferramenta e seus controles podem ser críticos. Com a diminuição da força de corte proporcionalmente ao aumento da velocidade de corte, a usinagem com alta velocidade pode ser utilizada com enormes vantagens na usinagem de peças de paredes finas, além, da diminuição da força de usinagem tem-se vantagens conforme já citado sobre a integridade da peça (SANDVIK, 1999).

\subsection{Temperatura de corte}

Já tem sido confirmado que a temperatura na interface cavaco-ferramenta aumenta com a velocidade aproximando-se do ponto de fusão do material da peça, em lugar da diminuição a velocidade muito alta como tinha sido afirmado por Salomon (FLOW \& KOMANDURI, 1989).

As pesquisas têm concluído que não existe redução de temperatura em HSC e que a maior parte do calor é transferido para o cavaco, a baixa distorção térmica da peça pode ser observada à medida que a maior parte do calor da usinagem aproximadamente $80 \%$ é transportada pelo cavaco e os $20 \%$ restante para a ferramenta (OLIVEIRA, 2003).

A carga térmica na aresta de corte permanece alta, da mesma forma, ou até cresce consideravelmente o aumento da velocidade de corte. Isto provoca uma redução drástica na vida da ferramenta. Dobrando a velocidade de corte pode-se reduzir a vida da 
ferramenta para até um décimo ou menos, dependendo da combinação do material da peça e do material da ferramenta de corte na operação (SINHOFF, 1999).

A usinagem com alta velocidade de corte em aços, ferro fundido e superligas causam temperaturas de corte extremamente altas, de modo que a tensão térmica da ferramenta é decisiva para o processo. Por outro lado à baixa condutividade térmica de alguns materiais, tais como ligas de titânio e superligas à de níquel dificultam a dissipação do calor, o qual conduz a uma substancial elevação na temperatura de corte.

Por causa da temperatura de fusão da liga de alumínio ser baixa (aproximadamente $540^{\circ}$ C) e estar bem abaixo das limitações de temperatura das ferramentas de metal duro e das revestidas, a velocidade de corte máxima para as ligas de alumínio parecem ilimitadas do ponto de vista da ferramenta de corte (FLOW \& KOMANDURI, 1989).

\subsection{Estratégias de usinagem}

As estratégias de usinagem têm um papel vital para a realização de um processo HSC eficiente, atualmente os sistemas CAM oferecem várias possibilidades de trajetórias de ferramenta para a usinagem de uma superfície, tais como raster, radial, espiral, 3D Offset e $\mathrm{Z}$ constante. A escolha dentre as diferentes trajetórias de ferramenta é realizada pelo usuário representando uma grande influência sobre o tempo necessário para a usinagem, desgaste de ferramentas de corte e qualidade superficial, segundo WEINERT \& GUNTERMANN, (2000).

Conforme descrito anteriormente, as operações de usinagem na manufatura de moldes e matrizes são: desbaste, pré-acabamento, alívio de cantos e acabamento.

Para se ter um processo HSC eficiente deve-se manter a ferramenta de corte em carregamento constante, variando o mínimo possível as forças de corte durante a usinagem. Para isto o volume de material a ser removido deve ser tão constante quanto possível. Portanto, evidencia-se a importância da operação de pré-acabamento, sendo em muitos casos mais importante para se obter bons resultados da usinagem HSC que o próprio processo de acabamento final, conforme evidenciado na figura 2.8. 
O pré-acabamento tem por finalidade eliminar as áreas com diferenças no volume de material, resultante da operação de desbaste, como no caso ilustrado pela figura 2.34 , e que deveria ser usinado no acabamento. Grandes alterações no volume de material a ser removido durante a usinagem, podem acarretar em instabilidade no processo, com flexões alternadas na ferramenta de corte, comprometendo a qualidade superficial, prejudicando a exatidão de contorno e diminuindo a vida útil da ferramenta. Utilizando o processo convencional, estas variações não têm grande influência devido às baixas velocidades (SCHUTZER \&SOUZA, 2000).

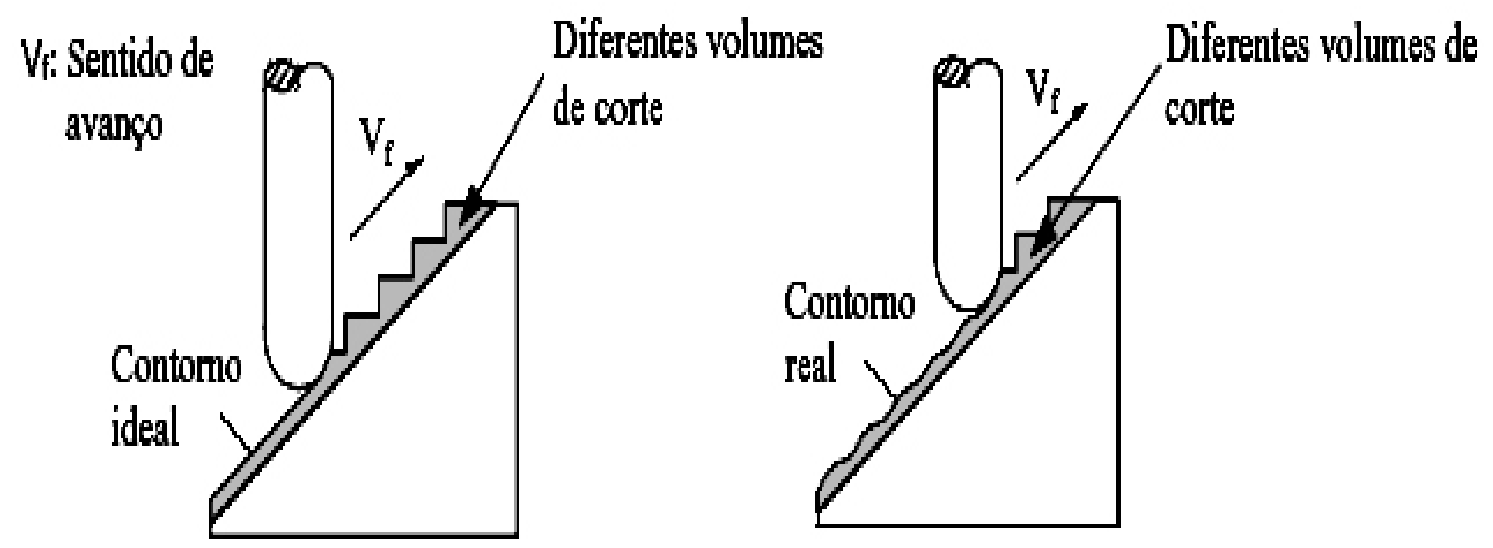

Figura 2.34 - Influência do pré-acabamento no resultado final (SCHUTZER \&SOUZA, 2000).

Como observado no caso da usinagem de superfícies complexas, volumes não uniformes de material a serem removidos são freqüentemente encontrados, estas variações de volumes de material acontecem devido à duas principais situações:

$\checkmark$ Observa-se um volume de material excedente em regiões que a ferramenta de desbaste não pode alcançar devido a limitações geométricas, em geral utiliza-se uma ferramenta com diâmetro relativamente grande para esta operação;

$\checkmark$ Outra situação, como observado na figura 2.35, refere-se à transição entre os diferentes níveis de usinagem (profundidade de corte), realizados pela operação de desbaste.

Este excedente de material está relacionado com a curvatura da superfície, com a profundidade de corte e com a geometria da ferramenta de corte (SOUZA, 2001). 


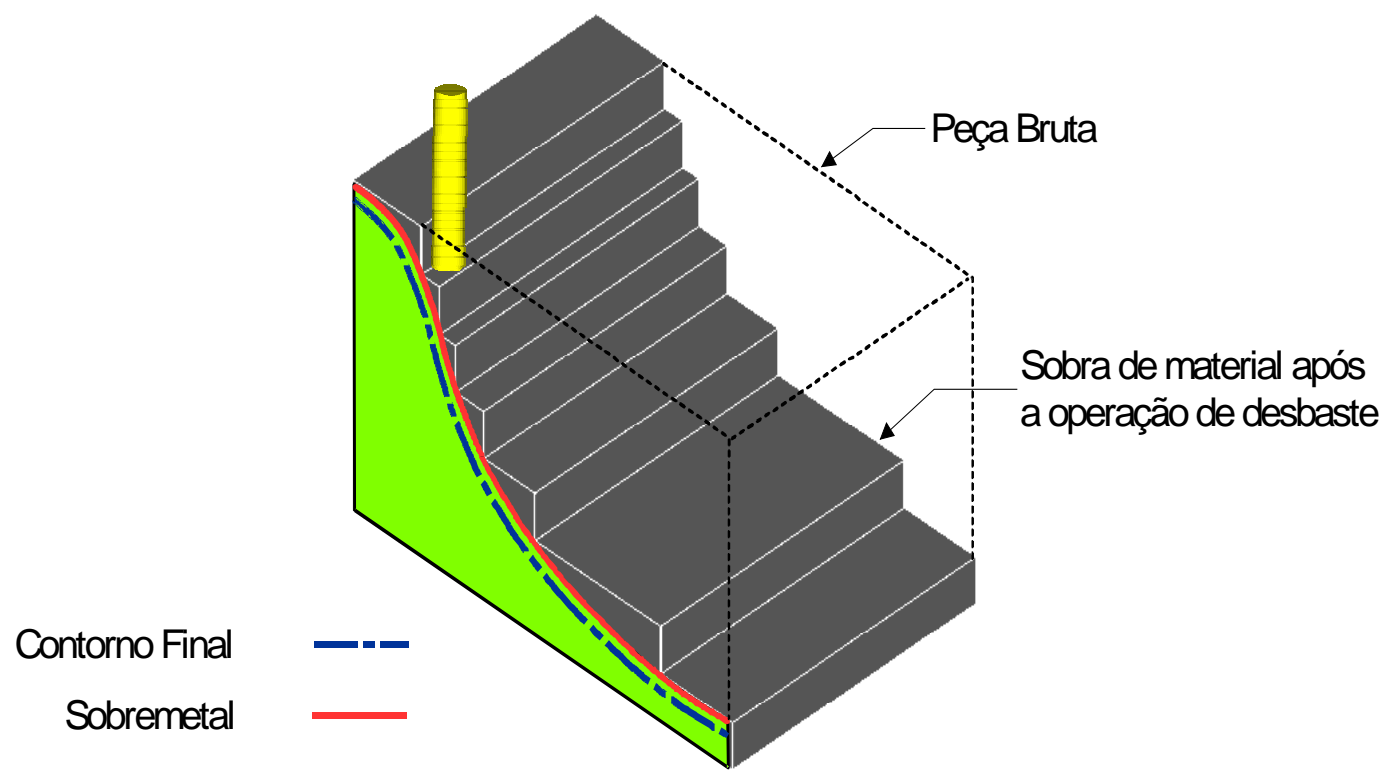

Figura 2.35 - Variação do volume de material após a operação de desbaste (SCHUTZER e SOUZA, 2000).

\subsection{Fatores que influenciam o acabamento final de usinagem.}

A qualidade da superfície usinada pode ser analisada principalmente através da exatidão dimensional e de forma, rugosidade e integridade superficial. A análise da rugosidade será relatada a seguir. A análise da exatidão dimensional não faz parte do escopo desta dissertação.

$\checkmark$ Exatidão dimensional e de forma - Excluindo as tolerâncias envolvidas na cadeia $\mathrm{CAD} / \mathrm{CAM}$ para o modelamento de produtos e geração de programas $\mathrm{NC}$, a exatidão de forma de um modelo usinado está relacionada às condições de usinagem, envolvendo deflexões da ferramenta de corte, vibrações durante o processo de usinagem e desvios de trajetória causados pela inércia de movimentação dos eixos, agravando-se quando se trabalha com altas acelerações e velocidades de avanço.

$\checkmark$ Utilizando uma ferramenta de ponta esférica, esta geometria de ferramenta é muito utilizada na usinagem de superfícies complexas e cavidades, a rugosidade 
superficial teórica, é dada em função do valor de passo radial, e do avanço por aresta de corte, conforme (CEBALO, 1999).

A figura 2.36 ilustra o excedente de material deixado por uma ferramenta esférica de raio (R) em função da espessura de corte (ae), para o fresamento de uma superfície plana.

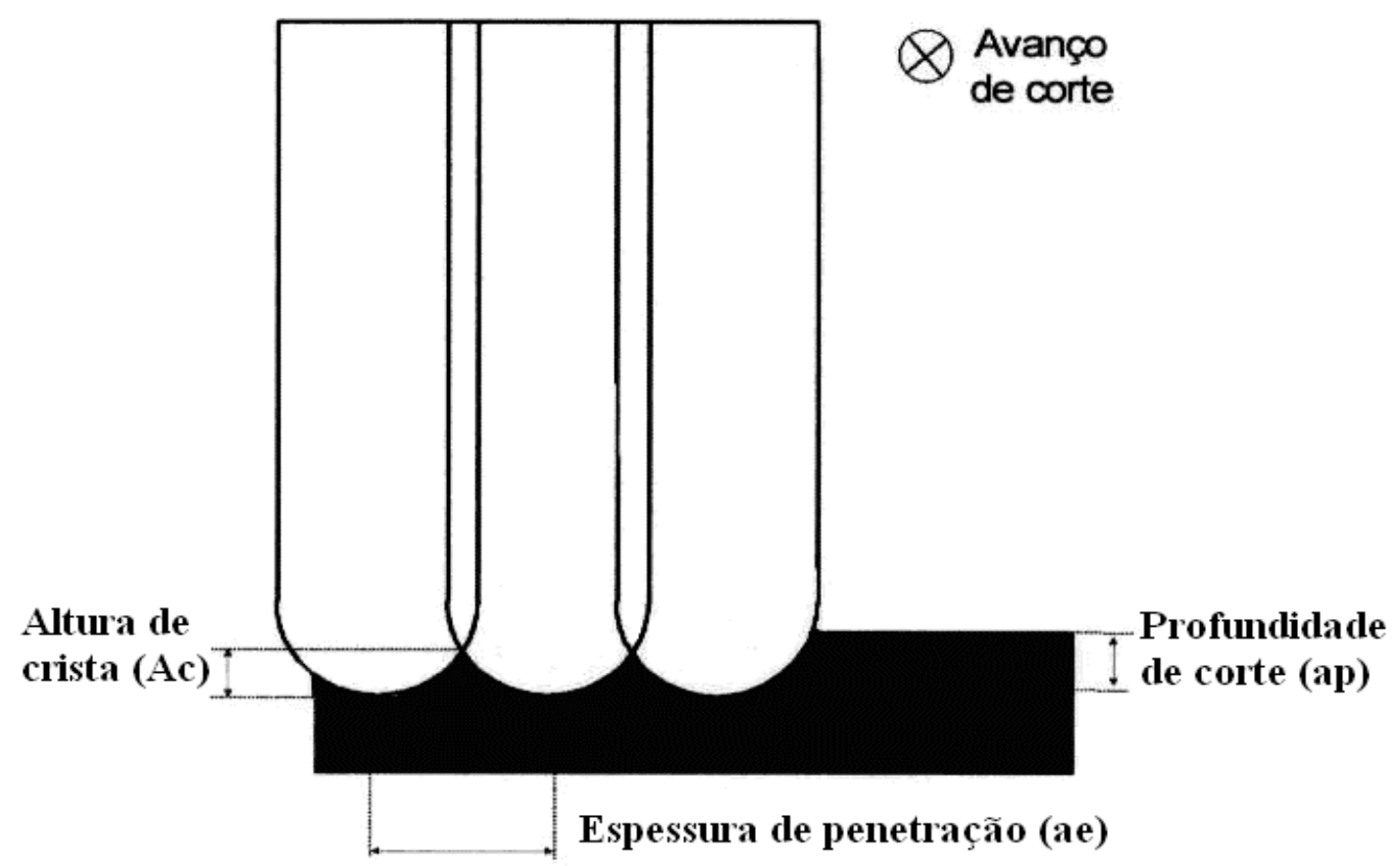

Figura 2.36 - Altura de crista (SOUZA, 2001).

Esta sobra de material é conhecida como Altura de Crista (Ac) e está relacionada com a espessura de corte (ae), com a profundidade de corte (ap) e com o valor do raio da ferramenta.

A altura de crista pode ser calculada através da equação 2.26:

$$
a e=\left(\sqrt{R^{2}-(R-A c)^{2}}\right) \times 2 \Rightarrow A c=\left(\sqrt{R^{2}-\left(\frac{a e^{2}}{2}\right)}\right)-R
$$

Onde:

Ac - Altura de crista, [mm];

ae - Passo radial (espessura de penetração), [mm];

$\mathrm{R}$ - Raio da ferramenta, [mm]; 
A figura 2.37 ilustra o cálculo trigonométrico da altura de crista.

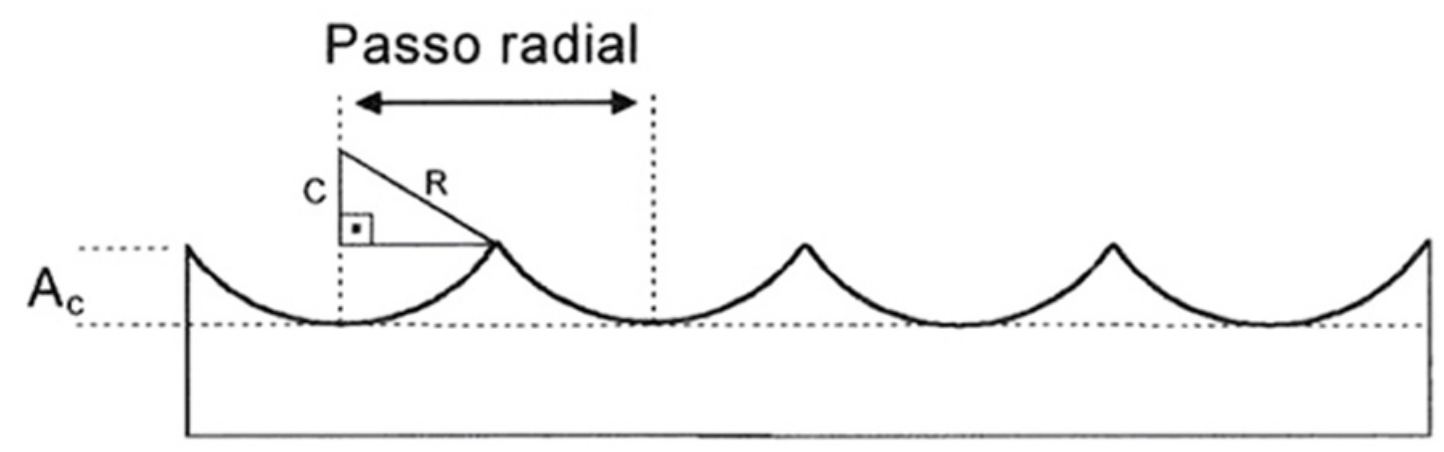

Figura 2.37 - Representação trigonométrica para cálculo da altura de crista (SOUZA,2001).

FERRARESI (1977) utilizou a equação 2.27 para simplificar o cálculo da altura de crista para operações de torneamento. Segundo CEBALO (1999) que extrapolou esta equação para encontrar o valor da altura de crista em operações de fresamento, podemos considerar de seguinte forma:

$A_{c}=f_{(a e, R)} \cong \frac{a e^{2}}{8 R}$

O segundo fator que influencia na rugosidade teórica da superfície usinada esta relacionado com o valor de avanço por aresta de corte (ad). O avanço por aresta é inversamente proporcional à qualidade de acabamento após a usinagem, a equação que descreve a rugosidade superficial em função do avanço por aresta é (CEBALO, 1999):

$r=\frac{a d^{2}}{4 D g \max }$

Onde:

ad - avanço por aresta, [mm];

Dgmax - Diâmetro efetivo de corte (ferramenta de ponta esférica), [mm];

$\mathbf{r}$ - rugosidade máxima, $[\mu \mathrm{m}]$; 
Para se atingir um grau de acabamento relativamente alto, em muitos casos é torna-se vantajoso igualar o avanço por aresta (ad) ao passo radial (ae), com a utilização destes parâmetros, pode-se obter (CEBALO, 1999):

$\checkmark$ Acabamento superficial muito liso em todas as direções;

$\checkmark$ Tempo de usinagem curto e competitivo;

$\checkmark$ Textura superficial simétrica, muito fácil de ser polida;

$\checkmark$ Aumento da precisão e resistência mecânica da superfície proporciona uma vida útil maior para a matriz ou molde;

A figura 2.38 ilustra a rugosidade teórica, em função do avanço por dente (fz) e da espessura de penetração (ae), onde a Figura a - representa o valor de espessura de penetração (ae) maior que o avanço por dente (fz), a figura b - ilustra a espessura de penetração (ae) com valor igual ao avanço por dente (fz).

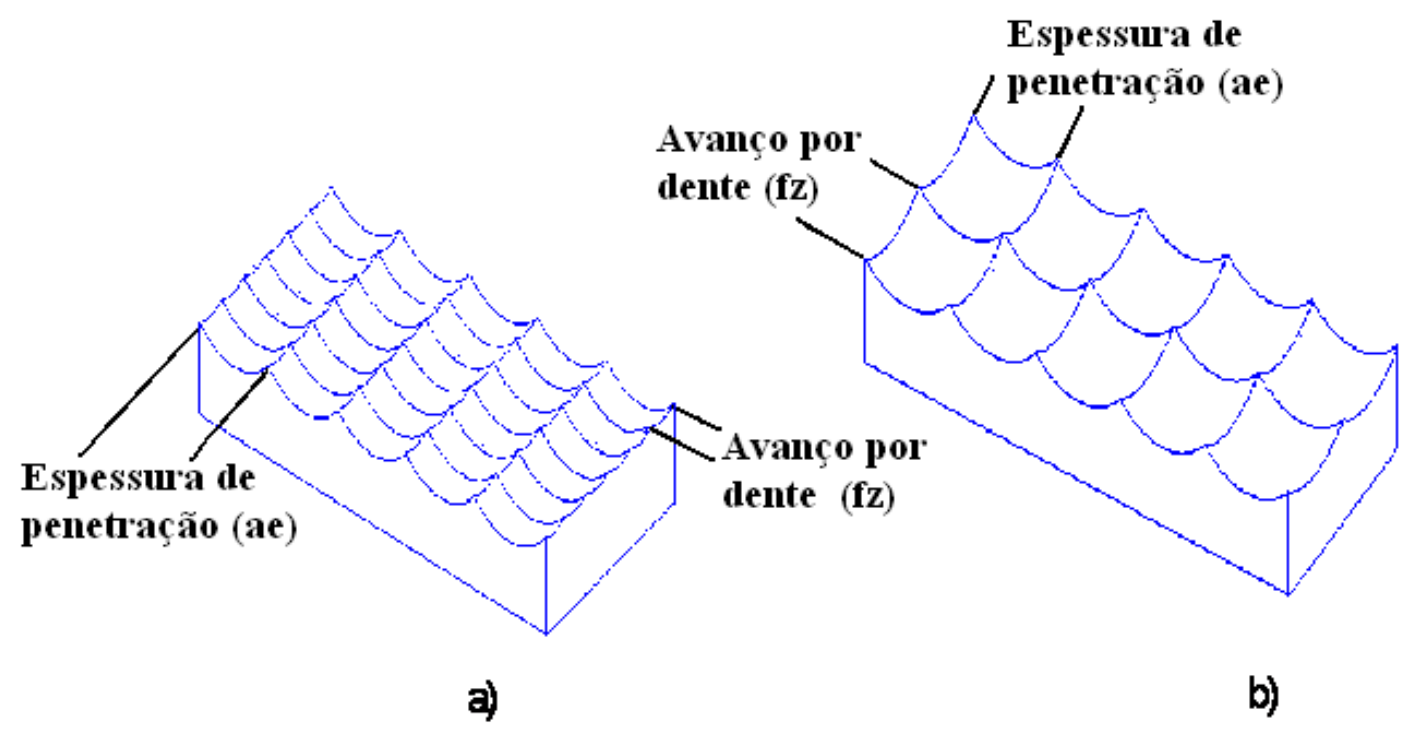

Figura 2.38 - Rugosidade de uma superfície plana após usinagem (SANDVIK, 1999).

A utilização da tecnologia de usinagem com Altas Velocidades de Corte tem demonstrado grande eficiência para a fabricação de moldes e matrizes com formas complexas, propiciando uma vantagem competitiva para as organizações. Entretanto, o fresamento de 
formas complexas ainda apresenta vários gargalos na linha produção. Após as operações de desbaste, além do sobremetal deixado para as operações de acabamento, um volume extra de material indesejado permanece na geometria. Este volume está relacionado com a estratégia de desbaste em $2 \frac{1}{2}$ eixos, ao grau de curvatura da superfície e à geometria da ferramenta de corte. Por não ser uniforme esta quantidade excedente de material acaba prejudicando o processo, especialmente quando uma das exigências é uma grande precisão dimensional. Este trabalho procurou identificar as características mais relevantes da usinagem com Altas Velocidades de Corte com o intuito de estudar a variação da qualidade superficial. Desta forma, as variáveis de influência consideradas foram o balanço e o diâmetro da ferramenta, sua trajetória e o volume não uniforme de material a ser removido.

Após está abordagem teórica inicial e sobre a tecnologia HSC e a descrição do processo produtivo envolvido para a manufatura de moldes e matrizes, voltado ao âmbito HSC, será apresentado a seguir os procedimentos e ensaios de usinagem realizados. 


\section{Procedimento Experimental}

\subsection{Máquina-ferramenta e acessórios}

A parte experimental do trabalho utilizou um centro de usinagem vertical HERMLE, MODELO C800-U, com três eixos de movimentação, possuindo capacidade de deslocamento de $800 \mathrm{~mm}$ na direção X, $600 \mathrm{~mm}$ na direção Y e $500 \mathrm{~mm}$ na direção Z. A potência fornecida pelo eixo-árvore é de $18 \mathrm{~kW}$ com rotação máxima de $24.000 \mathrm{rpm}$, vide Figura 3.1. A máquina é equipada com o CNC Siemens 840D com alta capacidade de processamento, 1,8 MBytes de memória disponível para programas e possui um disco rígido de 40 GBytes, para armazenamento e execução de programas.

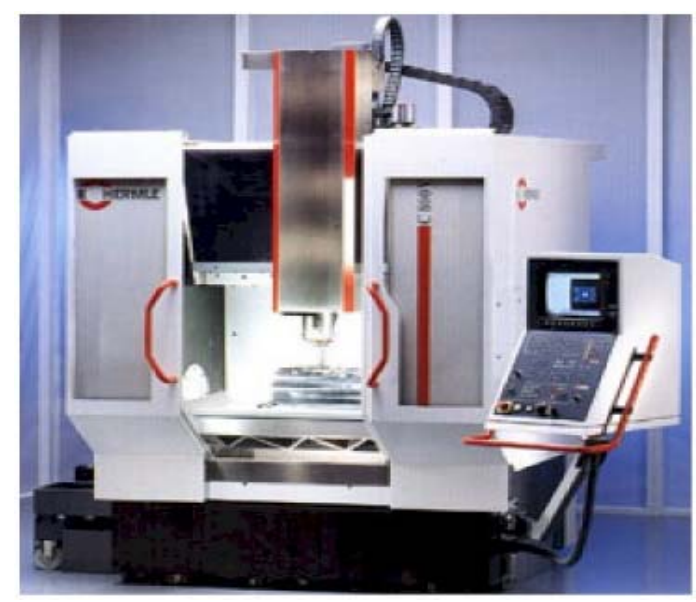

Figura 3.1 - Centro de Usinagem HSC.

O centro de usinagem possui Pre-setter para determinar o comprimento e o diâmetro das ferramentas de corte e possui apalpador para referenciamento da peça na mesa da máquina, Figura 3.2. 


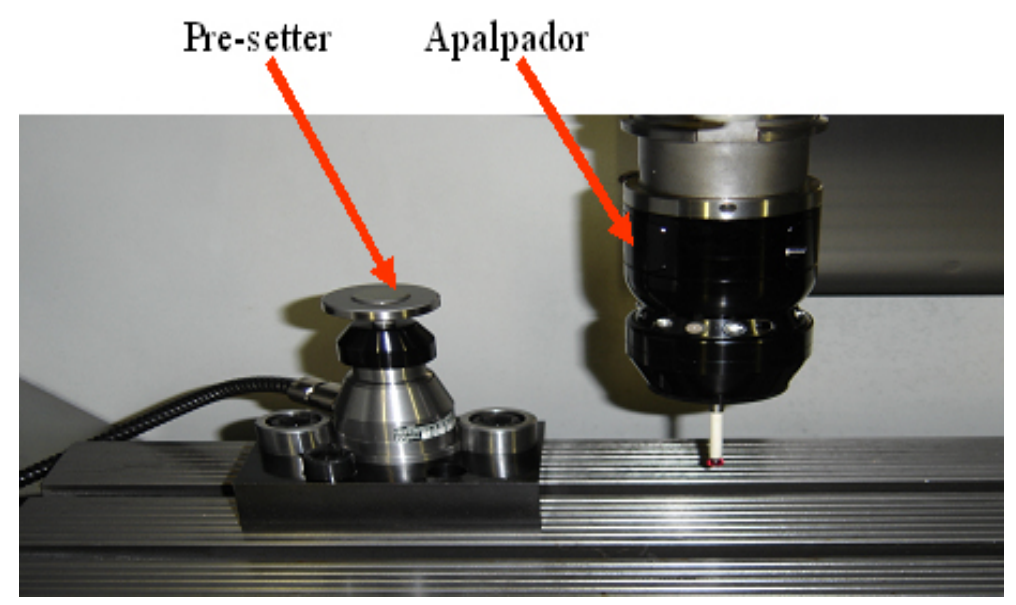

Figura 3.2 - Acessórios do centro de usinagem.

Foi utilizado o sistema hidro-mecânico CoroGrip SANDVIK para fixar a ferramenta de corte, Figura 3.3.

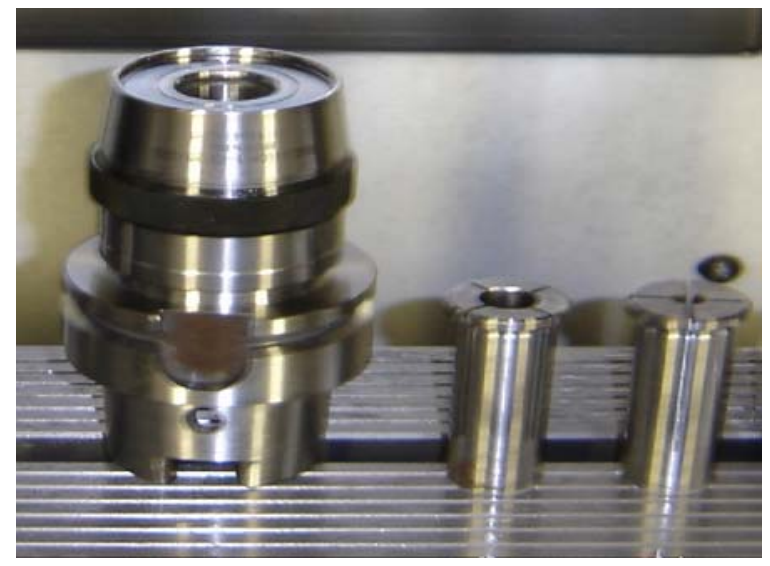

Figura 3.3 - Sistemas de fixação de ferramentas

\subsection{Programas CAD/CAM}

Para a geração dos programas $\mathrm{NC}$ e modelamento dos corpos de prova necessários para o desenvolvimento dos experimentos deste projeto, foram utilizados os sistemas CAD/CAM disponíveis no Laboratório OPF, Powershape Versão 4.232 e Powermill 
Versão 4.003. A geração do pós-processador utilizado foi realizada com o software PostBuilder Versão 2.0.1, desenvolvido pela EDS.

O aplicativo Microsoft Excel foi utilizado para o tratamento dos dados obtidos e geração de resultados gráficos.

\subsection{Dinamômetro}

Para a aquisição de forças decorrentes do processo de usinagem, foi utilizado um dinamômetro KISTLER-9272, ilustrado na Figura 3.4, e um amplificador de carga multicanal modelo 5019 também fornecido pelo KISTLER, vide Figura 3.5, que possibilita o ajuste de parâmetros individuais para cada um dos quatro canais, trabalhando com uma faixa de tensão para os sinais de $-10 \mathrm{a}+10$ Volts.

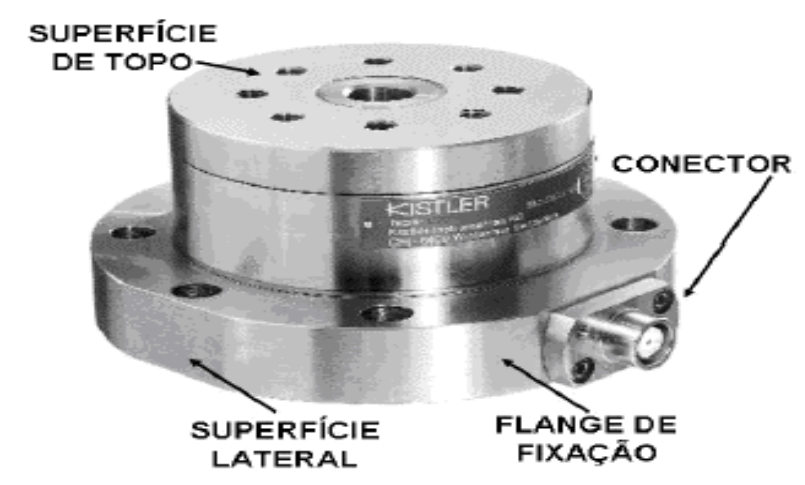

Figura 3.4 - Dinamômetro utilizado.

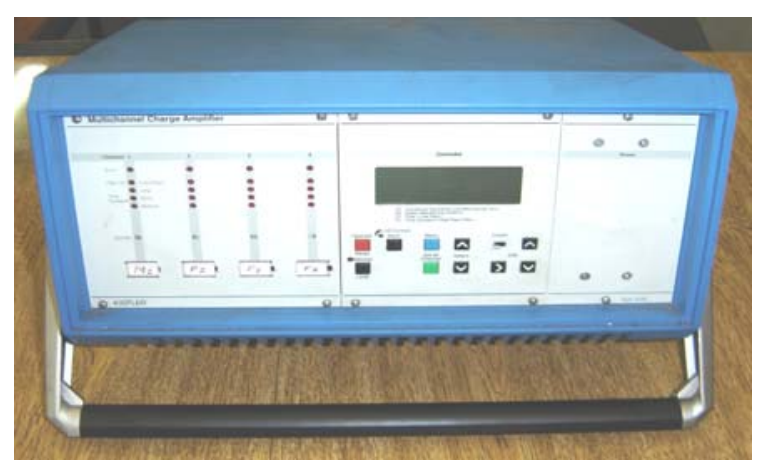

Figura 3.5 - Amplificador utilizado. 


\subsection{Aquisição de dados}

O software Labview Versão 6.0 foi utilizado para coletar os sinais em volts provenientes do amplificador do dinamômetro. Desta forma, o equipamento utilizado permitiu a aquisição das componentes da força de usinagem. Os parâmetros utilizados no amplificador para a aquisição das forças foram definidos individualmente para cada direção, durante as etapas preliminares.

Após cada experimento os valores numéricos de tempo e força de usinagem ( $\mathrm{Fx}, \mathrm{Fy}$ e $\mathrm{Fz}$ ) foram exportados do programa Labview para a planilha de cálculos para tratamento dos dados obtidos e geração de resultados gráficos.

A Figura 3.6 mostra esquematicamente o sistema de aquisição e tratamento de sinais utilizados nos ensaios.

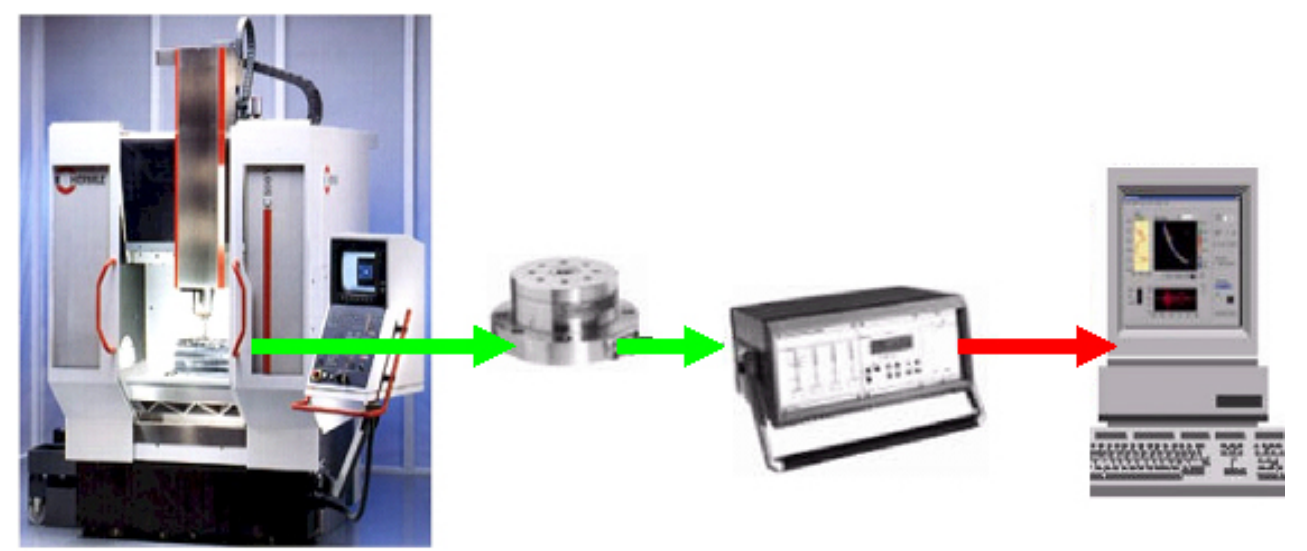

Figura 3.6 - Sistema de aquisição e tratamento de sinais.

\subsection{Preparação do corpo de prova para análise da variação do sobremetal deixado para a usinagem de acabamento.}

O corpo-de-prova elaborado contém 03 superfícies planas, com diferentes ângulos de inclinação, conforme ilustrado na Figura 3.7. Estas regiões são definidas como:

Região a: apresenta uma inclinação de $75^{\circ}$

Região b: apresenta uma inclinação de $45^{\circ}$ 
Região c: apresenta uma inclinação de $7^{\circ}$, todas em relação ao plano horizontal x , y. As faces planas das regiões possuem $25 \mathrm{~mm}$ de comprimento.

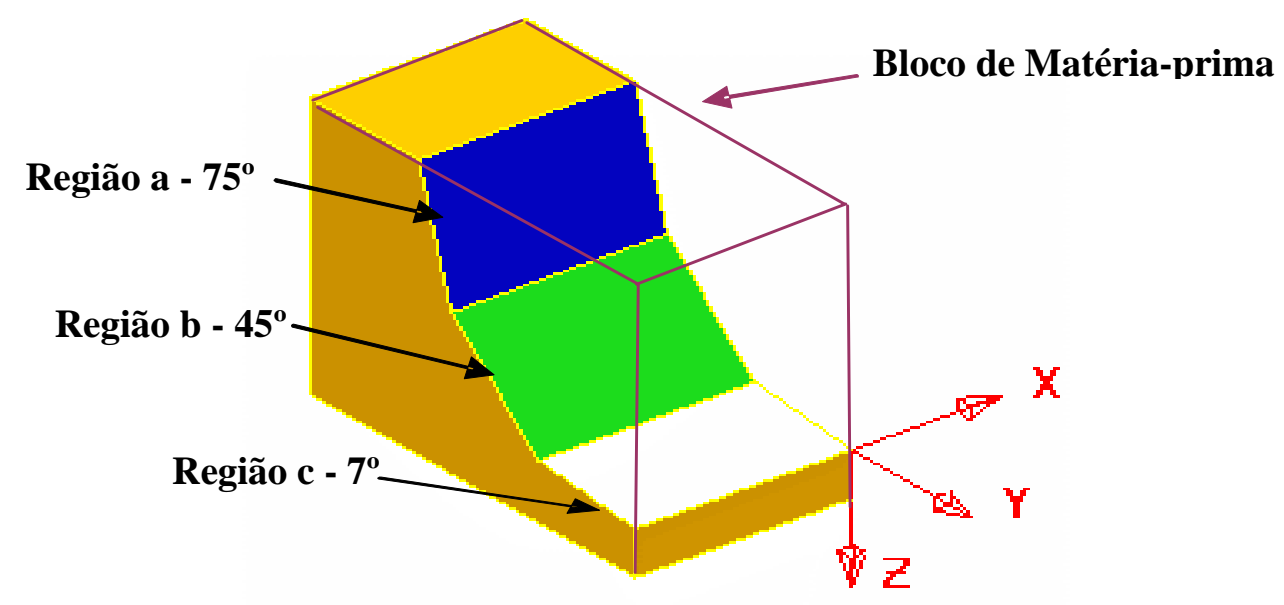

Figura 3.7 - Geometria do corpo de prova e os degraus formados pela usinagem 2 1/2 eixos.

Foi utilizado um bloco de matéria-prima com 80 × 50 × $70 \mathrm{~mm}$, com suas faces previamente retificadas. O corpo de provas foi desbastado utilizando a usinagem em $2 \frac{1}{2}$ eixos.

Este ensaio de usinagem foi realizado em material AISI P20, com dureza de 30 RHC. A escolha deste material foi devida a sua ampla aplicação nos setores de moldes e matrizes. Portanto, este experimento analisa a influência dos volumes inconstantes de material remanescente após a operação de desbaste, para a usinagem posterior de acabamento, em função da inclinação da superfície.

\subsection{Descrição das operações}

As condições de usinagem e as ferramentas de corte foram selecionadas de acordo com o catálogo do fornecedor das ferramentas. Para cada condição foi utilizado um jogo novo de ferramentas de corte para se evitar influências de desgastes nos resultados obtidos. As ferramentas de corte utilizadas para as operações de acabamento foram fresas de topo esférico de diâmetro de $6 \mathrm{~mm}$ e $12 \mathrm{~mm}$ e para a operação de desbaste uma fresa de topo 
reto de diâmetro de $12 \mathrm{~mm}$, conforme ilustrado pela Figura 3.8. Os detalhes técnicos das ferramentas utilizadas nas operações de desbaste e acabamento serão mostrados na Tabela 3.1. As operações de usinagem são descritas nos tópicos seguintes.

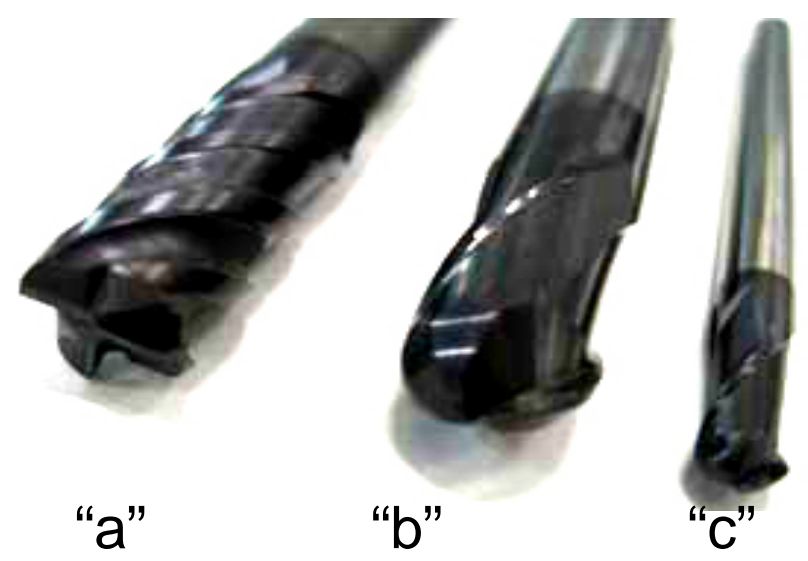

Figura 3.8 - Aspectos gerais das ferramentas utilizadas nos testes.

Tabela 3.1 - Detalhes das ferramentas utilizadas para desbaste e acabamento.

\begin{tabular}{|c|c|c|c|c|c|c|}
\hline $\begin{array}{c}\text { Diâmetro } \\
\text { [mm] }\end{array}$ & Operação & $\begin{array}{c}\text { Ângulo } \\
\left.\text { hélice } \mathbf{(}^{\circ}\right)\end{array}$ & $\begin{array}{c}\text { Comprimento } \\
\text { total [mm] }\end{array}$ & $\begin{array}{c}\text { Comprimento } \\
\text { corte [mm] }\end{array}$ & $\begin{array}{c}\text { Número } \\
\text { dentes }\end{array}$ & Revestimento \\
\hline $6-$ "c" & Acabamento & 30 & 100 & 10 & 2 & $(\mathrm{TiAl}) \mathrm{N}$ \\
\hline $12-" \mathrm{~b} "$ & Acabamento & 30 & 100 & 22 & 2 & $(\mathrm{TiAl}) \mathrm{N}$ \\
\hline $12-" \mathrm{a} "$ & Desbaste & 30 & 73 & 16 & 4 & $(\mathrm{TiAl}) \mathrm{N}$ \\
\hline
\end{tabular}

\subsubsection{Desbaste}

O corpo-de-prova foi inicialmente fresado em $2 \frac{1}{2}$ eixos restando os degraus, em forma de escada, com variação típica de sobremetal, o qual deve ser removido na operação posterior. O valor teórico de sobremetal, atribuído ao software CAM para cálculo dos programas foi de $0,2 \mathrm{~mm}$. Partindo do bloco de matéria-prima, o desbaste foi realizado seguindo os parâmetros de usinagem recomendados pelo fornecedor, apresentados na Tabela 3.2. 
Tabela 3.2 - Parâmetros de corte utilizados no desbaste.

\begin{tabular}{|c|c|c|c|c|c|c|c|}
\hline Operação & Ferramenta & $\begin{array}{c}\mathbf{a}_{\mathbf{e}} \\
{[\mathbf{m m}]}\end{array}$ & $\begin{array}{c}\mathbf{a}_{\mathbf{p}} \\
{[\mathbf{m m}]}\end{array}$ & $\begin{array}{c}\text { Rotação } \\
{[\mathbf{r p m}]}\end{array}$ & $\begin{array}{c}\mathbf{f}_{\mathbf{z}} \\
{[\mathbf{m m}]}\end{array}$ & $\begin{array}{c}\mathbf{V c} \\
{[\mathbf{m} / \mathbf{m i n}]}\end{array}$ & Estratégia \\
\hline Desbaste & $\begin{array}{c}\text { Fresa de topo plana } \\
\text { com Ø } 12 \mathrm{~mm}, 4 \\
\text { arestas de corte }\end{array}$ & 3,0 & 0,5 & 2700 & 0,10 & 100 & $\begin{array}{c}\text { Passes com } \\
\text { offset fixo } \\
\text { no eixo Z }\end{array}$ \\
\hline
\end{tabular}

Após o desbaste restaram os degraus ilustrados na figura 3.9 para cada inclinação.

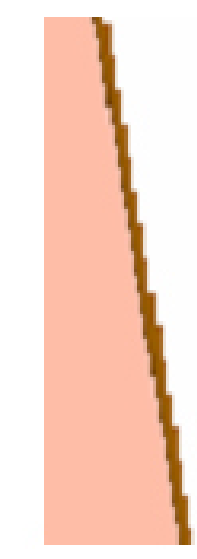

Região a

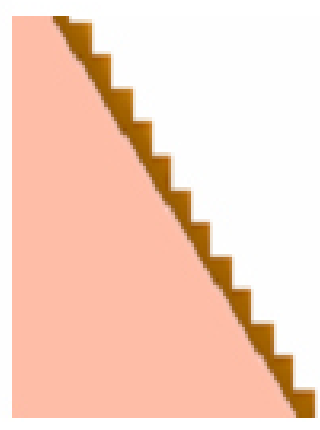

Região b

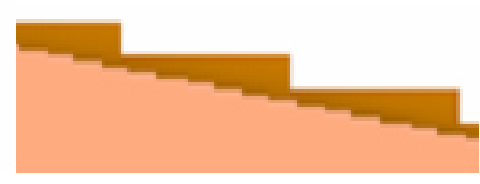

Região C

Figura 3.9 - Ilustração das Regiões a, b e c com superfície com brusca transição de sobremetal em forma de escada para uma inclinação de $75^{\circ}, 45^{\circ}$ e $7^{\circ}$ respectivamente.

\subsubsection{Acabamento}

Para a operação de acabamento, as duas fresas de topo de ponta esférica foram usadas com balanços diferentes de $75 \mathrm{~mm}$ e $45 \mathrm{~mm}$ (comprimento fora do sistema de fixação). Foram utilizados parâmetros de usinagem, de acordo com a recomendação do fornecedor, conforme Tabela 3.3. 
Tabela 3.3 - Dados e parâmetros utilizados nas operações de acabamento.

\begin{tabular}{|l|l|c|c|c|c|c|c|}
\hline Operação & \multicolumn{1}{|c|}{ Ferramenta } & $\begin{array}{c}\mathbf{a}_{\mathbf{e}} \\
{[\mathbf{m m}]}\end{array}$ & $\begin{array}{c}\mathbf{a}_{\mathbf{p}} \\
{[\mathbf{m m}]}\end{array}$ & $\begin{array}{c}\text { Rotação } \\
{[\mathbf{r p m}]}\end{array}$ & $\begin{array}{c}\mathbf{f}_{\mathbf{z}} \\
{[\mathbf{m m}]}\end{array}$ & $\begin{array}{c}\text { Vc } \\
{[\mathbf{m} / \mathbf{m i n}]}\end{array}$ & Estratégia \\
\hline Acabamento & $\begin{array}{l}\text { Fresa esférica com } \varnothing \\
6 \mathrm{~mm}, 02 \text { arestas de } \\
\text { corte }\end{array}$ & 0,2 & 0,2 & 10000 & 0,08 & 188 & Raster \\
\hline Acabamento & $\begin{array}{l}\text { Fresa esférica com } \varnothing \\
12 \mathrm{~mm}, 02 \text { arestas de } \\
\text { corte }\end{array}$ & 0,2 & 0,2 & 10000 & 0,08 & 376 & Raster \\
\hline
\end{tabular}

Para cada ângulo de inclinação do corpo-de-prova haverá um ponto de contato diferente entre a ferramenta e a superfície do corpo-de-prova, que por sua vez influenciara no diâmetro efetivo de corte e na velocidade de corte, conforme ilustrado na Tabela 3.4.

Tabela 3.4 - Valores máximo e mínimo para a velocidade de corte para cada inclinação.

\begin{tabular}{|c|c|c|c|c|}
\hline Ferramenta & $\mathbf{V}_{\mathbf{c}}[\mathbf{m} / \mathbf{m i n}]$ & Região “a” & Região “b” & Região “c” \\
\hline \multirow{2}{*}{$\varnothing 12 \mathrm{~mm}$} & Máximo & 376,9 & 342,4 & 201,06 \\
\cline { 2 - 5 } & Mínimo & 364,4 & 263,8 & 43,98 \\
\hline \multirow{2}{*}{ Ø $6 \mathrm{~mm}$} & Máximo & 188,5 & 182,2 & 131,94 \\
\cline { 2 - 5 } & Mínimo & 182,2 & 131,9 & 25,13 \\
\hline
\end{tabular}

A Figura 3.10 ilustra a estratégias de usinagem utilizada.

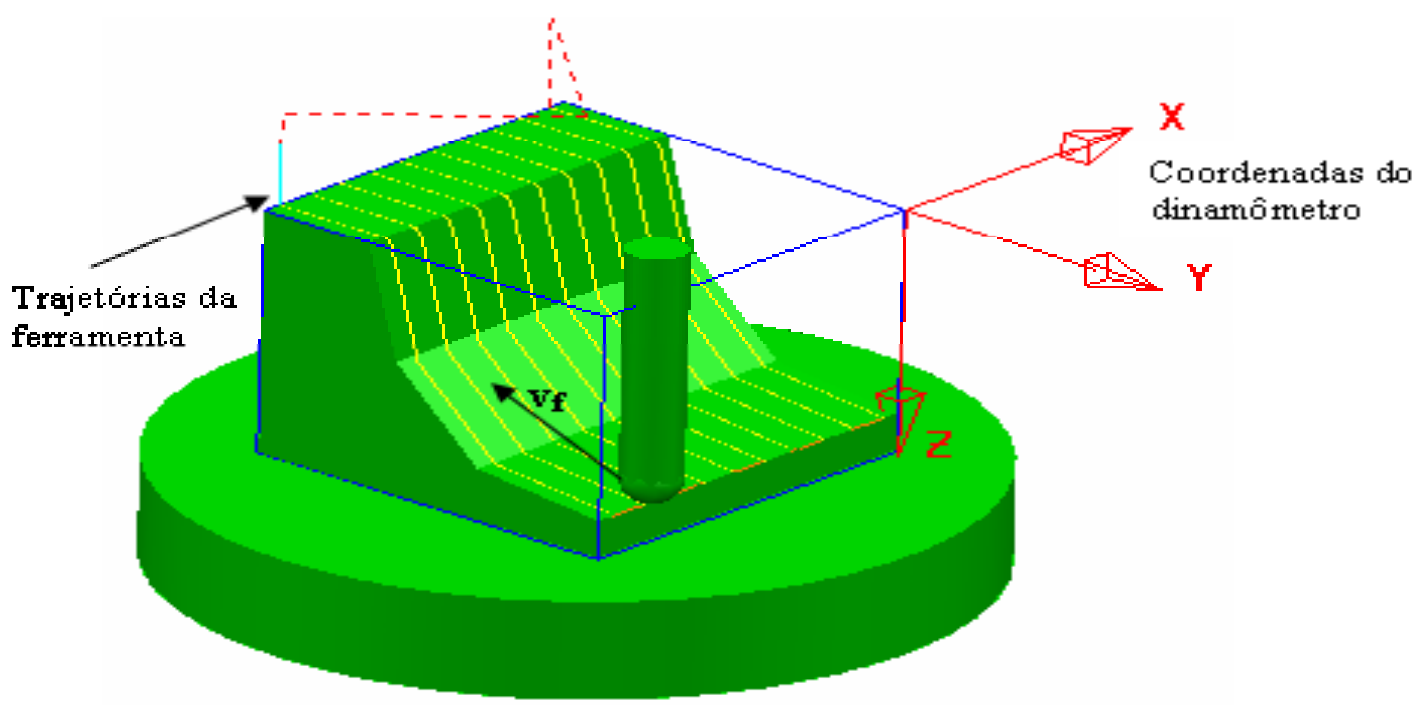

Figura 3.10 - Estratégia e posição do corpo de prova em relação ao dinamômetro. 
Foram utilizados passes de ferramentas paralelas ao eixo (Raster) em apenas um sentido de corte (one-way), assim sendo os passes de usinagem foram realizados no sentido transversal ao corpo-de-prova no sentido ascendente e descendente. Esta estratégia de corte foi escolhida por facilitar as análises dos resultados, pois os passes de corte sempre na mesma direção e sentido, resultam em melhor acabamento.

\subsection{Medição experimental da rigidez estática da ferramenta}

Uma estimativa da rigidez estática das ferramentas foi obtida experimentalmente pressionando a ferramenta de corte (sem rotação), com avanços de 0,01 por vez, contra o corpo-de-prova fixado ao dinamômetro, nas superfícies fresadas em acabamento.

A cada incremento de deslocamento a força foi medida no dinamômetro, sendo registrada uma curva força em função da deformação elástica da fresa. A Figura 3.11 mostra a disposição para cada caso.

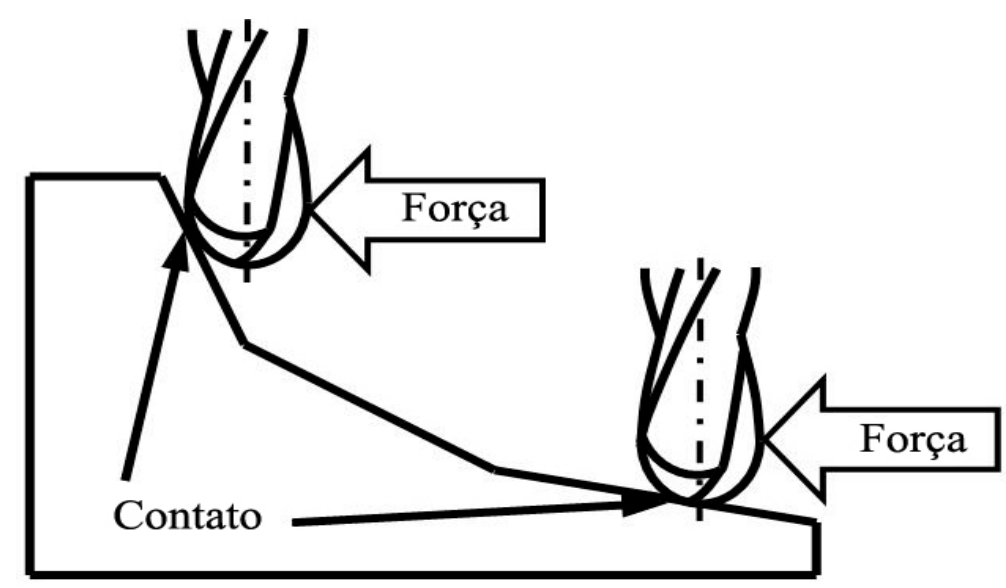

Figura 3.11 - Esquema do método experimental utilizado para estimativa da rigidez estática das fresas esféricas.

Desprezando-se uma possível deformação na região de contato ferramenta-peça, esse procedimento fornece de forma aproximada, a rigidez da ferramenta. Para diferentes inclinações da superfície o comprimento de balanço varia ligeiramente, devido à variação no ponto de contato entre a ferramenta e a superfície do corpo-de-prova. Para a fresa de 6 mm de diâmetro na Região "a” do corpo-de-prova o comprimento em balanço é de 42,75 
$\mathrm{mm}$ e 72,75 mm para os respectivos valores nominais de $45 \mathrm{~mm}$ e $75 \mathrm{~mm}$., enquanto que para a Região "b" é de 44,25 mm e 74,25 mm.

\subsection{Medição do perfil usinado}

Para uma avaliação do desvio de retilineidade da superfície fresada em cada inclinação, a peça acabada foi posicionada na mesa da máquina conforme a Figura 3.12 (a) em relação á fresa de topo.

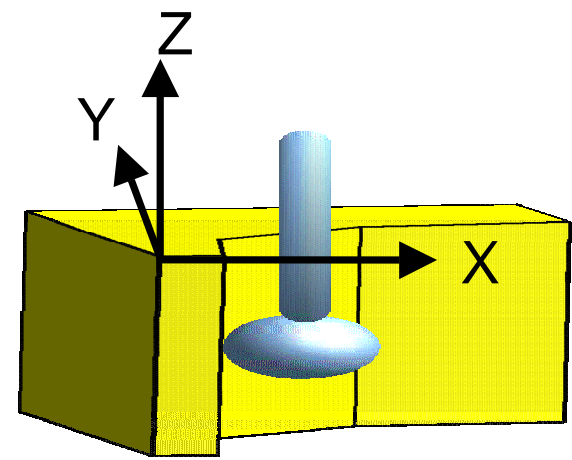

(a) Posicionamento da peça na máquina-ferramenta.
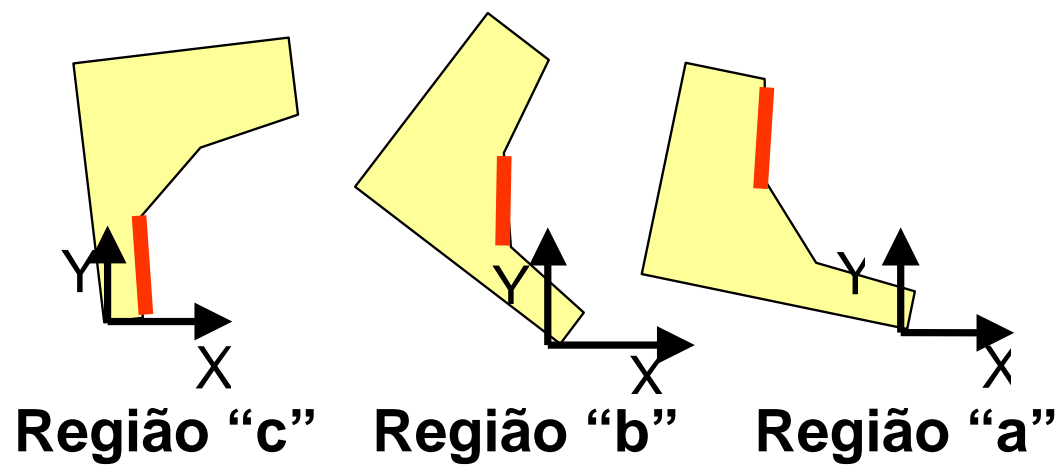

(b) Esquema de alinhamento da superfície inclinada a ser medida, em relação ao eixo Y da máquina.

Figura 3.12 - Esquema de alinhamento e de medição das regiões "a, b e c" do corpo-deprova.

Nesta posição cada superfície a ser medida foi alinhada com o eixo Y da máquina e 100 pontos foram medidos em cada uma das superfícies inclinadas, conforme o esquema mostrado na Figura 3.12 (b). 


\section{Resultados e Discussões}

\subsection{Análise da variação do sobremetal resultante da operação de desbaste deixado para a usinagem de acabamento.}

Após o desbaste as superfícies usinadas apresentaram degraus em forma de escada com variação brusca de sobremetal, o qual deve ser removido na operação posterior de acabamento. Isso é característico do processo de desbaste normalmente empregado. Obteve-se regiões do corpo-de-prova com sobremetal conhecido e distinto entre as áreas, conforme evidenciado na Figura 4.1.

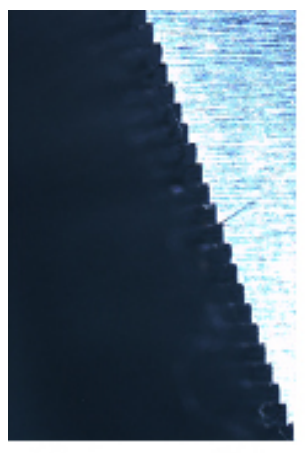

Região $\mathrm{a}-75^{\circ}$

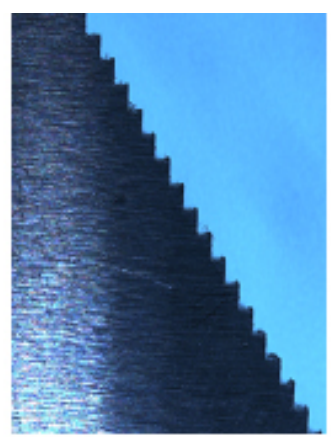

Região $b-45^{\circ}$

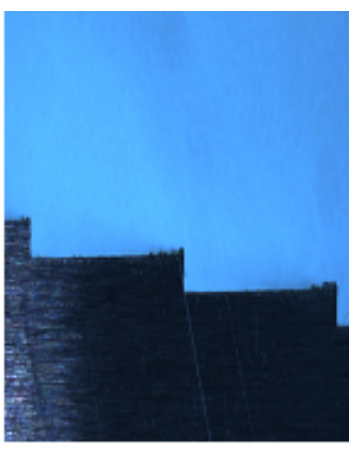

Região $c-7^{\circ}$

Figura 4.1 - Superfícies com diferentes inclinações e com brusca transição de sobremetal em forma de escada.

O corpo-de-prova, após a usinagem em acabamento está mostrado na Figura 4.2, contendo uma estreita faixa com as características do desbaste. 


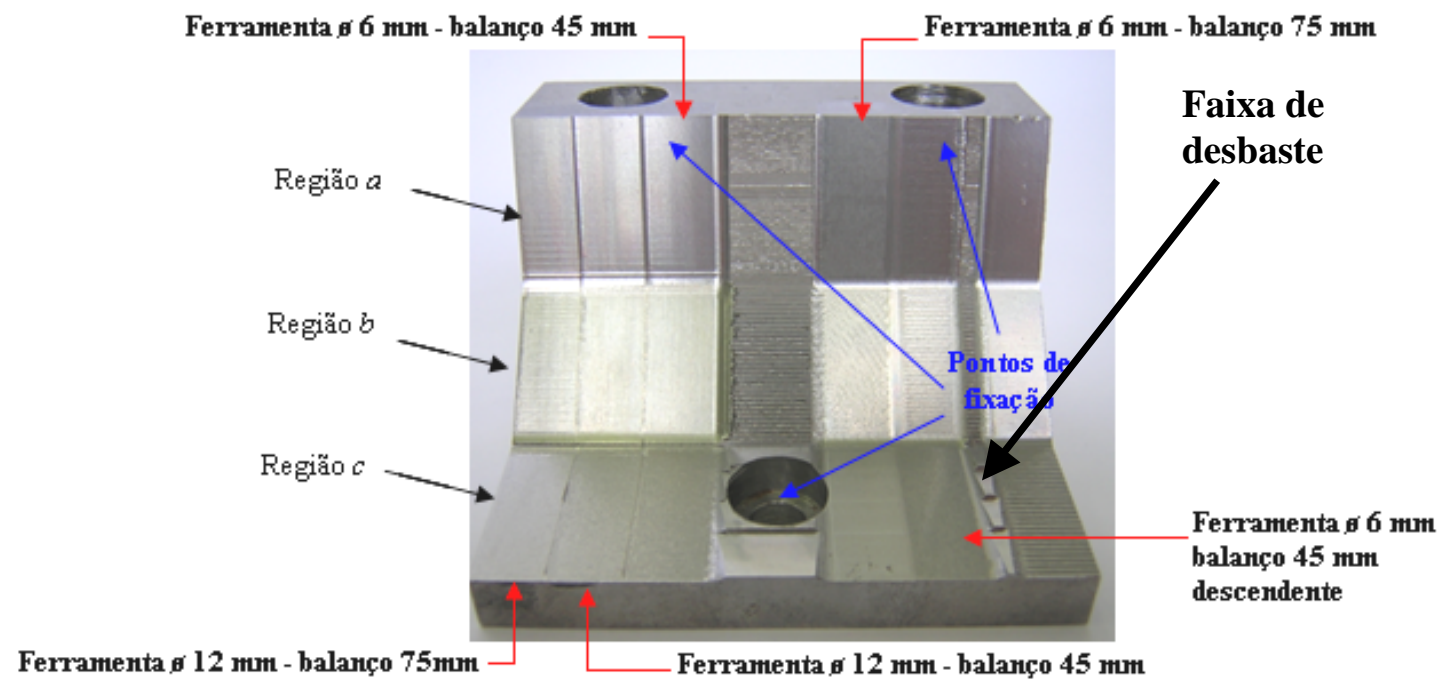

Figura 4.2 - Corpo-de-prova após as usinagem de acabamento contendo uma estreita faixa com as características do desbaste.

Nas operações de acabamento a forma de contato da ferramenta/peça sofreu grandes variações ocasionadas pelas características do processo, sendo definidas em função do grau de inclinação ou curvatura da superfície, da geometria da ferramenta de corte, do volume de material a ser removido e da trajetória de usinagem, conforme evidenciado na Figura 4.3 .

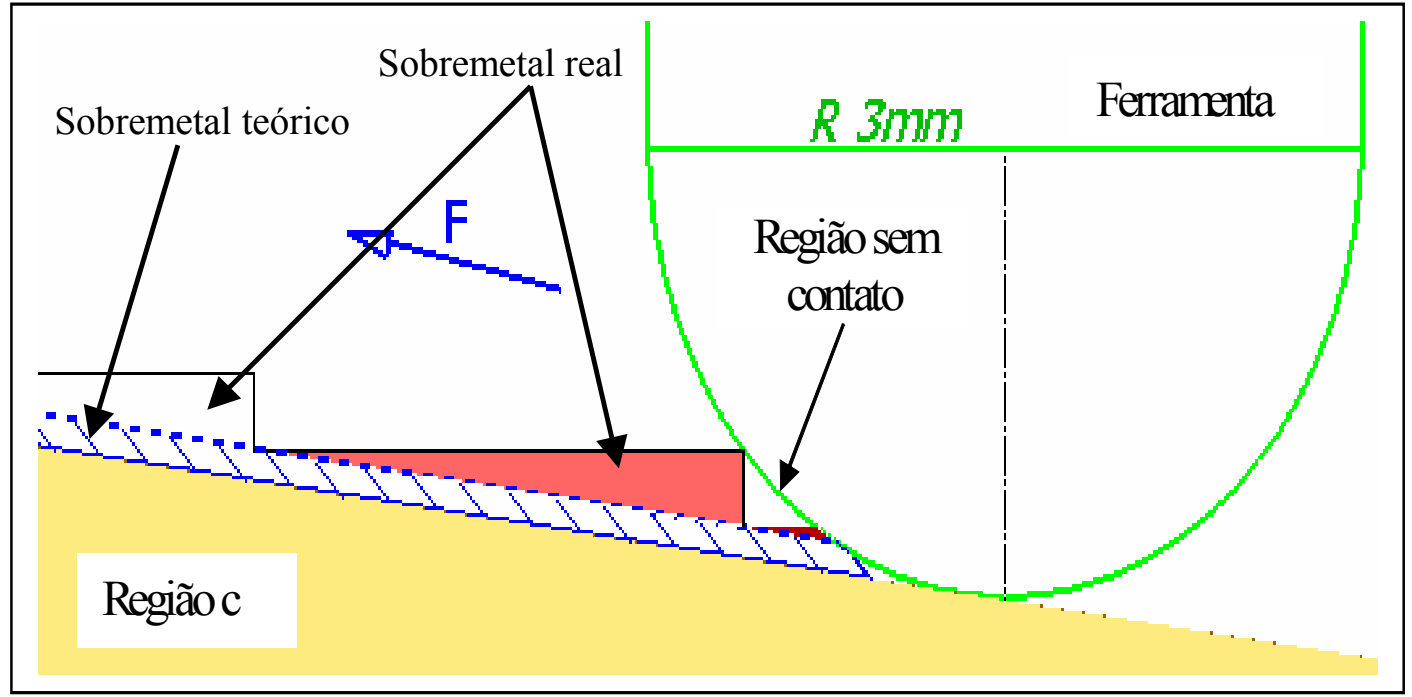

Figura 4.3 - Características geométricas do sobremetal na Região “c”. 
A figura 4.3 mostra teoricamente como é o contato de usinagem na região "c" com a ferramenta esférica de diâmetro $6 \mathrm{~mm}$ com trajetória de usinagem no sentido ascendente. Pode-se constatar a diferença entre o valor teórico do sobremetal calculado pelo sistema CAM e o real obtido, incluindo-se o excedente.

A área hachurada em azul corresponde ao sobremetal teórico constante em relação ao perfil final da peça, definido para o sistema CAM como sendo de $0,2 \mathrm{~mm}$, no exemplo. A área em vermelho demonstra o sobremetal excedente após o desbaste com uma ferramenta de topo plana. Portanto, durante a operação de acabamento em questão, há uma significativa variação da profundidade de usinagem e, conseqüentemente variação nas forças de corte, as quais podem provocar flexão na fresa.

Nota-se ainda que durante a transição de corte entre os degraus, o ponto de contato entre a aresta de corte e a superfície fica interrompido em determinada região. Estas características de processo podem contribuir significativamente para a instabilidade da usinagem.

Normalmente, para evitar essa variação executam-se operações de semi-acabamento, com ferramentas mais rígidas, com maiores diâmetros e menores comprimentos em balanço, conforme permitido pela geometria da peça. Entretanto, nem sempre isso é possível, devido a restrições do próprio perfil da superfície, ou acesso à cavidade da peça.

Para ilustrar a diferença entre corte ascendente e descendente, a figura 4.4 mostra o contato da ferramenta esférica de diâmetro $6 \mathrm{~mm}$ com sobremetal de $0,2 \mathrm{~mm}$ na região "b" do corpo de prova.

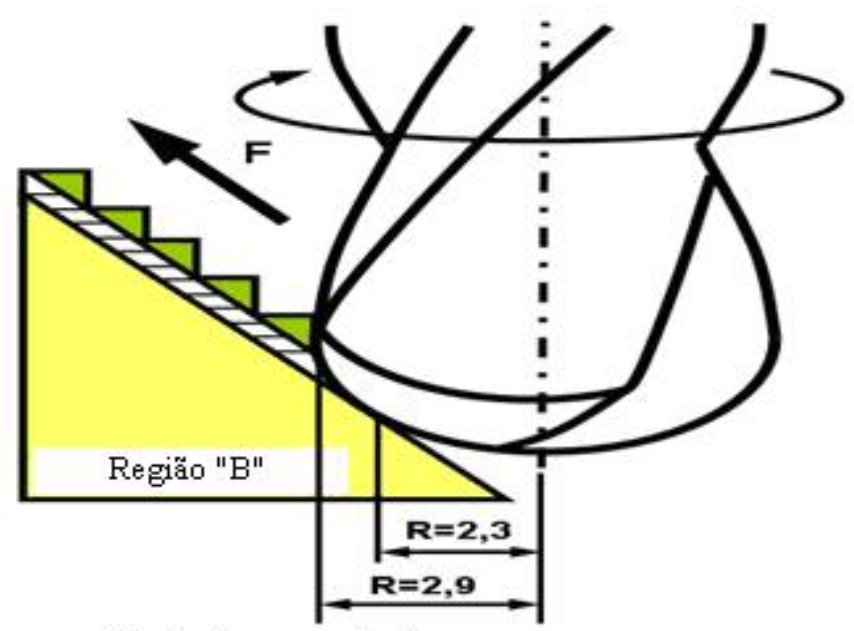

(a) Corte ascendente

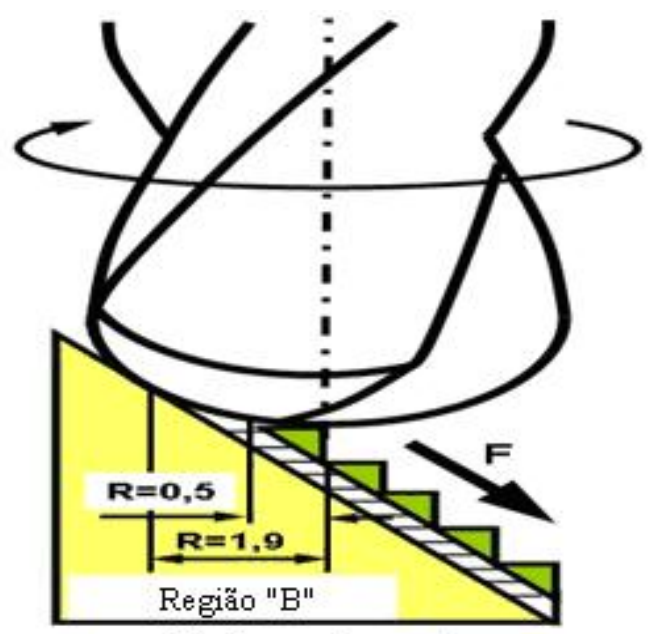

(b) Corte descendente

Figura 4.4 - Contato da ferramenta em função do sentido de corte. 
Pode-se observar que há significativa variação do diâmetro efetivo de corte para as duas situações. No sentido ascendente o raio de contato varia entre 2,9 e 2,3 mm (ferramenta de $6 \mathrm{~mm}$ de diâmetro) e no sentido descendente o raio efetivo varia entre $1,9 \mathrm{~mm}$ e 0,5 mm. Estas variações consideram o sobremetal de $0,2 \mathrm{~mm}$ sobre o perfil final e o excedente de sobremetal deixado pela operação de desbaste. Em vista deste aspecto, recomenda-se o corte ascendente para esta aplicação para que a velocidade de corte seja a maior possível e coincida com a máxima espessura do cavaco.

Nas simulações gráficas foram obtidas as áreas transversais de corte em função de cada região, como apresentadas pela Tabela 4.1.

Tabela 4.1 - Material excedente em função das superfícies do corpo de prova.

\begin{tabular}{|c|c|}
\hline $\begin{array}{c}\text { Regiões do corpo de } \\
\text { prova }\end{array}$ & $\begin{array}{c}\text { Área transversal de material } \\
\text { excedente em cada nível }\end{array}$ \\
\hline $\mathrm{a}$ & $0,03 \mathrm{~mm}^{2}$ \\
\hline $\mathrm{b}$ & $0,12 \mathrm{~mm}^{2}$ \\
\hline $\mathrm{c}$ & $1,03 \mathrm{~mm}^{2}$ \\
\hline
\end{tabular}

Dois fatos importantes foram observados neste estudo:

- A variação da área de contato da ferramenta-peça, devido ao sobremetal excedente. Uma outra variação também pode ocorrer devido à mudança entre corte ascendente e descendente.

- E o volume de sobremetal excedente, inerente à estratégia de desbaste usando-se fresas de topo reto.

\subsection{Análise da qualidade superficial.}

A rugosidade superficial, Ra foi medida para cada condição no sentido perpendicular ao de avanço da ferramenta.

A figura 4.5 mostra, para as fresas esféricas de diâmetro de $12 \mathrm{~mm}$ a rugosidade Ra para os dois valores de comprimento em balanço, para cada uma das regiões do corpo-de-prova. 


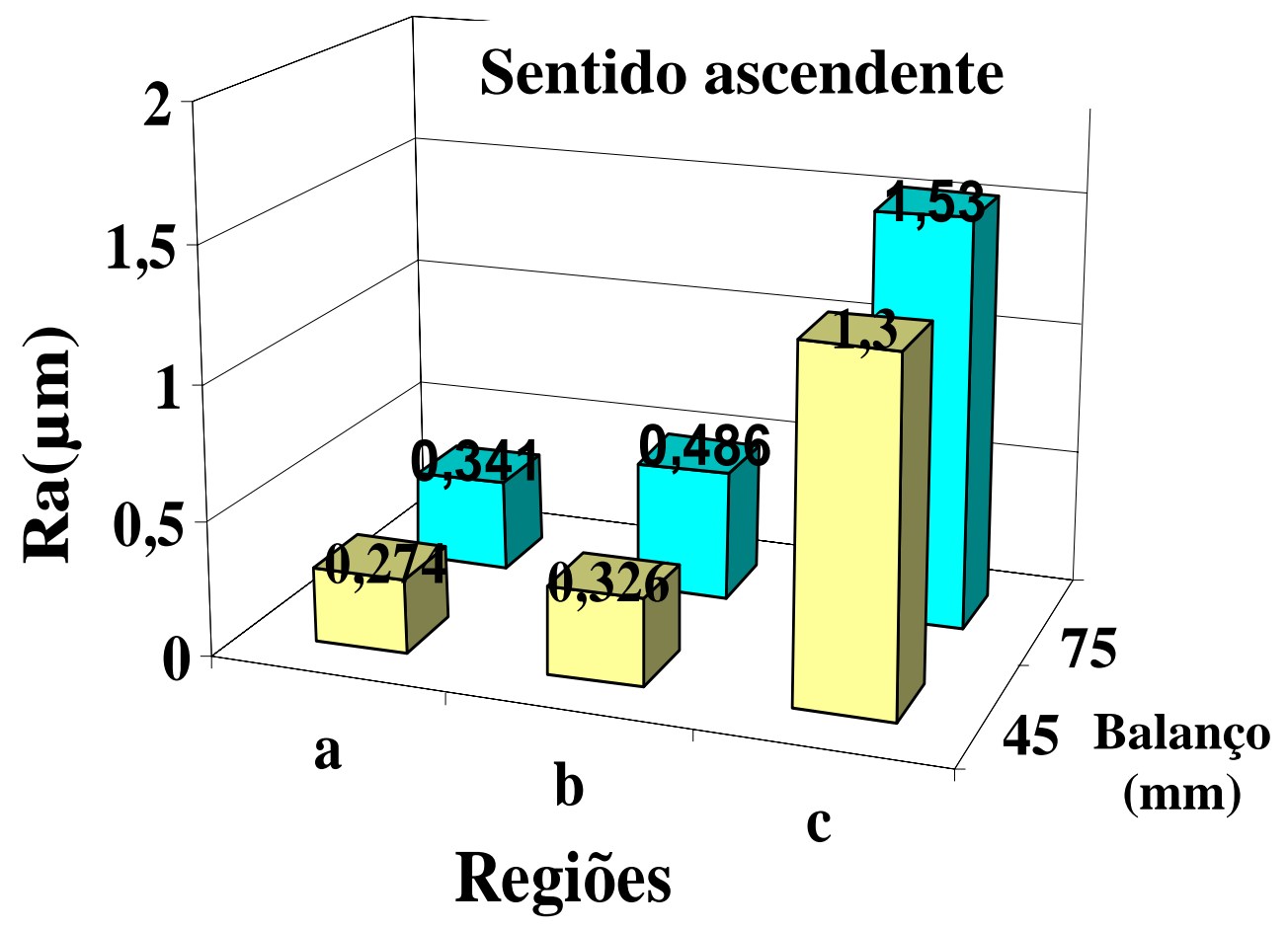

Figura 4.5 - Rugosidade Ra para a fresa esférica de ø $12 \mathrm{~mm}$.

A variação na inclinação da superfície fresada foi decisiva para a rugosidade Ra, pois, em geral, quanto menor foi o ângulo de posição da ferramenta maior a rugosidade obtida, independentemente do balanço de fresa. A área mais crítica, para fresas esférica é a parte central onde a velocidade de corte é zero, ocasionando amassamento de material que ocorre com maior intensidade em planos com inclinações menores, o que é muito desvantajoso para o processo de corte. Sendo assim, a formação de cavacos no centro também é mais crítica e seu escoamento dificultado devido ao pequeno espaço do bolsão de cavacos. Isso pode indicar que menores valores de rugosidade são obtidos com altos valores de velocidade de corte e ângulos de saída positivos, ambos encontrados na Região "a" do corpo de prova.

Com o aumento do comprimento em balanço também foi verificado um ligeiro aumento de Ra. Neste caso, pode-se atribuir este fato à tendência de instabilidade dinâmica do conjunto eixo-árvore com a ferramenta montada.

A figura 4.6 mostra, para a fresa esférica de diâmetro de $6 \mathrm{~mm}$ as diferenças de rugosidade Ra para diferentes valores de comprimento em balanço para cada uma das regiões do corpo-de-prova. 


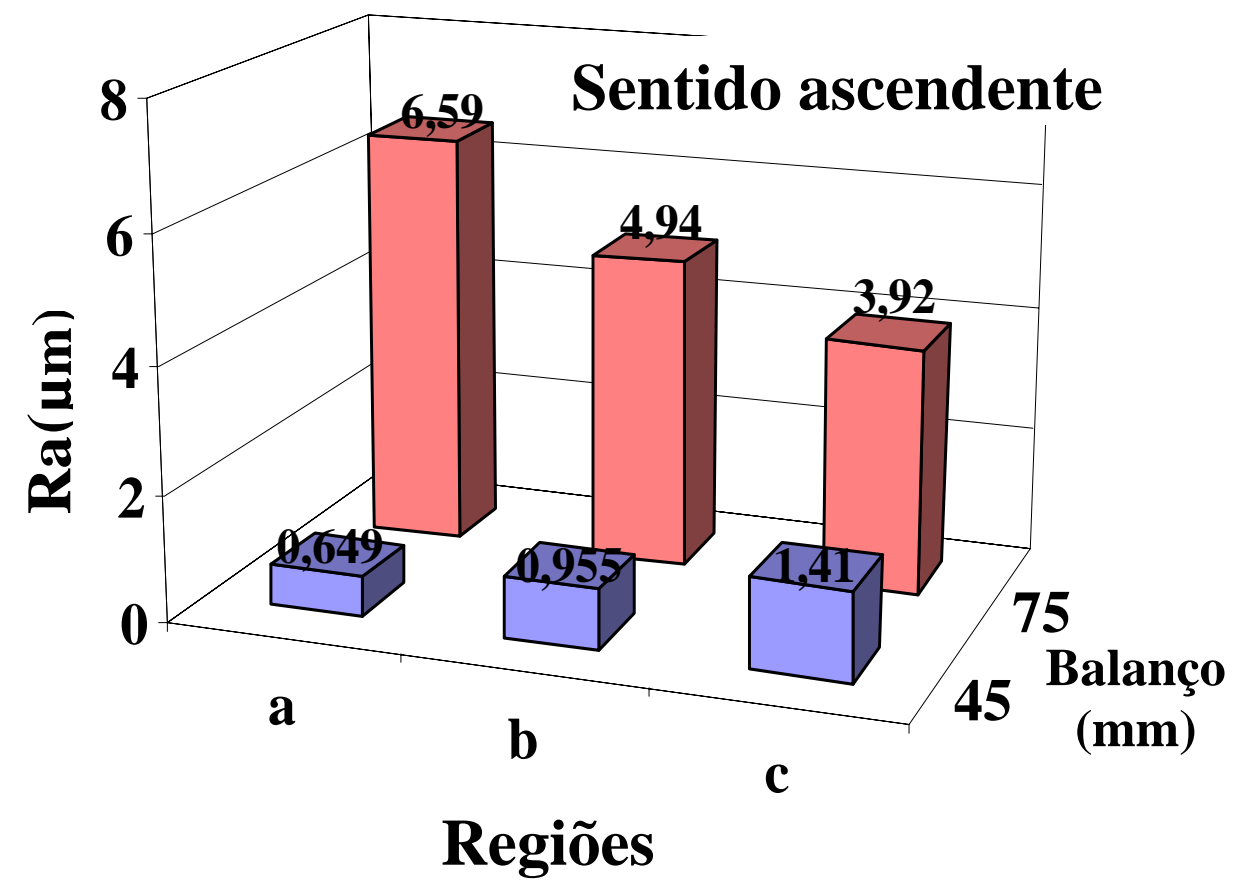

Figura 4.6 - Rugosidade Ra para a fresa esférica de ø $6 \mathrm{~mm}$.

Para a fresa esférica de ø $6 \mathrm{~mm}$ com balanço de $45 \mathrm{~mm}$ foi observada a mesma tendência de aumento da rugosidade com o ângulo de inclinação da superfície.

Em contraste, com o aumento do comprimento do balanço da ferramenta de $45 \mathrm{~mm}$ para 75 $\mathrm{mm}$ há um aumento geral na rugosidade Ra nas três regiões do corpo de prova, conforme as figuras 4.5 e 4.6 .

Há, no entanto, uma tendência inversa na rugosidade quando se passa da região "a" para a "c" utilizando-se a fresa de $6 \mathrm{~mm}$, com balanço de $75 \mathrm{~mm}$. Está é a condição dinâmica mais instável, principalmente no caso da região"c", então pode-se atribuir esse aumento excessivo de rugosidade à vibração. Essa constatação não pode ser medida, mas ouvida durante os ensaios.

A figura 4.7 mostra os valores de Ra tanto para o fresamento com sentido ascendente e descendente para a ferramenta com diâmetro de $6 \mathrm{~mm}$ e balanço de $45 \mathrm{~mm}$. 


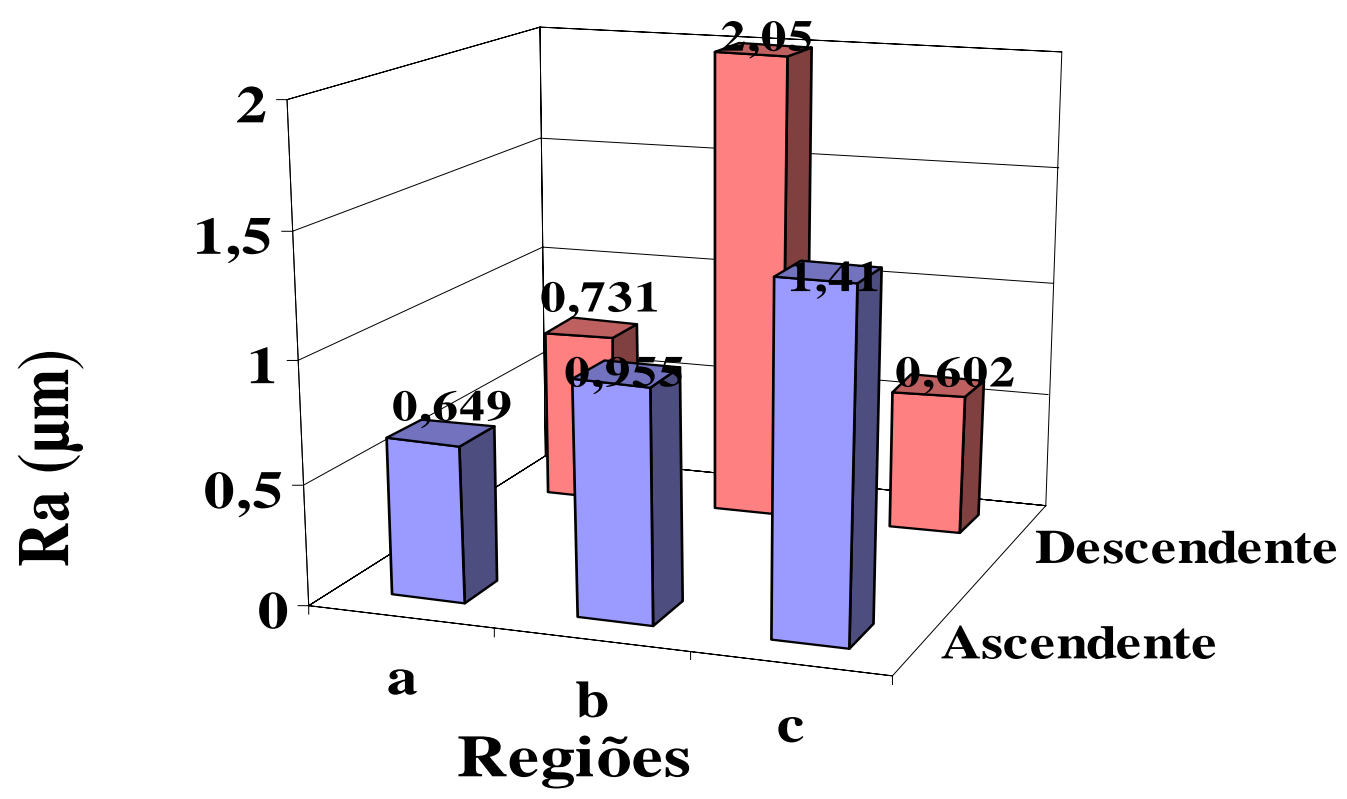

Figura 4.7 - Rugosidade Ra para a fresa esférica de ø $6 \mathrm{~mm}$, balanço $45 \mathrm{~mm}$.

Quando se usou corte descendente a rugosidade Ra foi maior nas regiões "a" e "b" do corpo-de-prova o que pode estar ligado ao ângulo de posição menor decorrente da geometria de contato entre a ferramenta e a superfície usinada, vide Figura 4.8.

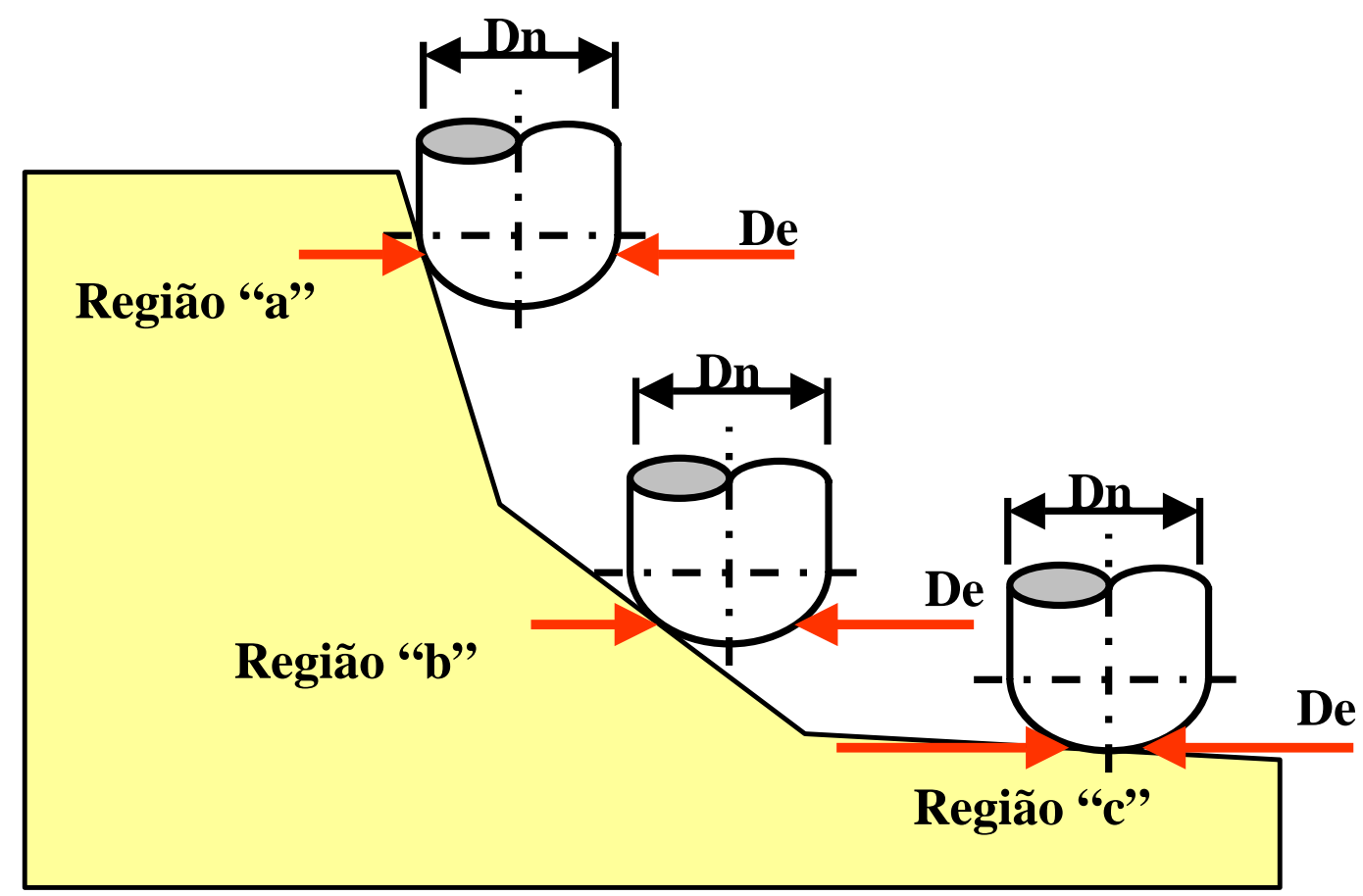

Figura 4.8 - Contato entre a ferramenta e as superfícies usinadas. 
Quando a fresa usina de baixo para cima, há menor possibilidade de "amassamento" de material. Na usinagem descendente a velocidade de corte é menor no centro da ferramenta o que, por sua vez, a obriga a trabalhar com seu diâmetro efetivo de corte muito menor do seu valor máximo. É importante salientar que o amassamento de material ocorre com maior intensidade em planos com inclinações menores, devido ao contato da parte central da fresa com a peça, causando picos que aumentam a rugosidade como deve ser notado na região "c". Portanto, o corte ascendente para grandes inclinações superficiais onde o efeito da transição de sobremetal remanescente em forma de escada não é muito alto e o amassamento de material na região central da ferramenta pode ser minimizado.

Em todas as regiões para a ferramenta de $\varnothing 6 \mathrm{~mm}$ com um balanço de $75 \mathrm{~mm}$ o contrário ocorreu, pois este caso em particular apresentou os piores valores de rugosidade e isso se deve à extrema instabilidade do corte durante toda a usinagem, o que acabou por prejudicar a qualidade da superfície e lascando a aresta da ferramenta de corte, conforme mostrado pela figura 4.9 .

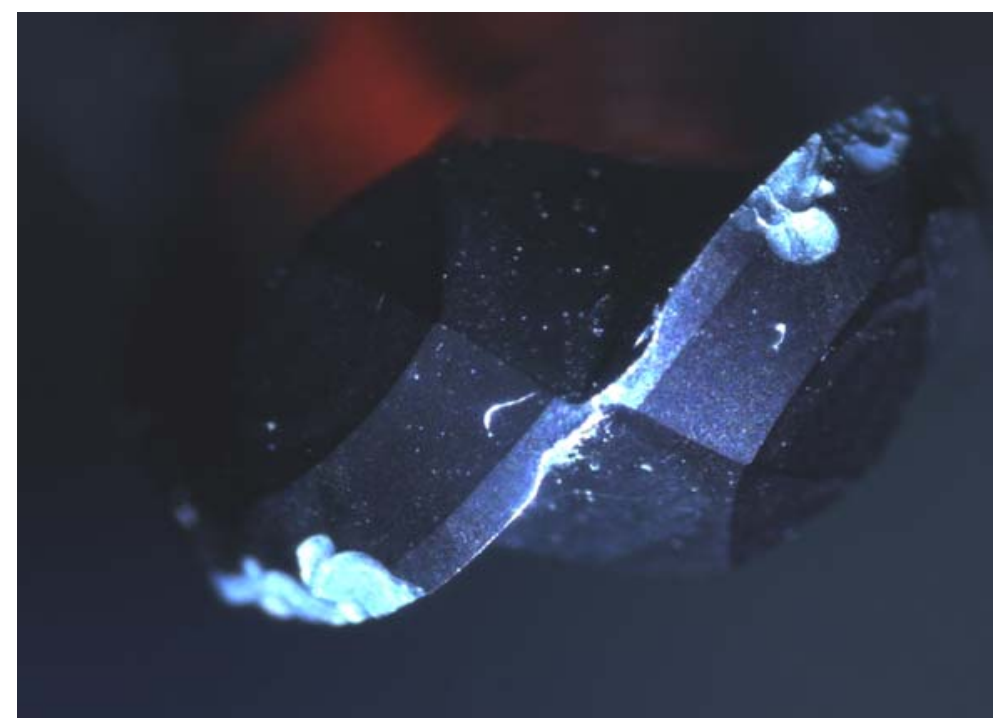

Figura 4.9 - Ferramenta diâmetro $6 \mathrm{~mm}$ lascada durante o processo de fresamento.

Observa-se que a única exceção para não ocorrer o aumento da rugosidade devido ao amassamento de material que ocorre com maior intensidade em planos com inclinações menores, verificou-se na usinagem no sentido de avanço descendente para a ferramenta de 
Ø6 mm com $45 \mathrm{~mm}$ de balanço (Figura 4.7), onde se obteve menor rugosidade na região "c" que tem inclinação de $7^{\circ}$. Comparando-se com o caso da trajetória ascendente com ferramenta de $\varnothing 6 \mathrm{~mm}$ com $45 \mathrm{~mm}$ de balanço, isto ocorreu devido à ferramenta iniciar o corte pela extremidade mais rasa dos degraus, conforme pode ser observado na Figura 4.10. De acordo com a figura 4.10, para um corte descendente, o carregamento sobre a ferramenta aumenta de forma suave e progressiva até o final de cada degrau. Pelo contrário, no sentido ascendente o degrau começa a ser removido pela região mais alta, representando um grande carregamento inicial, o que por sua vez implica em uma flexão brusca da ferramenta, evidenciado o início dos degraus.

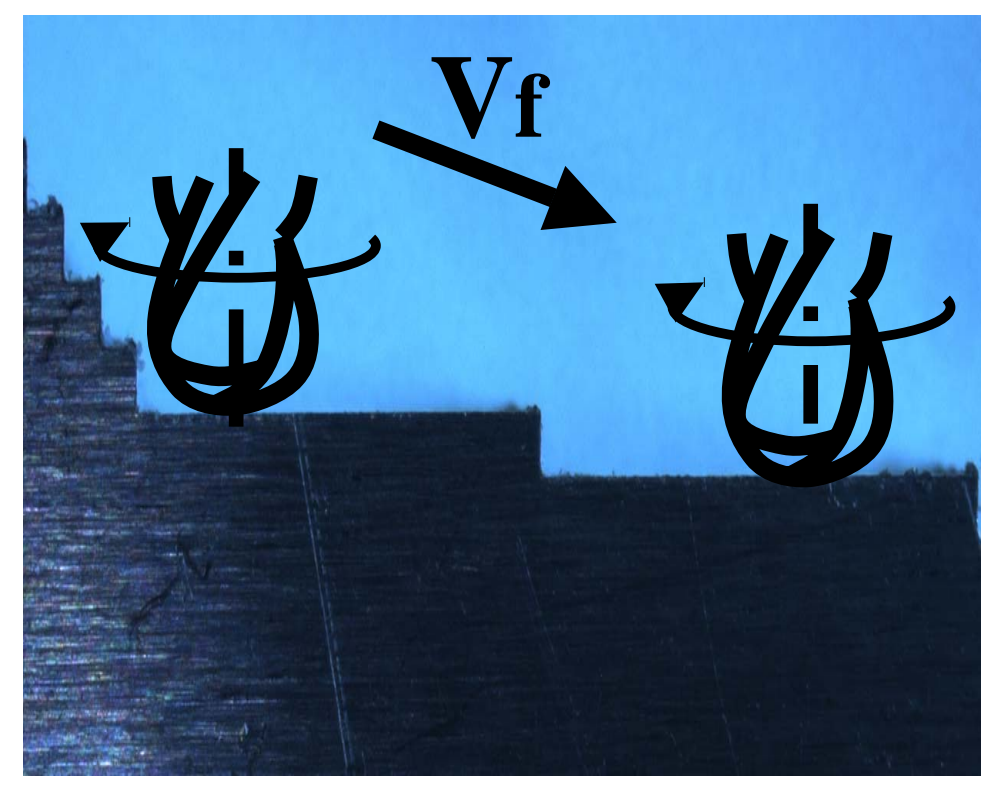

Figura 4.10 - Sentido descendente, a ferramenta inicia o corte pela extremidade mais rasa.

\subsection{Análise do desvio de forma.}

O desvio de forma entre a geometria projetada, um plano, e a peça após a usinagem pode ser causado por diferentes fontes, como: estrutura da máquina-ferramenta, algoritmos de comando do $\mathrm{CNC}$, características do processo de corte, flexão da ferramenta devido à força de usinagem, dentre outras. Neste trabalho é analisado o desvio de forma devido à flexão da ferramenta, pois este é o fator que representa um erro dimensional significativo na 
usinagem de moldes e matrizes, devido à freqüente necessidade de se utilizar ferramentas com excessivo comprimento em balanço.

A figura 4.11 mostra os valores do erro de forma para a região "a" do corpo de prova onde o valor máximo do desvio de retilineidade foi de $0,5 \mu \mathrm{m}$ para as ferramentas de $6 \mathrm{~mm}$ de diâmetro e $12 \mathrm{~mm}$ de diâmetro.

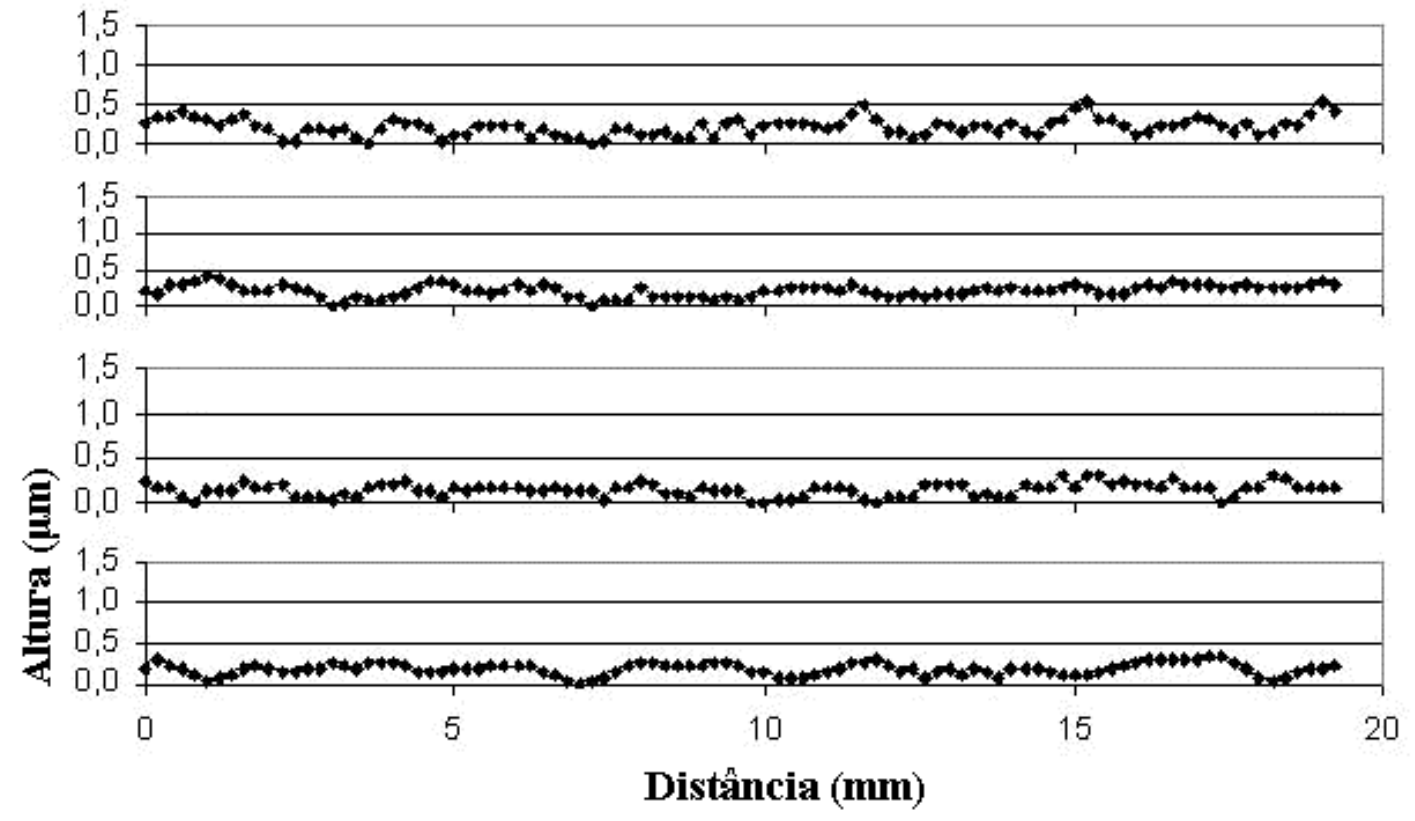

D6- 75

D6-45

D12-75

D12-45

Legenda: Dxx - XX = Diâmetro da fresa - comprimento em balanço

Figura 4.11 - Erro de retilineidade da região "a" da superfície usinada.

A figura 4.12 mostra o perfil da região "b" do corpo de prova, onde o valor máximo de desvio de retilineidade foi do que $1 \mu \mathrm{m}$ para a ferramenta de $6 \mathrm{~mm}$ de diâmetro e menos do que $0,5 \mu \mathrm{m}$ para a ferramenta de $12 \mathrm{~mm}$ de diâmetro. 


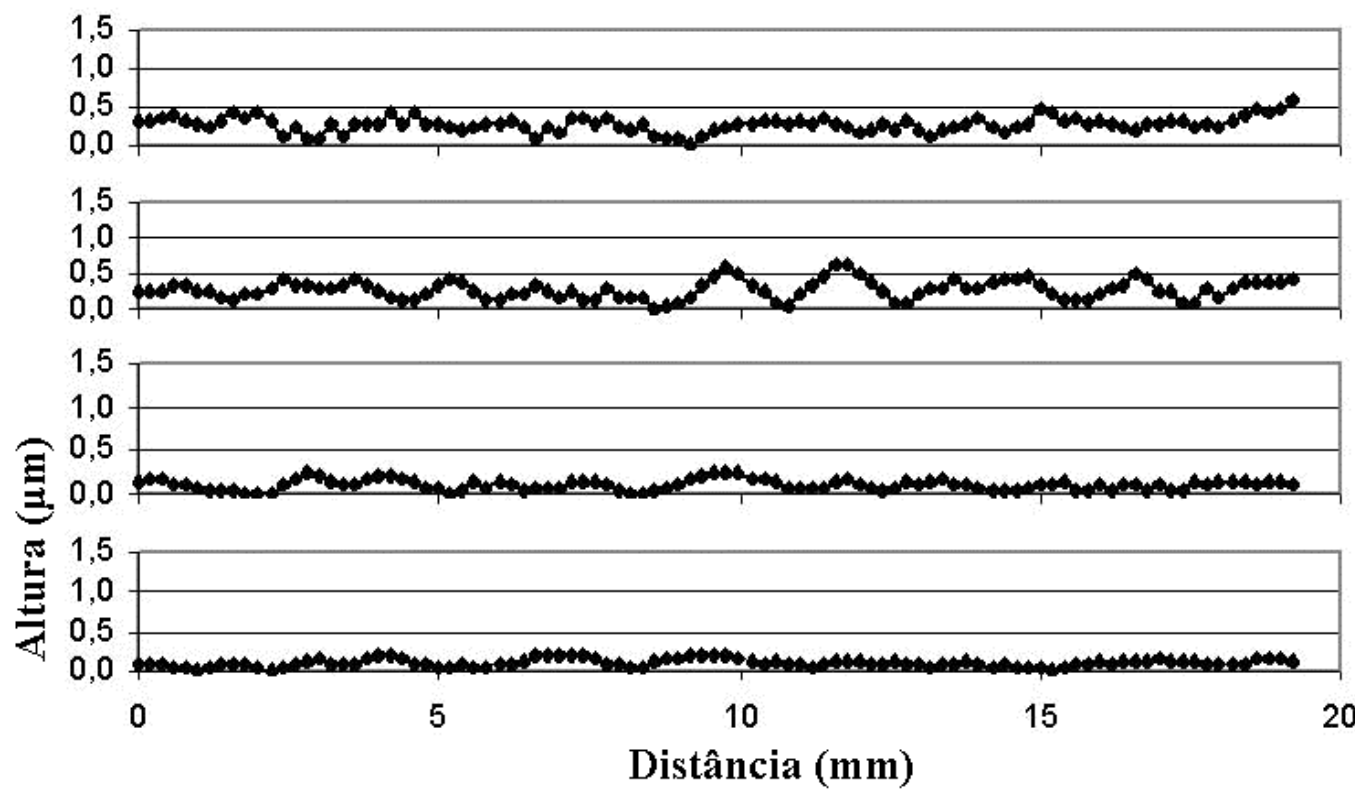

D6- 75

D6-45

D12-75

D12-45

Legenda: Dxx - XX = Diâmetro da fresa - comprimento em balanço

Figura 4.12 - Erro de retilineidade da região "b" da superfície usinada.

A figura 4.13 mostra os desvios de retilineidade na região "c", sendo o máximo de $1,5 \mu \mathrm{m}$ para a ferramenta $6 \mathrm{~mm}$ de diâmetro e balanço de $75 \mathrm{~mm}$.
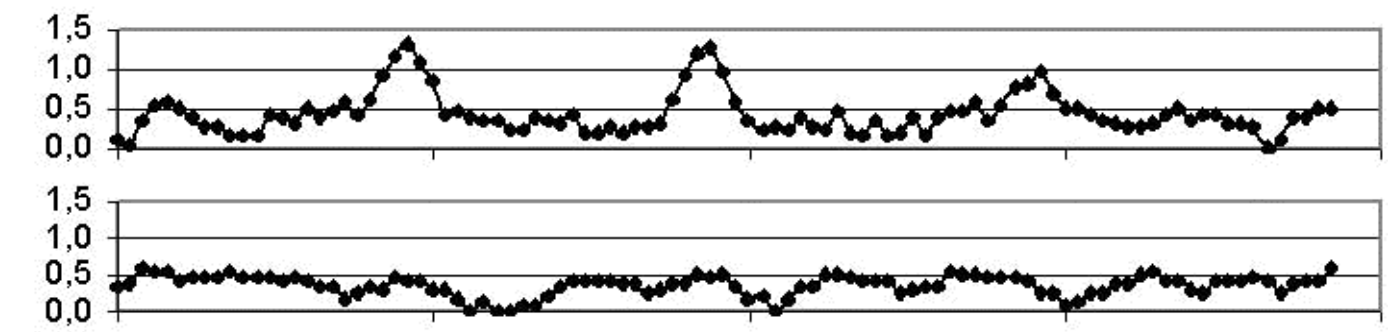

D6-45

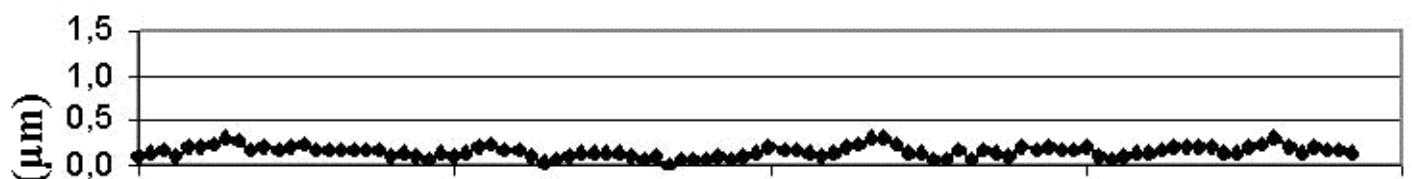

D12-75

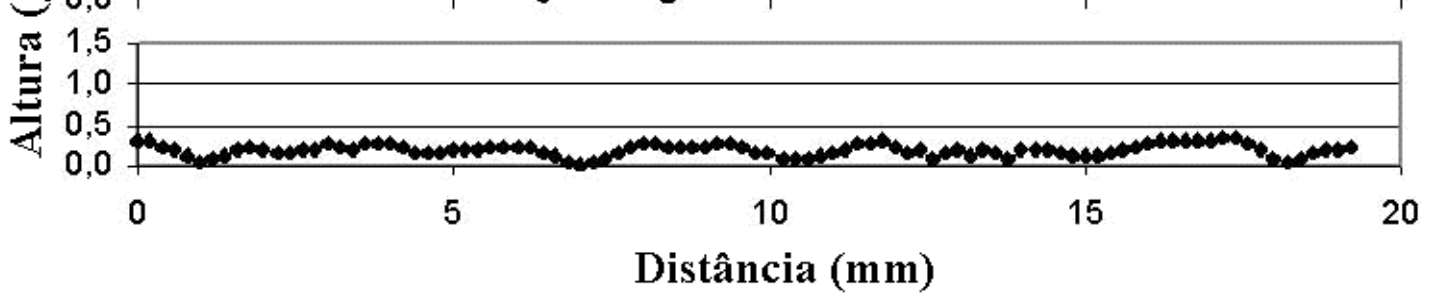

D12-45

Legenda: Dxx - XX = Diâmetro da fresa - comprimento em balanço

Figura 4.13 - Erro de retilineidade da região "c" da superfície usinada. 
Na curva medida, para o caso da fresa de $6 \mathrm{~mm}$ de diâmetro e balanço de $75 \mathrm{~mm}$, podem ser observados três picos, correspondentes aos inícios dos três degraus deixados pela operação anterior de desbaste. A combinação entre o balanço máximo da ferramenta com a transição brusca de sobremetal remanescente em forma de escada e a estratégia de usinagem ascendente, ocasionou um aumento das forças de corte devido ao excesso de sobremetal que por sua vez foi o suficiente para provocar uma flexão na ferramenta. Os picos de $1,5 \mu \mathrm{m}$ podem ser uma quantia significativa de material em algumas aplicações. Em todas as de demais condições de corte o excesso de sobremetal pode ser removido sem deixar erros de forma maiores do que $0,5 \mu \mathrm{m}$.

Para a ferramenta de diâmetro de $6 \mathrm{~mm}$ e $75 \mathrm{~mm}$ de balanço notam-se três marcas lineares na superfície usinada (figura 4.14-a), correspondentes aos três picos na medição de erro de forma (figura 4.13). As marcas correspondem aos degraus mostrados na Figura 4.14 b.

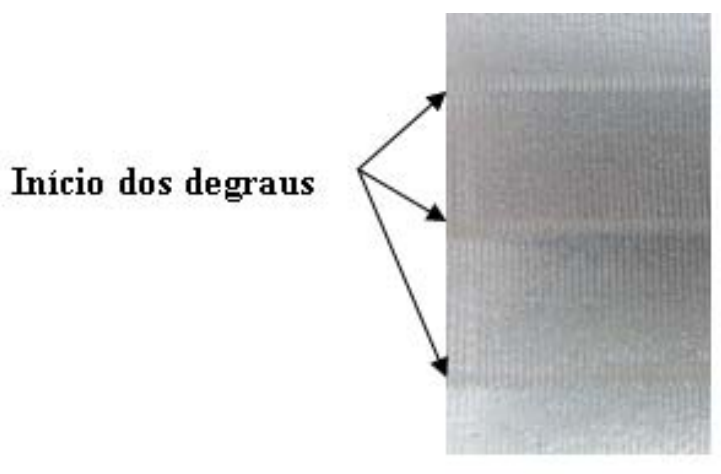

Fig. a

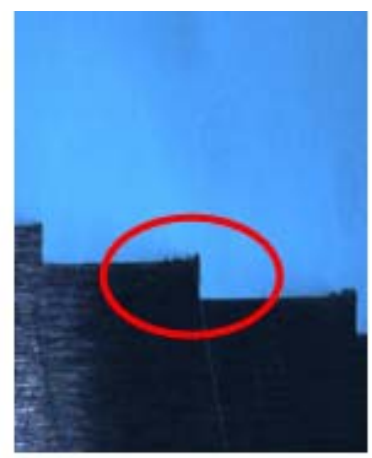

Fig. b

Figura 4.14 - Aspecto visual das superfícies obtidas com fresa ø $6 \mathrm{~mm}$ e balanço $75 \mathrm{~mm}$ na região "c".

\subsection{Análise da força de usinagem}

A força de usinagem foi medida para acrescentar informações à análise qualitativa. Os gráficos abaixo apresentam o comportamento das componentes cartesianas da força de usinagem (Fx, Fy e Fz) em função do tempo. A figura 4.15 ilustra as componentes da força de usinagem utilizando a ferramenta de $6 \mathrm{~mm}$ de diâmetro e comprimentos de fixação de 
$75 \mathrm{~mm}$ e $45 \mathrm{~mm}$, respectivamente. Já a figura 4.16 refere-se ao experimento utilizando a ferramenta de $12 \mathrm{~mm}$ de diâmetro e comprimentos de fixação de $75 \mathrm{~mm}$ e $45 \mathrm{~mm}$, respectivamente.

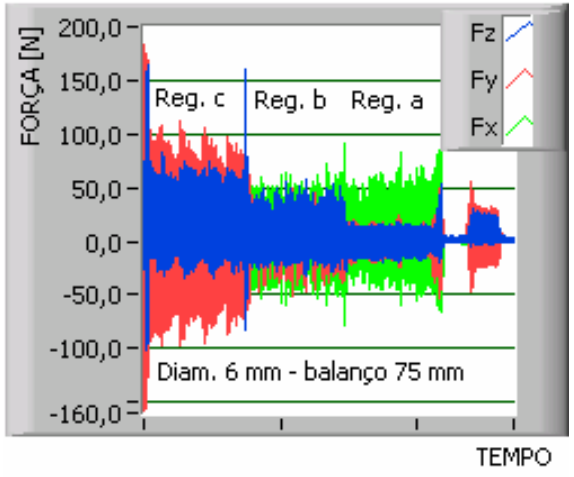

Fig. a - Balanço de $75 \mathrm{~mm}$

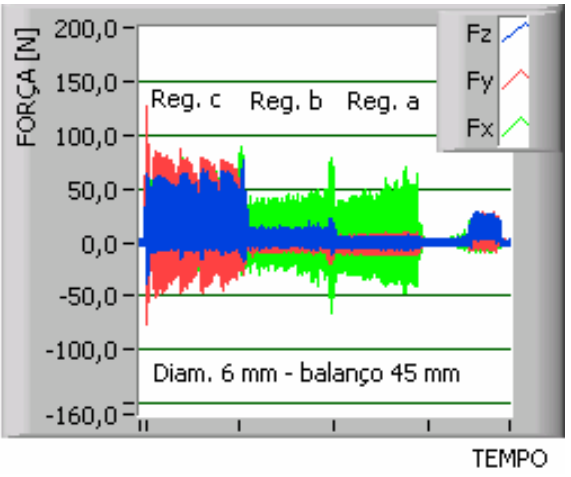

Fig. $\mathrm{b}$ - Balanço de $45 \mathrm{~mm}$

Figura 4.15 - Gráfico das forças de usinagem para a ferramenta de $6 \mathrm{~mm}$ de diâmetro.

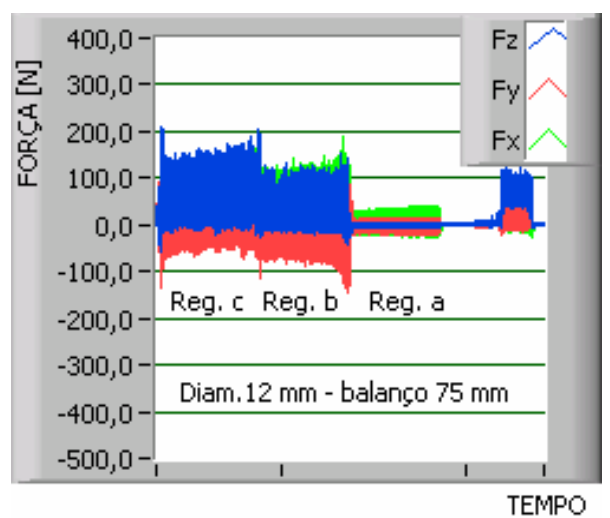

Figura a - Balanço de $75 \mathrm{~mm}$

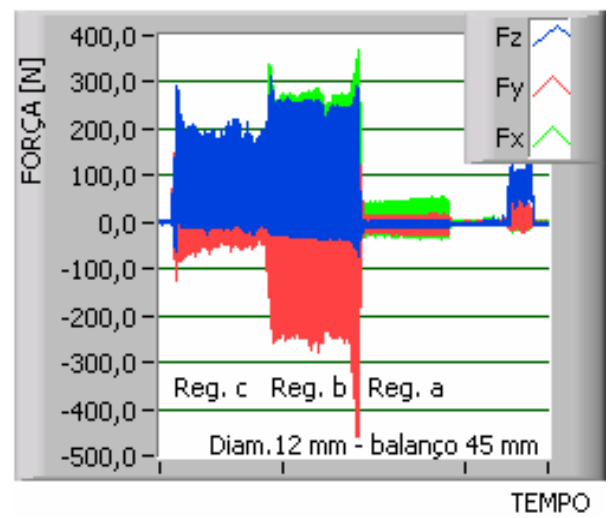

Figura $\mathrm{b}$ - Balanço de $45 \mathrm{~mm}$

Figura 4.16 - Gráfico das forças de usinagem para a ferramenta de $12 \mathrm{~mm}$ de diâmetro.

Devido às altas freqüências das forças agindo no corpo de provas $(333 \mathrm{~Hz})$ os gráficos registrados contém uma significativa componente dinâmica. A freqüência natural do dinamômetro e de $1 \mathrm{kHz}$, valor de catálogo. Os valores máximos em cada região inclinada, no entanto, são bastante distintas, evidenciando as diferenças de forcas. Podese observar, principalmente na região "c", com a ferramenta de $6 \mathrm{~mm}$ de diâmetro e comprimento em balanço de $75 \mathrm{~mm}$ e $45 \mathrm{~mm}$ picos de força, que isto ocorreu pois a 
região "c" com inclinação de $7^{\circ}$ apresenta uma superfície com brusca transição de sobremetal em forma de escada.

Observa-se que a ferramenta de maior diâmetro exerceu maior força de usinagem o que pode ser atribuído à uma maior área de secção de cavaco.

Ampliando-se as curvas de força no tempo, observam-se picos de força cuja freqüência é de $333 \mathrm{~Hz}$. Estes picos indicam ser as componentes da força de usinagem, pois coincidem com a freqüência de atuação das arestas de corte da ferramenta (duas arestas - 10.000 rpm), conforme indicada na Figura 4.17 (a).

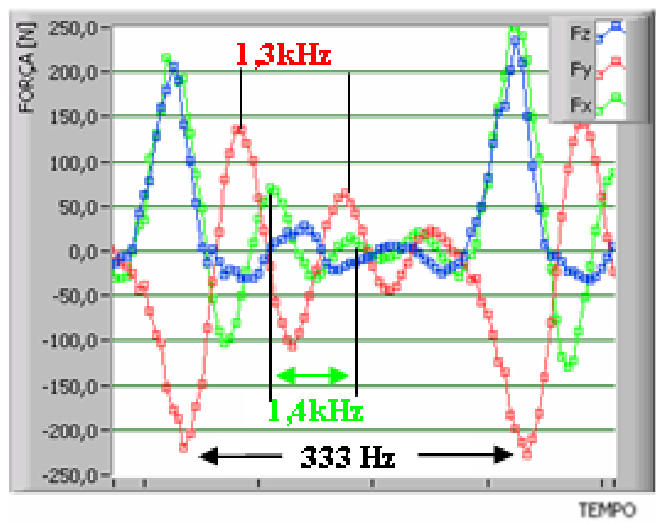

Fig. a: Aquisição das forças durante a usinagem

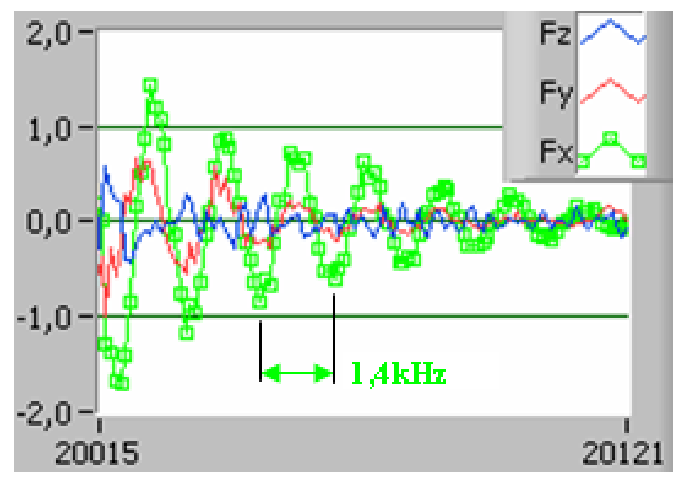

Fig. b: Freqüência natural do sistema na direção $x$

Figura 4.17 - Vibração do dinamômetro/peça e a ação de cada aresta de corte.

Os gráficos também mostram que no intervalo de atuação das arestas, as componentes da força de usinagem estão oscilando, ocorrendo constantes alterações de sinal. Em uma análise simplificada, através de uma entrada impulso, estimou-se a freqüência de vibração livre do sistema dinamômetro/peça e detectaram-se as freqüências predominantes: $1,4 \mathrm{kHz}$ na direção X e 1,3 kHz na direção Y. A Figura 4.17 (b) demonstra a vibração natural do sistema na direção $X$, após a excitação externa, verifica-se que esta freqüência natural de $1,4 \mathrm{kHz}$. 


\subsection{Análise da flexão da ferramenta}

O modelo simplificado da viga engastada foi utilizado para se obter uma estimativa inicial da flexão da ferramenta. Empregando a componente Fy da força de usinagem, a qual é a mais influente nos erros dimensionais. A flexão da ferramenta também foi estimada de forma experimental, com a ferramenta sem rotação sendo flexionada contra o corpo-de-prova fixo ao dinamômetro. Esta movimentação foi realizada na direção Y, por incrementos centesimais, até a componente Fy atingir um valor de grandeza semelhante ao valor obtido no experimento de usinagem. Desprezando-se a deformação de contato, esse procedimento fornece de forma aproximada a rigidez da ferramenta, conforme já descrito no procedimento experimental.

$\mathrm{O}$ gráfico da figura 4.18 mostra no eixo $\mathrm{X}$ a distância que a máquina se movimentou se após o contato da ferramenta com o corpo de prova e o eixo y corresponde à força Fy referente a esta movimentação.

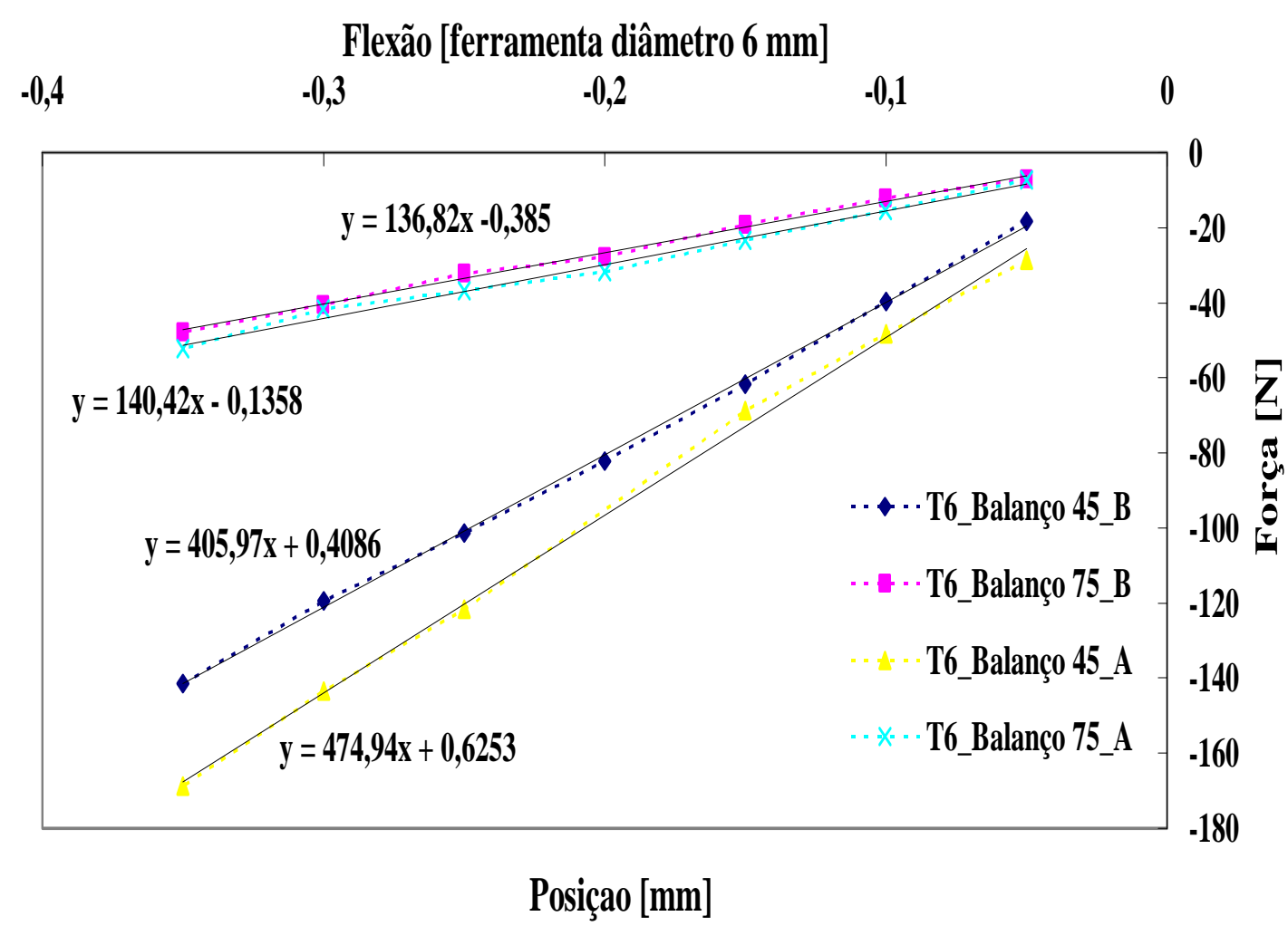

Figura 4.18 - Resultado da rigidez da fresa de $6 \mathrm{~mm}$ obtida experimental. 
O gráfico da figura 4.18 mostra uma boa linearidade evidenciando a pouca deformação plástica ou escorregamento da ferramenta nas superfícies. A rigidez da fresa com balanço de $45 \mathrm{~mm}$ é maior do que a de $75 \mathrm{~mm}$, por um fator de aproximadamente 3 vezes.

Conforme esperado uma diminuição no comprimento em balanço de 75 para $45 \mathrm{~mm}$, a rigidez deveria se aumentada na proporção do cubo da razão entre os comprimentos. Esse valor teórico é de 4,63 para esse caso, superior, portanto ao encontrado experimentalmente. A razão está no fato de estar-se medindo experimentalmente a rigidez de todo o sistema: eixo-árvore/sistema de fixação/ferramenta/corpo de provas/fresa, que certamente é menor, do que o valor teórico somente da fresa engastada.

Os valores de rigidez encontrados experimentalmente, são também menores que aqueles calculados teoricamente, cerca de $87,5 \%$ para o comprimento de $75 \mathrm{~mm}$ e $63,2 \%$ para o comprimento de $45 \mathrm{~mm}$. Novamente se aplicam as mesmas razões anteriores para os valores experimentais terem sido menores que os teóricos. Deve-se também considerar que para permitir o cálculo simplificado da flexão à ferramenta de corte foi considerada um cilindro uniforme e com rigidez homogênea.

A menor rigidez do sistema quando trabalhando com a fresa de $6 \mathrm{~mm}$ com $75 \mathrm{~mm} \mathrm{em}$ balanço, em combinação com o corte interrompido, típico do processo de fresamento, e a força de corte variável, devido às variações na espessura do cavaco, provavelmente foram responsáveis pela alta rugosidade Ra obtida neste caso. A menor rigidez proporciona maiores oportunidades de flexão em resposta às solicitações da força de corte. Como as solicitações são variáveis no tempo, o sistema todo tende a vibrar em amplitudes que, muitas vezes, podem ser da mesma ordem de grandeza da espessura do cavaco. O corte por fresamento é interrompido com uma freqüência de atuação das arestas, próxima àquelas naturais do sistema mecânico em ação. 


\section{Conclusões e sugestões para futuros trabalhos}

Dos resultados encontrados neste trabalho, usando técnicas de usinagem com altas velocidades de corte em operações de fresamento de superfícies complexas, algumas s conclusões podem ser declaradas:

$\sqrt{ }$ O desbaste de superfícies complexas com fresa de topo plana com estratégia de corte “off-set em z" em 2 1⁄2 eixos deixa um excesso de material, além do sobremetal teórico, cujo volume varia em função da inclinação da superfície. Quanto menor a inclinação em relação ao plano XY da máquina-ferramenta, maior será o volume do material excedente. Este sobremetal excedente influencia diretamente, e de forma significativa, as operações subseqüentes de acabamento.

$\sqrt{ }$ No fresamento de superfícies complexas a constante alteração do ponto de contato entre a peça e a fresa de ponta esférica depende da inclinação da superfície. Isso provoca uma significante variação na velocidade efetiva de corte, com conseqüências importantes para o acabamento superficial. O sentido de corte, ascendente ou descendente, altera significativamente a cinemática de corte, modificando o ângulo de contato e a velocidade efetiva de corte. No corte descendente, dependendo da inclinação da superfície, pode-se aproximar muito do centro da fresa de ponta esférica, prejudicando a formação de cavacos devido à baixa velocidade efetiva de corte.

$\sqrt{ }$ Para superfícies com baixa inclinação o corte descendente proporciona um crescimento suave e constante da profundidade de corte, sobre os degraus, o que resultou em melhor acabamento superficial, apesar da aproximação ao centro da fresa.

$\sqrt{ }$ Foram observadas as influências do comprimento de fixação da ferramenta, na usinagem HSC. A rugosidade superficial foi prejudicada pelo maior comprimento de balanço, tanto para a ferramenta de ø $6 \mathrm{~mm}$ quanto para a ferramenta de $\varnothing 12 \mathrm{~mm}$ nas três regiões do corpo-de-prova.

$\sqrt{ }$ Mantendo-se o avanço por dente constante a fresa de diâmetro de $12 \mathrm{~mm}$ produziu sempre valores de rugosidade Ra menores, em comparação com a ferramenta de $6 \mathrm{~mm}$ de diâmetro, conforme esperado teoricamente.

$\sqrt{ }$ A rugosidade superficial poderia ser tão baixa quanto a 1,0 $\mu \mathrm{m}$ Ra, mas depende do diâmetro e do comprimento em balanço da ferramenta de ponta esférica. Valores mais altos tanto quanto $6,0 \mu \mathrm{m}$ Ra foram obtidos usando uma ferramenta com $6,0 \mathrm{~mm}$ de diâmetro combinado com $75 \mathrm{~mm}$ de comprimento em balanço. Valores baixos também 
foram obtidos quanto usinando com uma ferramenta de $6,0 \mathrm{~mm}$ de diâmetro e com 45 $\mathrm{mm}$ de balanço, ambos para estratégias de corte ascendente e descendente.

$\sqrt{ }$ A maneira proposta de medição da rigidez da ferramenta esférica demonstrou produzir resultados mais baixos que os cálculos teóricos, mas isso leva em consideração a rigidez de todo o sistema. O método, entretanto, mostrou que pode haver uma diferença na rigidez quando fresando superfícies de $3 \mathrm{D}$ complexas, nas quais o ponto de contato varia na ferramenta de ponta esférica, isso é particularmente significante quando se usa fresa de $6 \mathrm{~mm}$ de diâmetro.

$\sqrt{ }$ A baixa rigidez da fresa de $6 \mathrm{~mm}$ de diâmetro, combinado com bruscas transições de sobremetal remanescente a serem removidos pela operação de acabamento foram os principais responsáveis pela variação dimensional na região "c" do corpo de prova, deixando marcas superficiais que correspondem aos inícios dos degraus deixados pela operação desbaste. Ao efetuar a medição foram constados degraus com picos tão altos quanto $1,5 \mu \mathrm{m}$, os quais podem ser significantes em algumas aplicações.

Baseados nas conclusões apresentadas e na experiência adquirida com a execução deste trabalho de pesquisa, sugerem-se as seguintes propostas para trabalhos futuros:

$\sqrt{ }$ Estudo e desenvolvimento de rotinas para o software CAM de forma a prever o volume de material remanescente após o desbaste em $2 \frac{1}{2} 2$ eixos, em função da geometria da ferramenta e da profundidade de corte $\left(a_{p}\right)$ Desta forma, em regiões críticas, os parâmetros de corte, como a velocidade de avanço e velocidade de corte poderão ser alterados para manter constante o carregamento sobre a ferramenta.

$\sqrt{ }$ Estudar as forças de corte para valores tão pequenos quanto os detectados neste trabalho e com alta freqüências, usando-se dinamômetros adequados.

$\sqrt{ }$ Buscar maneiras de se medir, experimentalmente a rigidez da ferramenta montada no eixo-árvore, com a finalidade de se evitar a flexão da mesma, melhorando a precisão dimensional da peça em aplicações onde este fator seja relevante. 


\section{REFERÊNCIAS BIBLIOGRÁFICAS}

\section{Referências Citadas}

AGOSTINHO, O. L. (1996) - Integração Estrutural dos Sistemas de Manufatura como Pré Requisito de Competitividade. Campinas. 256p. Tese (Livre Docência) Universidade Estadual de Campinas.

APQP - Planejamento Avançado da Qualidade do Produto (1995) - Manual de Referência, IGA, junho, 1995.

ARNONE, M. (1998) - High Performance Machining, Hanser Gardner Publications, Capítulo 03.

BEART, T. (1997) - Making machines move faster, Moder Machine Shop, pg 72-81, agosto, 1997.

BECK, H.W. (1998) - Alta velocidade e ferramentas de alto desempenho reduzem o tempo de usinagem, Máquinas e Metais, n.387, p.40-47, abr., 1998.

BLACK, J. T. (1989) - mechanics of chip formation. In: DAVIS, J. R (Ed.). Metals handbook: machining. 9. ed. Ohio, USA: ASM, 1989. v. 16 p7 -18.

CAVALHEIRO, A. Z. (1998) - Dissertação - Sistematização de planejamento da programação CAM do fresamento de cavidades de moldes para peças injetadas, UFSC, 1998.

CAVICHIOLLI, F.A. (2003) - A importância da fixação em HSM. In: SANDVIK. Usinagem em altíssimas velocidades. São Paulo; Editora Érica Ltda. Cap.10, p. 136146. 
CEBALO, R. (1999) - Machined surface quality by High speed Milling, 5 th Internacional Scientific Conference on Production Engineering, Opatija, Croat, p. i-015$\mathrm{i} 020$.

CHRISTOFFEL, K (2001) - High Speed Machining, from a tool manufacturer perspective, In Anais do $6^{\circ}$ Seminário Internacional de Alta Tecnologia, Manufatura Avançada, p. 121-151, Unimep, 2001.

COELHO, R. T. (2002) - Junto com a rapidez é preciso ganhar eficiência, Máquinas e Metais, pg 128 - 153, setembro, 2002.

DINIZ, ANSELMO. E., Coppini, N. L., Marcondes, F. C. (2000) - Tecnologia da usinagem dos materiais, 2000, Editora Artliber.

FALLBOHMER, P.; ALTAN, T.; TONSHOFF, H.; NAKAGAWA, T. (1996) Survey of the Die and Mold Manufacturing Industry, Journal of Materials Processing Technology, pg 158 - 168, 1996.

FERRARESI, DINO (1977) - Fundamentos da Usinagem dos Materiais, Editora Edgard Blucher.

FLOW, D.G.; KOMANDURI, R. (1989) - High speed machining. In: AMERICAN SOCIETY FOR METALS. Metals handbook. $9^{\text {th }}$. Metals Parks, Ohio, USA. V.16Machining, p. 597-606. (1989).

FURUKAWA, Y.; MORONUKI, N. - Contact deformation of a machine tool slideway and its effects on machining accuracy, JSME INTERNATIONAL JOURNAL, v.30 , p.868-874, 1987.

GEIST, J. (1999) - Influence of HSC - Appropriate machining parameter on NC programming. In: Anais do $4^{\circ}$ Seminário Internacional de alta tecnologia Inovação na manufatura para ano 2000 , pg 57-68, ago 1999, Unimep. 
GOMES, J. O. (2001) - Tese de Doutorado - Fabricação de superfícies de forma livre por fresamento no aço ABNT-420, na liga de alumínio AMP8000 e na liga de cobre $\mathrm{Cu}-\mathrm{Be}$. UFSC.

HELLENO, A. L.; SCHUTZER, K. (2003) - HSM - Programação e Transmissão de dados na tecnologia HSC. In: SANDVIK. Usinagem em altíssimas velocidades. São Paulo; Editora Érica Ltda. Cap.11, p. 147-178.

KIRSCHNIK, G. M. (1997) - Características técnicas de comando numérico computadorizado para HSC. In SEMINÁRIO INTERNACIONAL DE ALTA TECNOLOGIA - USINAGEM COM ALTÍSSIMA VELOCIDADE DE CORTE E ALTA PRECISÃO, 02., UNIMEP, p. 1 -15, 1997.

LACERDA, A. C.;REIS, D. R.;WEVER,H.(2001) - Tecnologia - Estratégia para a Competitividade. O Caso Siemens, Editora Nobel, 2001.

LIMA, A. M. A.; NETO, R. (1994) - Projeto de moldes para injeção de plástico , Máquinas e Metais, pg 96 - 101, Agosto.

LIMA, V. T; LACERDA, H B.; LIMA, A M. (2003): Análise e predição de forças de corte e vibrações tipo"Chatter"no fresamento. In: COBEF, maio, 2003.

MACHADO, A. R.; BACCI, M. (2003) - Fluidos de corte para HSM. In: SANDVIK. Usinagem em altíssimas velocidades. São Paulo; Editora Érica Ltda. Cap.05, p. 4981.

MACHADO, A. R.; SILVA, M. B. (1999) - Usinagem dos metais. 4.versão. Uberlândia: Ed. UFU. Apostila.

MARCONDES, F. C. (2003) - Influência da tecnologia HSM/HSC no marketing industrial. In: SANDVIK. Usinagem em altíssimas velocidades. São Paulo; Editora Érica Ltda. Cap.03, p. 36-38. 
MARINAC, DAN (2001) - Estratégias de trajetória da ferramenta, Máquinas e Metais, pg $110-123, \mathrm{n}^{\circ} 425$, junho, 2001.

Mc GEE, F. J. (1979) - Study: Methods for aluminum work pieces. American Machinist, v. 123, n.3, p. 121-126, Marc.

MOREIRA, JOSÉ (2002) - Tecnologia CNC para High Speed Cutting -HSC, Usinagem 2002- Feira e Congresso.

MODERN MACHINE SHOP (2003) - High speed machining, Disponível em: http://www.mmsonline.com/hsm, Acessado em 26 maio, 2003.

MULLER, P.; SOTO, M. (1999) - Usinagem sem refrigeração de furos e roscas. In: $4^{\circ}$ SEMINARIO INTERNACIONAL DE ALTA TECNOLOGIA - INOVAÇOES TECNOLOGICAS NA MANUFATURA PARA O ANO 2000, Agosto, 1999, Santa Bárbara d' Oeste. Unimep, pg. 127-133.

NEVES, DAVI; (2003) - O fresamento de material endurecido com fresa de ponta esférica - análise da influência dos parâmetros de usinagem de desbaste na força de corte, COBEF, Uberlândia, MG.

NOVASKI, O; CORRÊA, M. (1998) - A HSC como vantagem competitiva, Máquina e Metais, n. 394, p. 74-89, nov, 1998.

NING, Y; RAHMAN, M; WONG, Y. S. (2001) - Investigation of chip formation in high speed end miling. Journal of Material Processing Technology, v113, pg. 360367.

OVTCHAROVA, J. (2002) - Virtual Vehicle Development at Adam Opel A Industrial Case Study, $7^{\circ}$ Seminário Internacional de Alta Tecnologia. Universidade Metodista de Piracicaba, p. 123 - 137, Outubro, 2002.

OLIVEIRA, F. G. (2003) - HSM - Conceito e Aplicações. In: SANDVIK. Usinagem em altíssimas velocidades. São Paulo; Editora Érica Ltda. Cap.01, p. 29-35. 
POPOLI, W. (2000) - Projeto e construção de um fuso de alta velocidade, pg 74 - 103 , Máquina e Metais $n^{\circ} 413$, Julho 2000.

SANDVIK (1999) - GUIA DE APLICAÇÃO - Fabricação de Moldes e Matrizes.

SARAIVA, M. (2000) - Dissertação - Fresamento por regiões como uma alternativa na usinagem de cavidades para moldes de injeção através de sistema CAD/CAM, UFSC, 2000.

SOUZA, A. F. (2001) - Dissertação -Análise das interpolações de trajetória de ferramenta na usinagem HSC em superfícies complexas. UNIMEP.

SOUZA, A. F. (2004) - Tese - Contribuições ao fresamento de geometrias complexas aplicando tecnologia de usinagem com altas velocidades. USP-SC.

SCHUTZER, K. (1999) - Introdução do Processo HSC na Indústria Brasileira, 4 Seminário Internacional de Alta Tecnologia, Universidade Metodista de Piracicaba, p. $79-98$, Agosto, 1999.

SCHUTZER, K; SOUZA, A. F. (2000) - Aplicação da usinagem com altíssima velocidade de corte na manufatura de moldes e matrizes. In: Usinagem 2000 Feira e Congresso.

SCHUTZER, K; SCHULZ, H. (2003) - Histórico da usinagem com altíssima velocidade até os dias atuais. In: SANDVIK. Usinagem em altíssimas velocidades. São Paulo; Editora Érica Ltda. Cap.01, p. 13-28.

SCHULZ, H. (1996) - High speed milling machining, In Anais do Seminário Internacional de Alta Tecnologia , Usinagem com altíssima velocidade de corte, Out 1996, p. 1-15, Unimep. 
SCHULZ, H. (1997) - State of art trends of high speed machining, In Anais do $2^{\circ}$ Seminário Internacional de Alta Tecnologia , Usinagem com altíssima velocidade de corte e alta precisão, July, p. 1-10, Unimep.

SCHULZ, H.; WURZ, T. (1997) - O projeto de máquinas-ferramentas tem de atender aos requisitos do HSC, Máquinas e Metais, n.375, p. 289-292, abr. 1997.

SCHULZ, H. (1999) - Trends in manufacturing technology at the threshold of the millenium, In: $4^{\circ}$ SEMÍNARIO INTERNACIONAL DE ALTA TECNOLOGIA INOVAÇÕES TECNOLOGICAS NA MANUFATURA PARA O ANO 2000, Unimep, p.1-17, 1999.

SCHULZ, H.; ABELE, E., SAHM, A. (2001) - High speed machining fundamentals and industrial application. In: $6^{\circ}$ SEMINÁRIO INTERNACIONAL DE ALTA TECNOLOGIA - MANUFATURA AVANÇADA, Piracicaba - SP. Anais... Santa bárbara d'Oeste - SP, Unimep. pg.25-44, 2001.

SINHOFF, V. (1999) - A usinagem a seco em alta velocidade: revolução ou evolução, Máquinas e Metais, n 404, p. 22 - 37, set, 1999.

SOGABE, M. (1996) - Otimizados os motores lineares poderão dar muito maior velocidade a usinagem, Máquinas e Metais, n.362, p. 36-41, mar, 1996.

TRENT, E. M.; WRIGHT. K. P. (2000) - Metal Cutting. Butterworth-Heinemnn, 466 pg.

URBANSKI, J.P.; KOSHY, P.; DEWES, R. C. (2000) - High speed Machining of Moulds and Dies for Net Shape Manufacture. Materials and Design, pg. 395 - 402, 2000 .

VAUGH, R.L; PETERSON, A. H (1958) - New machine tolls needed for metals of tomorrow, Aviation, R\&D Handbook - Production Engineering Section, , p. 5-7, June. 
WATANABE, K. (1996) - Exemplos de projetos de fusos de alta velocidade e os métodos de balanceamento, Máquinas e Metais, n.366, p.74-86, jul., 1996.

WALZ, T. (1996) - Utilização de motores lineares em máquinas - ferramentas. Seminário de usinagem com altíssima velocidade de corte: Fresamento, torneamento, furação, Unimep, outubro de 1996.

WECK, M.; SCHUMACHER, A; QUEINS, M. (1999) - Nova geração de máquinasferramenta de alta velocidade, Máquinas e Metais, n.401, p.16-39, jun, 1999.

WEINERT, K.; GUNTERMANN, G. (2000) - Usinagem de superfícies complexas, Máquinas e Metais, nº 415, pg. 18-27, 2000. 


\section{APÊNDICES}

\section{APÊNDICE 01}

Rotina para a aquisição das componentes da força de usinagem.

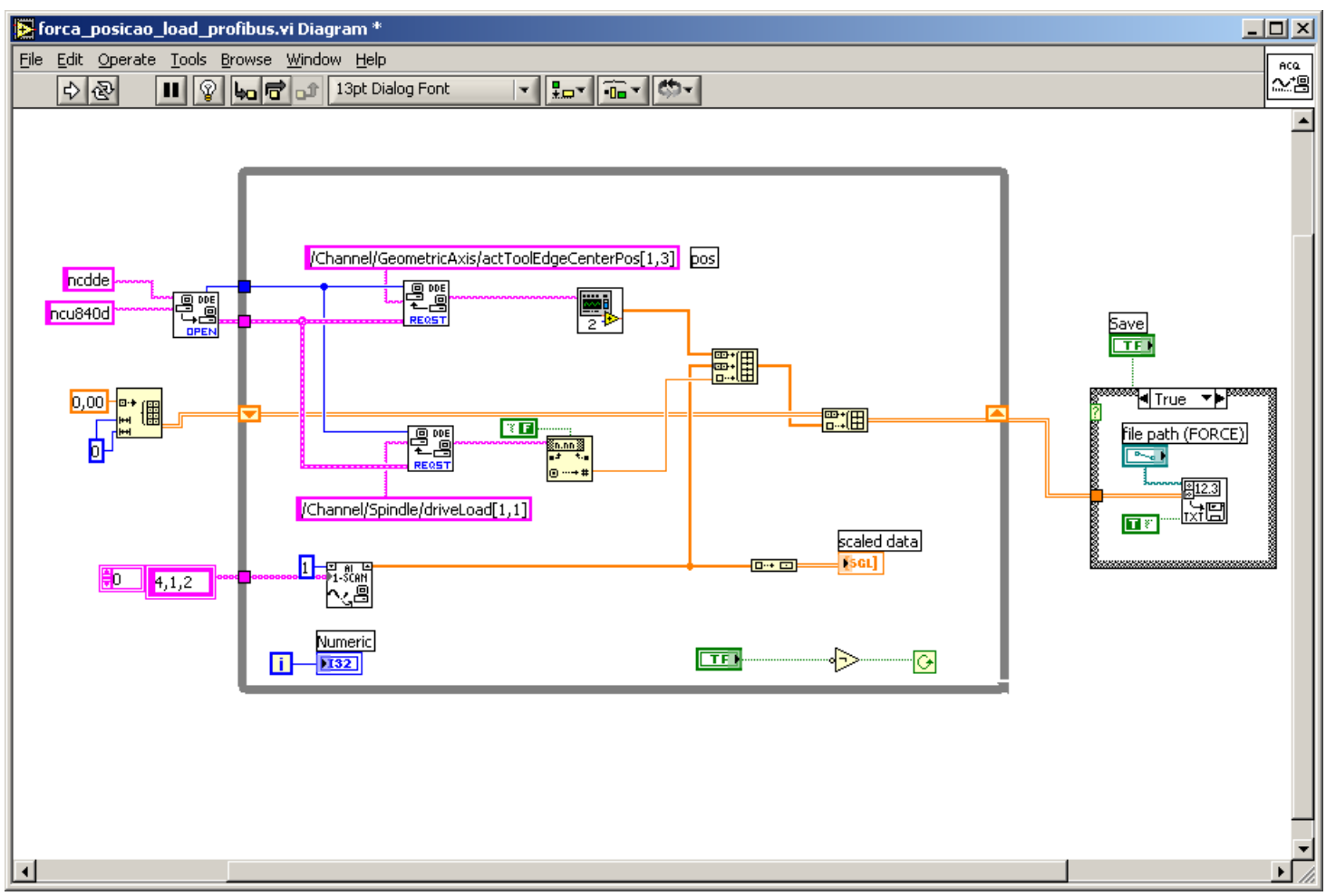

